Universidade de São Paulo

Faculdade de Ciências Farmacêuticas de Ribeirão Preto

Efeito da ocitocina sobre a ansiedade experimental induzida em voluntários saudáveis 
DANIELLE I. CHAVES

\section{Efeito da ocitocina sobre a ansiedade experimental induzida em voluntários saudáveis}

Dissertação apresentada a Faculdade de Ciências Farmacêuticas de Ribeirão Preto da Universidade de São Paulo para obtenção do título de Mestre em Toxicologia.

Área de Concentração: Toxicologia Orientadora: Profa. Dra. Regina Helena Costa Queiroz.

Ribeirão Preto 


\section{FICHA CATALOGRÁFICA}

Chaves, Danielle Igreja

Efeito da ocitocina sobre a ansiedade experimental induzida em voluntários saudáveis. Ribeirão Preto, 2007.

84 p. : il. ; $30 \mathrm{~cm}$

Dissertação de Mestrado, apresentada à Faculdade de Ciências Farmacêuticas de Ribeirão Preto/USP. Área de concentração: Toxicologia.

Orientador: Queiroz, Regina Helena Costa

1. Ocitocina. 2. Ansiedade. 3. Teste de Simulação de Falar em Público. 4. Carga mecânica. 5. Voluntários saudáveis. 


\section{FOLHA DE APROVAÇÃO}

\section{Danielle I. Chaves}

Efeito da ocitocina sobre a ansiedade experimental induzida em voluntários saudáveis

Dissertação apresentada a Faculdade de Ciências Farmacêuticas de Ribeirão Preto da Universidade de São Paulo para obtenção do título de Mestre em Toxicologia.

Área de Concentração: Toxicologia

Aprovado em:

Banca Examinadora

Prof. Dr.

Instituição:

Assinatura:

Prof. Dr.

Instituição:

Assinatura:

Prof. Dr.

Instituição:

Assinatura: 


\section{DEDICATÓRIA}

Com todo o meu amor e carinho dedico esta conquista aos meus pais, Gilmar e Isabel, a minha irmã, Michelle, e aos meus avós, Ambrosina e Franciso (in memoriam).

“Ser mestre em Toxicologia é mais que um título. Para mim, representa o encerramento de uma etapa de outras que estão por vir para eu conquistar um grande sonho que busco constantemente com muito amor, a carreira acadêmica. E nada disso seria possível sem o amor, o carinho, a confiança e o apoio incondicional de vocês. Palavras não conseguiriam expressar a minha gratidão, por isso, só tenho a dizer: muito obrigada. Amo vocês.” 


\section{AGRADECIMENTOS}

À Profa. Dra. Regina Helena Costa Queiroz, pela orientação e oportunidade de realização do curso de mestrado.

Ao Prof. Dr. José Alexandre de Souza Crippa, meu grande incentivador, pela oportunidade e confiança que sempre me foi depositada.

Ao Prof. Dr. Antônio Waldo Zuardi, por toda a contribuição durante a execução do projeto.

Ao Prof. Dr. Frederico Guilherme Graeff, pela contribuição na discussão das análises dos dados.

Ao Prof. Dr. José Antunes Rodrigues, por ceder gentilmente o laboratório e contribuir com as análises. 


\section{AGRADECIMENTOS}

Ao CEMEQ pela contribuição nas análises estatísticas.

À Sônia e Cidinha pela ajuda constante no laboratório e pela amizade.

Ao Wilson Malfará pela amizade e contribuição no trabalho.

À Edna e Ana Luiza pela ajuda nas análises dos hormônios.

À Marina e Valdeci pela ajuda e paciência nas análises de ocitocina.

À Sandra Bernardo pela paciência e pelo carinho durante todo o trabalho.

À Cecília, Alaor, Flávia, João Paulo e Rafael Zanetti pela ajuda durante a seleção dos voluntários.

Aos amigos Emílio, Roberto Molina e Davi Aragon pela ajuda e ensinamentos na análise estatística e pela amizade.

À amiga Raquel Cocenas e sua família, ao Renato Menezes e à Camila Guimarães pela amizade e carinho.

Aos voluntários que participaram da pesquisa pela contribuição. 


\section{AGRADECIMENTOS}

Aos meus pais, Isabel e Gilmar, pela minha vida, amor, confiança e apoio em minhas decisões.

A minha irmã, Michelle, pela amizade, carinho e por me ouvir nos momentos difíceis.

A minha avó Nena e ao meu avô Quico (in memoriam) pela dedicação e amor desprendidos durante toda a minha educação.

Ao Richard Boarato David pelo amor e carinho e por tudo que sempre fez por mim.

Às minhas tias Vera e Regina por terem sempre participado da minha vida me dando amor e carinho.

Agradeço a Deus pela vida.

Agradeço a Vida por me deixar sentir como é bom viver. 


\section{RESUMO}

CHAVES, D. I. Efeito da ocitocina sobre a ansiedade experimental induzida em voluntários saudáveis. 2007. 84f. Dissertação (mestrado) - Faculdade de Ciências Farmacêuticas de Ribeirão Preto, Universidade de São Paulo, Ribeirão Preto, 2007.

Introdução: A ocitocina (OT) é um nonapeptídeo sintetizado nos núcleos paraventricular e supraóptico do hipotálamo. Quando liberada perifericamente pela neurohipófise, a OT atua como um hormônio e promove a liberação do leite durante a lactação e a contração uterina no parto. No entanto, quando liberada centralmente, a OT age como um neurotransmissor ou neuromodulador de diversos processos, tal como na modulação da ansiedade e na regulação das respostas neuroendócrina e cardiovascular. Sendo assim, o presente trabalho tem como objetivo avaliar os efeitos agudos da administração intranasal da OT na ansiedade em voluntários saudáveis submetidos ao Teste de Simulação de Falar em Público (TSFP), bem como seu papel na modulação das respostas neuroendócrina e hemodinâmica. Métodos: Ocitocina ou veículo foram administrados intranasalmente em voluntários saudáveis $(n=14)$ 50 minutos antes do TSFP. Durante a sessão experimental foram realizadas as seguintes medidas: (1) basal ( $\mathrm{t}=-30 \mathrm{~min})$ ), (2) pré-teste $(\mathrm{t}=-15 \mathrm{~min})$, (3) preparação ( $\mathrm{t}=+50 \mathrm{~min})$, (4) desempenho $(\mathrm{t}=+1: 03 \mathrm{~h})$, pós-teste $1(\mathrm{t}=1: 26 \mathrm{~h})$ e pós-teste $2(\mathrm{t}=1: 46 \mathrm{~h})$. Para a avaliação dos estados subjetivos de ansiedade foram utilizadas as seguintes escalas de auto-avaliação: 1.Escala Analógica de Humor; 2.Escala de Sintomas Corporais; 3. Versão de "estado" da escala de auto-avaliação ao falar em público. Para a dosagem de cortisol sérico e ACTH plasmático foi utilizada a técnica de radioimunoensaio. Também foram realizadas as medidas de freqüência cardíaca, pressão arterial, condutância da pele e número de flutuações espontâneas da condutância da pele. Resultados: O grupo OT apresentou-se menos ansioso nas fases PT (p-valor = 0,03), com maior sedação nas fases PT (p-valor = 0,003), Pr (p-valor $=0,01)$ e $\mathrm{S}(\mathrm{p}$-valor $=0,02)$ e com nível de condutância da pele menor nas fases PT ( $\mathrm{p}$-valor $=$ 0,02), Pr (p-valor $=0,02), S(p$-valor $=0,03)$ e F2 (p-valor $=0,02)$. Nos outros parâmetros mensurados não foram encontradas diferenças intergrupos. Conclusão: O presente estudo sugere que a OT na dose de 24 UI possui ação na ansiedade antecipatória em voluntários saudáveis. Espera-se que este estudo contribua com o desenvolvimento de intervenções terapêuticas em transtornos de ansiedade e com o desenvolvimento de possíveis fármacos agonistas.

Palavras-chaves: Ocitocina, Ansiedade, Teste de Simulação de Falar em Público, Voluntários saudáveis. 


\begin{abstract}
CHAVES, D. I. The effect of oxytocin on experimentally induced anxiety in healthy volunteers. 2007. 84f. Dissertação (mestrado) - Faculdade de Ciências Farmacêuticas de Ribeirão Preto, Universidade de São Paulo, Ribeirão Preto, 2007.

Introduction: Oxytocin is a nonapeptide that is synthesized in the hypothalamus paraventricular and supraoptic nuclei. When released peripherally by the neurohypophysis, it acts as a hormone that will promote milk ejection during lactation and uterine smooth muscle contraction during labor. However, when centrally released, OT acts as a neurotransmitter or neuromodulator of several processes, such as anxiety modulation and regulation of cardiovascular and neuroendocrine responses. The objective of this study was to assess the acute effect of OT, intranasally administered, on anxiety levels of healthy volunteers who submitted themselves to the Public Speaking Simulation Test as well as its role in the modulation of neuroendocrine and hemodynanic responses. Methods: Oxytocin, or vehicle, was intranasally administered to healthy volunteers $(n=14)$ fifty minutes before the Test. During the experimental session, the following assessments were performed: 1$)$ Baseline $(\mathrm{t}=$ 30 minutes); 2) Pre test ( $\mathrm{t}=-15$ minutes) ;3) Preparation ( $\mathrm{t}=+50$ minutes) ; 4) Performance ( $\mathrm{t}=+1: 03$ hours), and post test $1(\mathrm{t}=1: 26$ hours) and post test $2(\mathrm{t}=1: 46$ hours $)$. In order to evaluate anxiety subjective states, the following self-assessment scales were used: 1) Mood Analogical Scale, 2) Bodily Symptoms Scale, and 3) "State" Self-Assessment Version of Public Speaking Scale. A radio immune assay was used for cortisol serum level and plasmatic ACTH measurements. Additionally, heart rate, blood pressure, skin conductance, and number of spontaneous fluctuations of skin conductance were checked. Results: The OT group was less anxious during the PT ( $\mathrm{p}$ value $=0,03$ ), with a higher sedation during the PT ( $\mathrm{p}$ value = $0,003)$, $\operatorname{Pr}(\mathrm{p}$ value $=0,01)$, and $S$ phases $(\mathrm{p}$ value $=0,02)$ and a lower level of skin conductance during the PT ( $\mathrm{p}$ value $=0,02), \operatorname{Pr}(\mathrm{p}$ value $=0,02), \mathrm{S}$ ( $\mathrm{p}$ value $=0,03$ ), and F2 phases ( $\mathrm{p}$ value $=0,02$ ). As for the other parameters evaluated, no differences were found between the groups. Conclusions: The present study suggests that an OT dose of 24 UI acts on the anticipation anxiety of healthy volunteers. This study is expected to contribute to the development of therapeutical interventions in anxiety disorders as well as possible agonist drugs.
\end{abstract}

Key Words: Oxytocin, Anxiety, Simulated Public Speaking , Healthy volunteers 


\section{LISTA DE FIGURAS}

Figura 1 - Esquema de algumas vias que se projetam do núcleo central da amígdala e do núcleo leito da estria terminal (BNST).

Figura 2- Efeitos da ocitocina e do placebo na ansiedade subjetiva avaliada pela Escala Analógica de Humor (EAH) em voluntários saudáveis submetidos ao Teste de Simulação de

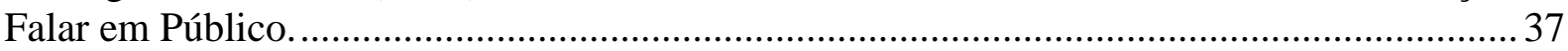

Figura 3 - Efeitos da ocitocina do placebo no prejuízo cognitivo avaliada pela Escala Analógica de Humor (EAH) em voluntários saudáveis submetidos ao Teste de Simulação de

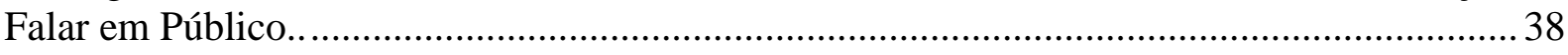

Figura 4 - Efeitos da ocitocina e do placebo na sedação avaliada pela Escala Analógica de Humor (EAH) em voluntários saudáveis submetidos ao Teste de Simulação de Falar em Público.

Figura 5 - Efeitos da ocitocina e do placebo no desconforto avaliada pela Escala Analógica de Humor (EAH) em voluntários saudáveis submetidos ao Teste de Simulação de Falar em Público.

Figura 6 - Efeitos da ocitocina e do placebo na auto-avaliação positiva ao falar em público em voluntários saudáveis submetidos ao Teste de Simulação de Falar em Público.

Figura 7- Efeitos da ocitocina e do placebo na auto-avaliação negativa ao falar em público em voluntários saudáveis submetidos ao Teste de Simulação de Falar em Público.

Figura 8 - Efeitos da ocitocina e do placebo na auto-avaliação ao falar em público (pontos totais) em voluntários saudáveis submetidos ao Teste de Simulação de Falar em Público. .... 46

Figura 9 - Efeitos da ocitocina e do placebo na freqüência cardíaca (FC) em voluntários saudáveis submetidos ao Teste de Simulação de Falar em público..

Figura 10 - Efeitos da ocitocina e do placebo na pressão arterial sistólica (PAS) em voluntários saudáveis submetidos ao Teste de Simulação de Falar em Público. ...................... 50

Figura 11 - Efeitos da ocitocina e do placebo na pressão arterial diastólica (PAD) em voluntários saudáveis submetidos ao Teste de Simulação de Falar em Público.

Figura 12 - Efeitos da ocitocina e do placebo na condutância em voluntários saudáveis submetidos ao Teste de Simulação de Falar em Público.

Figura 13 - Efeitos da ocitocina e do placebo no número de flutuações da condutância em voluntários saudáveis submetidos ao Teste de Simulação de Falar em Público. 54

Figura 14 - Efeitos da ocitocina e do placebo no cortisol em voluntários saudáveis submetidos ao Teste de Simulação de Falar em Público.

Figura 15 - Efeitos da ocitocina e do placebo no hormônio adrenocorticotrófico (ACTH) em voluntários saudáveis submetidos ao Teste de Simulação de Falar em Público. 56 


\section{LISTA DE TABELAS}

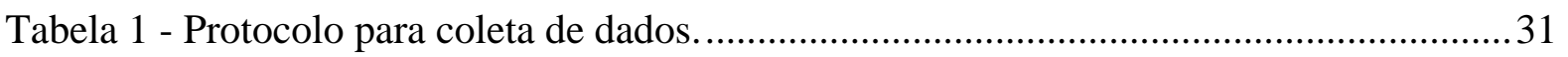

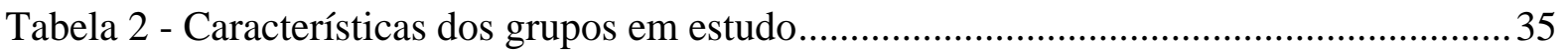

Tabela 3 - Distribuição da Escala Analógica de Humor de acordo com seus maiores pesos

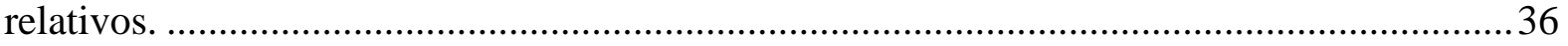

Tabela 4- Diferenças encontradas na escala de sintomas somáticos. ....................................47 


\section{LISTA DE ABREVIATURAS E SIGLAS}

\begin{tabular}{|c|c|}
\hline AAFP & Auto-avaliação ao falar em público \\
\hline ACTH & Hormônio adrenocorticotrófico \\
\hline $\mathrm{AM}$ & Amígdala \\
\hline ANOVA & Análise de variância \\
\hline $\mathrm{B}$ & Basal \\
\hline BNST & Núcleo leito da estria terminal \\
\hline CCSE & Critério de Classificação Socioeconômico Brasileiro \\
\hline $\mathrm{CPF}$ & Córtex pré-frontal \\
\hline $\mathrm{CRF}$ & Fator liberador de corticotrofina \\
\hline EAH & Escala analógica de humor \\
\hline EGTA & Ácido etileno glicol-bis ( $\beta$-aminoetil éter) - N,N-tetracético \\
\hline ESS & Escala de sintomas somáticos \\
\hline $\mathrm{F} 1$ & Pós-teste 1 \\
\hline F2 & Pós-teste 2 \\
\hline $\mathrm{FC}$ & Freqüência cardíaca \\
\hline GC & Giro cíngulo \\
\hline HP & Hipotálamo \\
\hline HPA & Hipotálamo-hipófise-adrenal \\
\hline HPLC & Cromatografia líquida de alta eficiência \\
\hline IAB & Inventário da ansiedade de Beck \\
\hline IMC & Índice de massa corpórea \\
\hline LC & Locus coeruleus \\
\hline MCP & Matéria cinzenta periaquedutal \\
\hline
\end{tabular}




$\begin{array}{ll}\text { NE } & \text { Norepinefrina } \\ \text { NOS } & \text { Núcleo supraóptico } \\ \text { NPV } & \text { Núcleo paraventricular } \\ \text { OT } & \text { Ocitocina } \\ \text { PA } & \text { Pré-estresse } \\ \text { PAD } & \text { Pressão Arterial } \\ \text { PAN } & \text { Peptídeo atrial natriurético } \\ \text { PAS } & \text { Pressão arterial sistólica } \\ \text { S } & \text { Performance } \\ \text { SCL } & \text { Média do nível da condutância da pele } \\ \text { SF } & \text { Número de respostas de flutuações espontâneas da pele } \\ \text { SNC } & \text { Sistema nervoso central } \\ \text { TSFP } & \text { Teste de simulação de falar em público }\end{array}$




\section{SUMÁRIO}

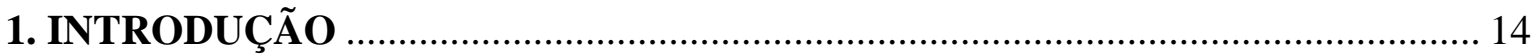

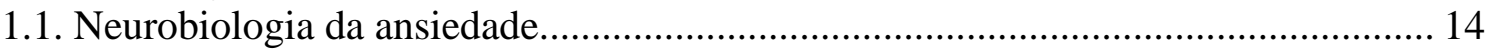

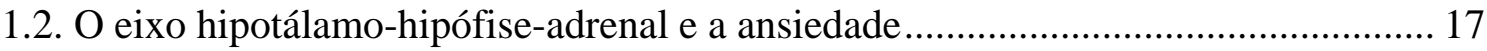

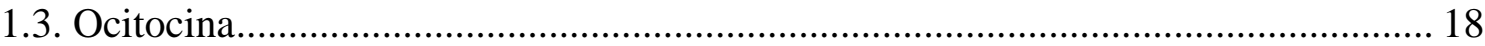

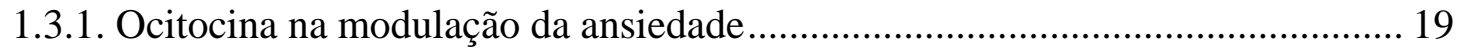

1.3.2. Ação da ocitocina na regulação neuroendócrina ................................................. 21

1.3.3. Função da ocitocina na regulação hemodinâmica ............................................... 23

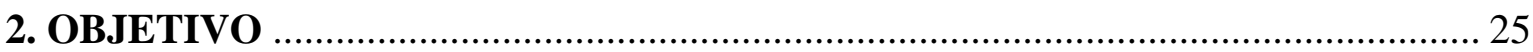

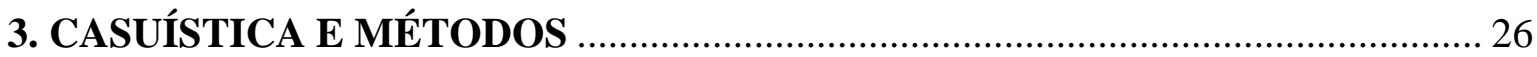

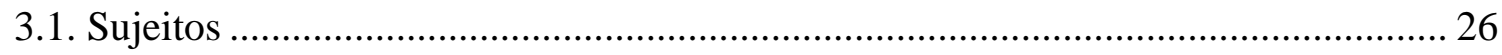

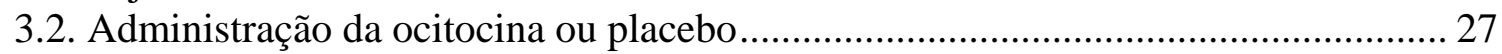

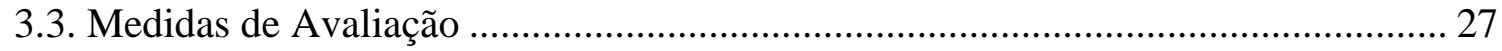

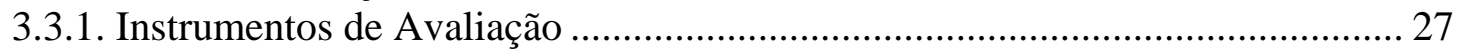

3.3.2. Medidas Fisiológicas / Psicofisiológicas....................................................... 29

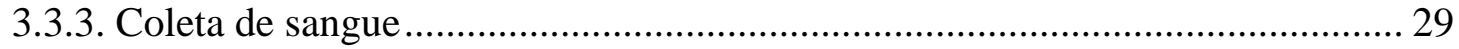

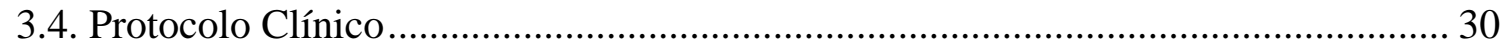

3.4.1. Teste de Simulação de Falar em Público............................................................ 30

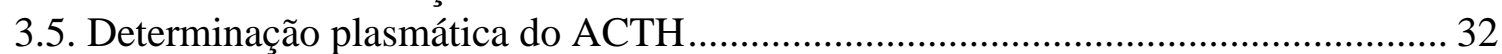

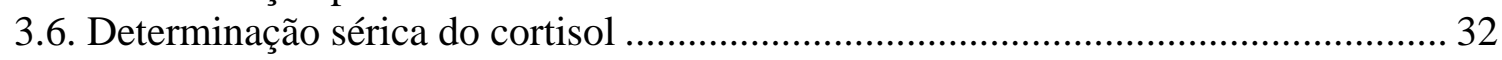

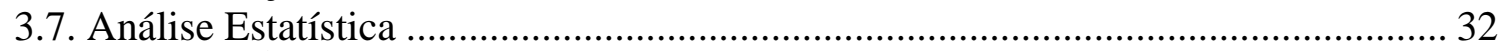

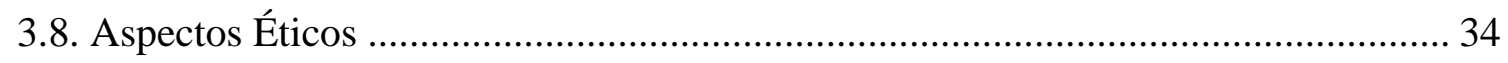

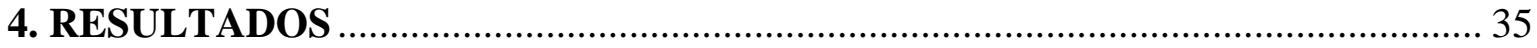

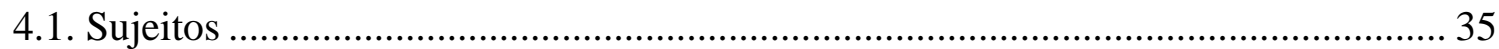

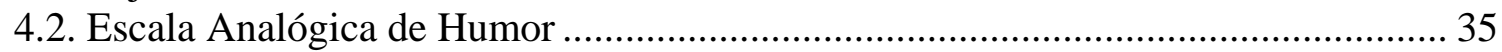

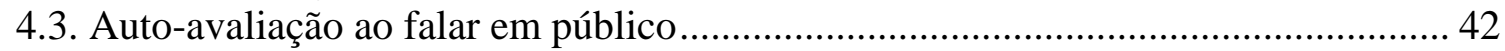

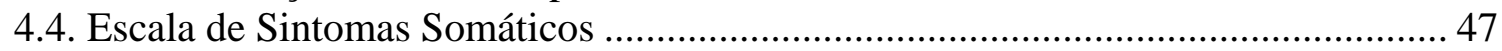

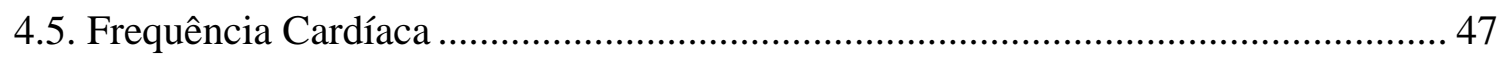

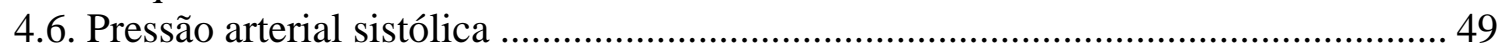

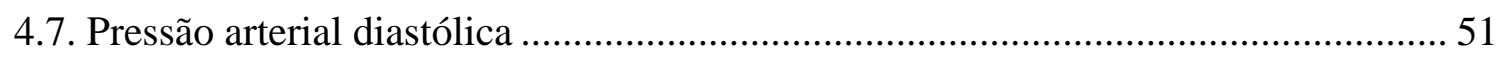

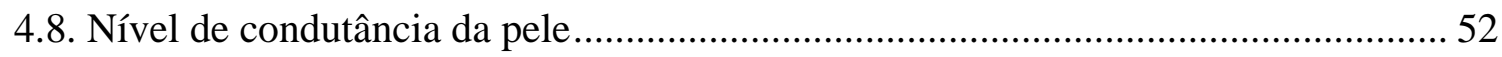

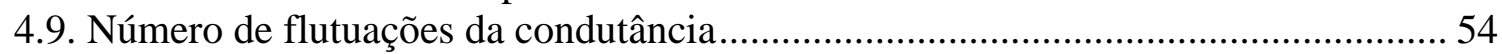

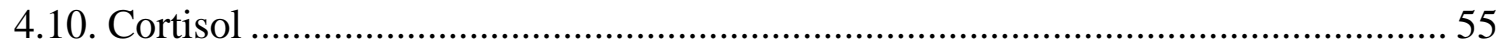

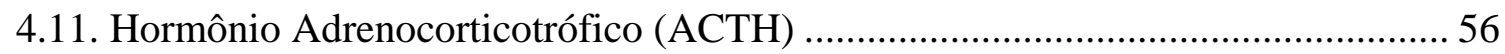

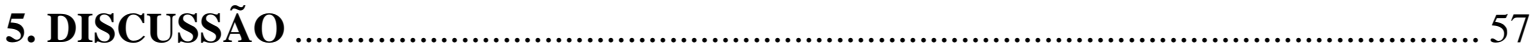

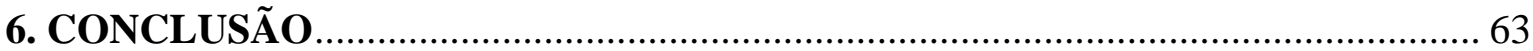

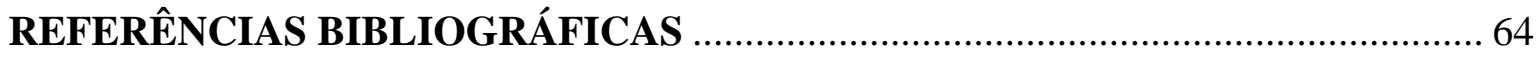

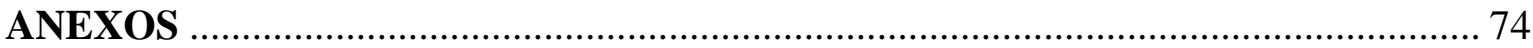

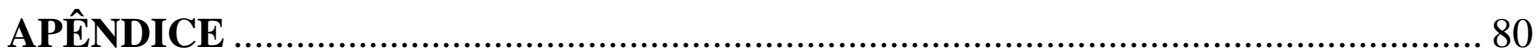


1. INTRODUÇÃO 


\section{INTRODUÇÃO}

\subsection{Neurobiologia da ansiedade}

O medo e a ansiedade normalmente compreendem respostas adaptativas ao perigo ou ao estresse e é considerado essencial para a sobrevivência do ponto de vista evolutivo (CHARNEY; DREVETS, 2002; KIM; GORMAN, 2005). Os transtornos de ansiedade incluem o pânico, a ansiedade generalizada, o estresse pós-traumático, o obsessivocompulsivo, a fobia social e fobias específicas. Estes distúrbios são muito comuns e possuem prevalência ao longo da vida estimada em cerca de $25 \%$ e freqüentemente apresentam comorbidades associadas a outros transtornos psiquiátricos, especialmente a depressão (HETTEMA; NEALE; KENDLER, 2001).

O sistema límbico é a parte do cérebro considerada o centro das emoções e inclui a amígdala (AM), o núcleo talâmico anterior, o giro cíngulo, o fórnix, o hipocampo, o hipotálamo (HP), os corpos mamilares, a parte medial do prosencéfalo, lobos pré-frontais, núcleo septal e outras áreas e vias do cérebro. As inter-relações entre essas estruturas são responsáveis pelo reconhecimento e ativação das emoções, incluindo a ansiedade (KIM; GORMAN, 2005). A AM merece destaque, uma vez que é a unidade principal do processamento do circuito do sistema límbico. Além disto, é nesta parte do cérebro que existem vias aferentes e eferentes ligadas a outras partes do cérebro que estão envolvidas com o processamento e com a sintomatologia da ansiedade (CHARNEY; DREVETS, 2002)

A AM é um núcleo denso formado por distintos grupos de células, incluindo os núcleos lateral, basal, central, basal acessório, medial e cortical. As regiões mais importantes e maiores são os núcleos central e basolateral. O núcleo basolateral da AM recebe vias provenientes do córtex pré-frontal (CPF), do giro cíngulo e também do hipocampo e do 
tálamo. O núcleo central é a região envolvida com o processamento e com a regulação das respostas comportamentais e autônomas da ansiedade, através de suas vias eferentes que se projetam para regiões como lócus ceruleus (LC), matéria cinzenta periaquedutal, HP e outras (DAVIS, 2002; LeDOUX, 2003). Projeções da AM basolateral para o núcleo central da AM e para a divisão lateral do núcleo leito da estria terminal (BNST) formam, para alguns autores, a AM lateral estendida. A amígdala central e BNST têm sido agrupados juntos porque fibras da amígdala basolateral que se projetam para o BNST atravessam pela amígdala central e células laterais desta porção se projetam para o BNST (DAVIS, 2002). Sendo assim, a amígdala central e o BNST desempenham importantes funções na regulação do medo e da ansiedade, uma vez que existem diversas vias eferentes destas regiões em direção a áreas envolvidas com os sintomas da ansiedade (DAVIS, 2000). A figura 1 ilustra algumas dessas vias.

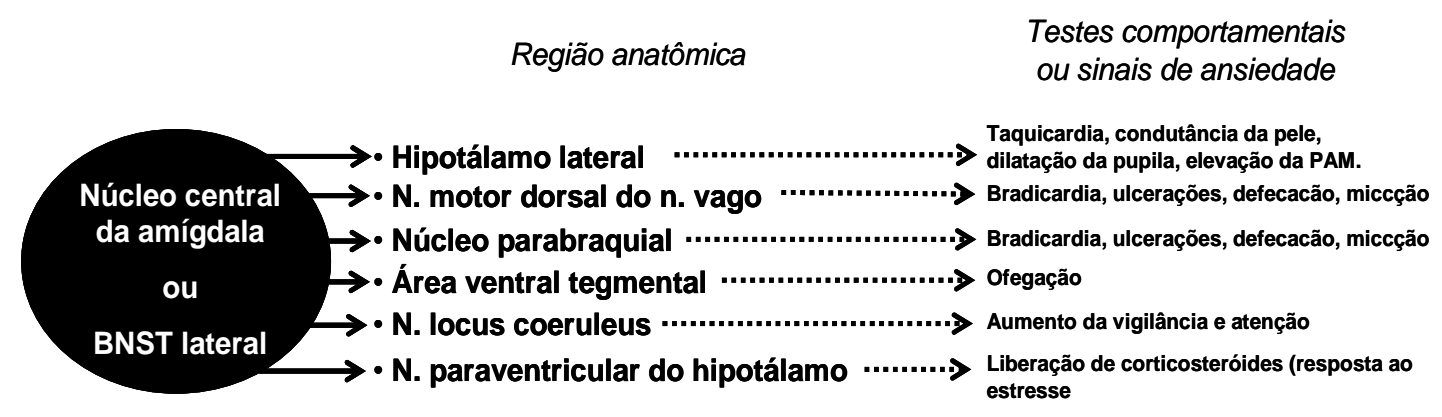

Figura 1 - Esquema de algumas vias que se projetam do núcleo central da amígdala e do núcleo leito da estria terminal (BNST). Note que estas vias se projetam para regiões anatômicas que estão relacionados com alguns sintomas somáticos. Modificado de DAVIS, 2002.

O CPF trata-se de uma importante região envolvida na modulação cognitiva e na interpretação da experiência que gera a ansiedade, além de estar envolvida na ativação da AM. Estudos de neuroimagem ainda são contraditórios quanto à relação entre a ativação AM / CPF no processamento da ansiedade (ANAND; SHEKHAR, 2003; CHARNEY, 2003). Kim e Gorman (2005) atentam que os trabalhos podem ser consistentes e as diferenças nos resultados podem ocorrer devido aos diferentes tipos de estímulo, bem como ao tipo do transtorno que foi estudado. Além disto, sabe-se que o CPF e a AM interagem por meio de vias complexas que ainda não estão bem estabelecidas. 
Outra estrutura que se tem demonstrado ter importante função no circuito do medo e da ansiedade é o giro cíngulo. Lesões nesta parte do cérebro resulta na hiperatividade do sistema autônomo em resposta a um estímulo, bem como em complicações comportamentais (DAMASIO et al., 1990; ROGERS et al., 2004). Esta estrutura é considerada uma ponte entre o subcórtex límbico (em especial a AM) e o CPF, sendo assim um importante intermediário nas associações emocionais e cognitivas do medo e da ansiedade (EISENBERGER et al., 2003).

Algumas teorias acerca da neurobiologia da ansiedade vêm sendo discutidas, sendo que uma das mais recentes foi proposta por McNaughton e Corr (2004). Os autores revisaram e expandiram os conceitos da teoria de Gray e McNaughton (2000) incluídos no livro Neuropsychology of Anxiety. Os autores propõem que o conjunto de estruturas neurais envolvidas nos sistemas de defesa que modulam comportamentos relacionados ao medo, os quais buscam evitar ou afastar o animal da ameaça (fuga e luta), e a ansiedade, os quais visam à aproximação do estímulo ameaçador (avaliação de risco), são entidades categoricamente distintas inter e intra-conectadas. Além disso, baseando-se no conceito de distância defensiva, postularam que as estruturas que comandam as reações de defesa envolvidas na ansiedade e no medo estão igualmente organizadas numa hierarquia funcional (do córtex ao tronco encefálico), atuando de acordo com a distância em que se encontra a fonte de perigo, de modo que todas as estruturas envolvidas participam da modulação de todos os comportamentos. Dessa forma, por exemplo, os comportamentos defensivos relativos à ansiedade (ex. avaliação de risco) seriam organizados e expressados principalmente por estruturas prosencefálicas (ex. córtex pré-frontal, sistema septo-hipocampal e amígdala). No entanto, as estruturas anatomicamente mais caudais, como a matéria cinzenta periaquedutal (MCP) e o hipotálamo também participariam sutilmente do controle de tais comportamentos. De fato, demonstram que além de controlar fundamentalmente comportamentos relacionados ao medo, tais como 
fuga e luta, a MCP participa da elaboração e expressão de comportamentos relacionados à ansiedade, tais como esquiva e avaliação de risco.

\subsection{O eixo hipotálamo-hipófise-adrenal e a ansiedade}

Acredita-se que vias provenientes da AM e possivelmente do BNST em direção ao HP, além de alguns neurotransmissores e neuropeptídeos são responsáveis pela ativação dos eixos neuroendócrino e simpático associados à sintomatologia da ansiedade. Neste contexto, o eixo hipotálamo-hipófise-adrenal (HPA) merece destaque no estudo da ansiedade (KIM; GORMAN, 2005).

A comunicação entre os eixos HPA e simpático ocorrem via LC, através da liberação de catecolaminas como a norepinefrina (NE). O eixo HPA, em especial o núcleo paraventricular (NPV) do HP, recebem vias do núcleo central da AM. Estas vias também se projetam em direção ao núcleo lateral do HP e LC. O NPV controla a liberação do fator liberador de corticotrofina (CRF), o qual por sua vez controla a liberação do hormônio adrenocorticotrófico (ACTH) pela hipófise anterior. O ACTH, via corrente sanguínea, atua no córtex da adrenal e então controla a liberação de corticosteróides (mineralocorticóides e glicocorticóides) (STROHLE; HOLSBOER, 2003).

O cérebro possui, em diferentes regiões, dois tipos de receptores para o CRF: (i) o receptor R1 que é encontrado principalmente na $A M$, no giro cingulo e no CPF e (ii) o receptor R2, o qual se localiza no NPV, septo, núcleo da rafe, lócus ceruleus e hipocampo (CHALMERS et al., 1995).Isso sugere que o CRF também está relacionado com a modulação da ansiedade. Estudos têm demonstrado que a administração intracerebral do CRF causa aumento da ansiedade e que o principal receptor envolvido é o R1 (HOLMES et al., 2003; SANCHEZ et al., 1999). Essas descobertas reforçam outros estudos que discutem que a 
ativação ou a desativação do eixo HPA são anormais em pessoas com algum tipo de transtorno de ansiedade. Essas considerações são feitas baseadas nos níveis de cortisol anormais encontrados em tais pacientes (SULLIVAN et al, 1998; YEHUDA et al., 1993).

Uma outra importante relação do eixo HPA na ansiedade envolve o sistema noradrenérgico via lócus ceruleus. O sistema locus coeruleus - norepinefrina (LC-NE) é responsável pela maior parte dos sintomas desagradáveis da ansiedade. A liberação de NE proveniente do LC leva a ativação do sistema nervoso autônomo e tal ativação resulta na liberação de epinefrina pela glândula adrenal. Essas alterações geram efeitos cardiovasculares como o aumento da pressão arterial e freqüência cardíaca. Uma revisão realizada por Sullivan et al. (1999) indica que provavelmente há uma relação entre o sistema LC-NE e o CRF. O aumento do CRF no LC acarreta o aumento de NE no córtex, o que gera, por sua vez, elevação dos níveis de CRF já que existem vias eferentes no LC proveniente do NPV e viceversa.

\subsection{Ocitocina}

No homem, a hipófise apresenta-se dividida em, basicamente, duas porções: (i) hipófise anterior ou adeno-hipófise e (ii) hipófise posterior ou neuro-hipófise. As células da adeno-hipófise são responsáveis pela síntese e secreção do ACTH, hormônio tireotrófico (TSH), gonadotrofinas (hormônio luteinizante - LH - e folículo estimulante - FSH), hormônio do crescimento (GH) e prolactina (Prl). A neuro-hipófise armazena e libera os dois hormônios que são produzidos pelo HP, a vasopressina e a ocitocina (OT) (AIRES, 2000).

A OT é um nonapeptídeo que é sintetizado nos núcleos paraventricular (NPV) e supraótico (NSO) do HP. Neurônios magnocelulares localizados nos NSO e NPV são os responsáveis pela maior fonte de OT. Este hormônio é conduzido por meio de proteínas 
transportadoras, dos neurônios magnocelulares dos NOS e NPV para a neuro-hipófise, local no qual o neuropeptídeo é armazenado e liberado para a corrente sanguínea. A OT também é liberada no Sistema Nervoso Central (SNC) por meio de neurônios parvocelulares, os quais estão localizados no NPV e em outras regiões do cérebro (BUJIS, 1978; KENDRICK et al., 1986). Sendo assim, a OT possui ações periférica e central. Sua ação periférica na amamentação e no parto está bem estabelecida. Quando liberada centralmente age como um neurotransmissor ou neuromodulador em diversos processos como no comportamento maternal (PEDERSEN, 1979), ingestão de comida (VERBALIS, 1986) e sódio (STRICKER, 1986), memória social (FERGUSON, 2000; FERGUSON 2001), comportamento sexual, promoção de relações sociais positivas (CARTER, 1998; HEINRICHS et al., 2002; INSEL e YOUNG, 2001; UVNAS-MOBERG, 1998; YOUNG et al., 2001), resposta ao estresse (GIBBS, 1984; WINDLE et al., 1997a) e ação ansiolítica em ratas (BALE et al, 2001; NEUMANN et al., 2000; WINDLE et al., 1997) e camundongos fêmeas (MCCARTHY et al., 1996; MANTELLA et al., 2005) e, mais recentemente, em humanos (HEINRICHS et al., 2003). Além disto, em 2005, Kosfeld et al demonstrou que a OT promove o comportamento pró-social de confiança em humanos.

\subsubsection{Ocitocina na modulação da ansiedade}

Vias e receptores ocitocinérgicos foram encontradas em regiões cerebrais envolvidas no circuito da ansiedade, o que fundamentou a hipótese de que vias e receptores de ocitocina podem estar relacionados com a modulação da ansiedade. As regiões identificadas incluem o BNST (INGRAM e MOOS, 1992; MANTELLA et al., 2003), núcleos central e medial da AM (CONDES-LARA et al., 1994; KREMARIK et al., 1993; MANTELLA et al., 2003), 
septo (INSEL et al., 1993; MANTELLA et al., 2003; McCARTHY et al., 1996), núcleo seleto do HP e hipocampo (MANTELLA et al., 2003; SOFRONIEW, 1983).

Poucos estudos foram feitos sob o ponto de vista comportamental promovido pela OT, mas parece que há a produção de OT durante situações que induzem a ansiedade e o estresse. Recentemente, investigações da ação da OT sob o ponto de vista fisiológico e comportamental do estresse e da ansiedade em animais têm sido realizadas. Estímulos estressantes com um componente psicológico, tais como o nado forçado (WIGGER e NEUMANN, 2002; WOTJAK et al., 1998; WOTJAK et al., 2001), andar em plataformas (HASHIGUCHI et al., 1997; NISHIOKA et al., 1998) e afastamento social (EBNER et al., 2000; ENGELMANN et al., 2000, NEUMANN, 2002) induzem a liberação da secreção periférica e central da OT em roedores.

Camundongos knockout de OT têm sido usados no entendimento das funções desempenhadas centralmente por esse neuropeptídeo. Alguns estudos nesses animais demonstraram que a administração exógena de OT diminui o estresse e a ansiedade ou, ainda, que o bloqueio dos receptores de OT no grupo controle produz o aumento dos mesmos. Entretanto, ainda não é possível concluir que a OT endógena desempenha necessariamente essas funções (AMICO et al., 2004). Mantella et al. (2003) demonstraram que camundongos fêmeas knockouts de OT (OT -/-) apresentaram níveis maiores de ansiedade quando comparados com o grupo controle $(\mathrm{OT}+/+)$ e que este quadro se revertia quando era administrada OT centralmente. Também foi demonstrado em camundongos OT +/+ que quando administrado o antagonista do receptor de OT houve um aumento da ansiedade. Os autores atribuíram o aumento da ansiedade em camundongos OT -/- à ausência de vias ocitocinérgicas, as quais podem estar relacionadas com a modulação da ansiedade Amico et al. (2004) também obteve o resultado de aumento da ansiedade em camundongos OT -/-. 
Além disto, estudos em ratas (WINDLE et al., 1997a) e camundongos fêmeas (MCCARTHY et al., 1996) demonstraram queda da ansiedade após administração central de OT.

Estudos em humanos ainda são escassos e relativamente limitados devido à dificuldade de administração de neuropeptídeos como a OT, uma vez que em roedores é realizada central ou intravenosamente. Uma alternativa prática e viável é a administração intranasal de neuropeptídeos, os quais através desta técnica são encontrados no líquor de humanos (BORN et al., 2002) e ainda em uma variedade de regiões cerebrais em ratos (ROSS et al., 2004). Dados iniciais utilizando a administração intranasal de OT em humanos sugerem que este neuropeptídeo pode reduzir o estresse e a ansiedade (HEINRICHS et al., 2003).

\subsubsection{Ação da ocitocina na regulação neuroendócrina}

Vias que são ativadas durante o estresse e que se projetam para o núcleo paraventricular (NPV) do HP são provenientes do tronco cerebral e do sistema límbico (HERMAN et al., 1996; HERMAN E CULLINAN, 1997; SAWCHENKO et al., 1996), sendo que parecem ser ativados durante o estresse físico (SAWCHENKO et al., 1996) e psicogênico (HERMAN et al., 1996; HERMAN E CULLINAN, 1997), respectivamente. Sabe-se que existem estruturas provenientes do sistema límbico que inervam diretamente a parte medial parvocelular do NPV, o que indica que esta região do cérebro está envolvida com a regulação do eixo HPA (CULLINAN et al., 1993; GRAY et al., 1989; HURLEY et al., 1991; PREWITT et al., 1998). A ativação da AM medial, parte importante para o processamento da ansiedade, está associada com a liberação de corticosterona e sua lesão impede a resposta ao estresse (DAYAS et al, 1999). No entanto, os fatores que controlam a regulação dos glicocorticóides (corticosterona em roedores) em resposta ao estresse psicológico são ainda desconhecidos (AMICO et al., 2004). 
Sabe-se que vários neurotransmissores e neuropeptídeos influenciam o eixo HPA, sendo que a OT também parece estar envolvida na sua modulação, como sugerido por estudos recentes. Observações feitas durante a amamentação em ratas, as quais liberam maiores concentrações de OT neste período, mostraram uma resposta neuroendócrina menor a situações que induziam a ansiedade e o estresse, como, por exemplo, atenuação da secreção de ACTH (LIGHTMAN e YOUNG, 1989; NEUMANN et al., 1998; WINDLE et al., 1997b), corticosterona (NEUMANN et al., 1998; WINDLE et al., 1997b) e catecolaminas (HIGUCHO et al., 1989).

A maior parte dos estudos sugere que a administração de OT diminui a secreção de glicocorticóides (HEINRICHs et al., 2003; NEUMANN et al., 2000b; NEUMANN, 2002; WINDLE et al., 1997a) e atenua a ansiedade (BALE et al., 2001; MCCARTHY et al, 1996; WINDLE et al., 1997a;). Por exemplo, ratas que foram submetidas à administração intracerebroventricular de OT secretaram menos corticosterona quando submetidas a um estresse psicológico (barulho) e ainda se mostraram menos ansiosas no teste de ansiedade aplicado (WINDLE et al., 1997a). Windle et al. (1997a) ainda demonstrou em ratas, uma relação dose-dependente entre a concentração administrada de OT e a liberação de corticosterona em resposta ao estresse (barulho).

Estudos em camundongos fêmeas knockout em OT também ajudam a esclarecer a função da OT na modulação do eixo HPA. Pesquisadores demonstraram um aumento significativo da liberação de corticosterona induzida pelo estresse (AMICO et al., 2004; BERNATOVA et al., 2004) e da ansiedade (MANTELLA et al., 2003). Mantella et al. (2004) ainda demonstraram que além de maiores níveis maiores de corticosterona, estes camundongos apresentaram menor expressão de cFOS na amígdala medial quando submetidos ao estresse psicogênico, já que esta parte está envolvida com a ativação do eixo HPA e conseqüente liberação de corticosterona (DUNN e WHITENER, 1986).

Além disto, pesquisas recentes sugerem que a OT está relacionada com a redução dos 
níveis de ACTH em macacos (PARKER et al., 2005) e de cortisol em humanos (HEINRICHS et al., 2003) quando submetidos a estímulos estressantes.

Dessa forma, acredita-se que a liberação central de OT diminui a ansiedade e atenua a resposta do eixo HPA a estímulos psicologicamente estressantes.

\subsubsection{Função da ocitocina na regulação hemodinâmica}

O sistema central ocitocinérgico influencia muitas áreas do cérebro que estão envolvidas com o controle cardiovascular e, além disto, são conhecidos receptores na periferia que podem diretamente modular a pressão arterial e outros parâmetros cardiovasculares.

Os mecanismos da regulação periférica foram propostos em ratos recentemente e se basearam em experimentos de expansão de volume sanguíneo e envolve a liberação de OT no plasma pela neurohipófise, o qual se liga a receptores ocitocinérgicos no coração induzindo a liberação do peptídeo atrial natriurético (PAN) (GUTKOWSKA et al., 1997). Como resultado haverá a produção de uma resposta negativa ionotrópica e cronotrópica no coração (FAVARETTO et al., 1997) que acarretará na redução do rendimento cardíaco, ou seja, haverá a diminuição da freqüência cardíaca e da força de contração. A expansão do volume sanguíneo também pode gerar OT localmente, já que o coração é um local de síntese de OT e secreção de PAN. Desta maneira, o aumento do retorno venoso ao coração seguido da expansão do volume sanguíneo pode promover o estiramento dos miócitos cardíacos ativando a liberação de OT e por conseguinte a liberação de PAN (JANKOWSKI et al, 1998).

Há também a ação da OT nos rins. Tanto a vasopressina quanto a OT secretadas promoverão a natriurese através de suas ações em receptores específicos das células tubulares renais (STOECKEL et al., 1987; TRIBOLLET et al., 1988). A natriurese gerada pela OT deve-se à ativação da enzima óxido nítrico sintetase (NOS) que é responsável pela formação 
de óxido nítrico (NO) e conseqüente aumento de guanosina monofosfato cíclica (GMPc) que é responsável pela mediação da natriurese. O aumento das concentrações de GMPc induz o fechamento de canais de $\mathrm{Na}^{+}$o que diminui a sua reabsorção e portanto o aumento da excreção. Jankowski et al. (2000) também demonstraram que a OT é localmente sintetizada e armazenada em vasos sanguíneos grandes de ratos e que ainda podem agir em seus receptores, os quais também são sintetizados nestes locais. Sendo assim, pode-se hipotetizar que a OT desempenha um importante papel fisiológico no controle do tônus vascular.

A ação central da OT no controle cardiovascular provavelmente também ocorre devido aos neurônios ocitocinérgicos originários no NPV que se projetam para importantes regiões envolvidas com o controle cardiovascular, as quais compreendem o núcleo do trato solitário, núcleo ambíguo, locus coeruleus, núcleo motor dorsal do nervo vago e núcleo dorsal da rafe (BUIJS, 1983). Petersson et al. (1996) demonstraram que a OT reduziu em longo prazo a pressão arterial de ratos.

Estudos recentes em camundongos knockouts de OT têm confirmado que esses animais possuem controle autônomo e reflexo baroreceptor anormais sobre a freqüência cardíaca e a pressão arterial (MANTELLA et al., 2003; MICHELINI et al., 2003). Os efeitos da OT na diminuição da pressão arterial em ratas (KNOX; UVNAS-MOBERG, 1998; MANTELLA et al.,2003; PETERSSON et al., 1996) têm sido demonstrados e em humanos os estudos de suas ações em tecidos cardiovasculares ainda são escassos. Light et al. (2004) estudou mães com história de uso de cocaína durante a gravidez. Essas mulheres apresentaram níveis plasmáticos menores de OT, pressão arterial superior e níveis de NE maiores em urina de 24 horas quando comparadas com o grupo que não usou o fármaco. Sendo assim, os estudos indicam ações central e periférica da OT na regulação de parâmetros hemodinâmicos, os quais estão sujeitos a alterações durante situações de estresse e ansiedade (BERNATOVA et al., 2004; LIGHT et al., 2004). 
2. OBJETIVO 


\section{OBJETIVO}

Avaliar os efeitos agudos da administração intranasal da OT no controle da ansiedade induzida em voluntários submetidos ao Teste de Simulação de Falar em Público (TSFP) e estabelecer uma possível relação com parâmetros endócrinos e hemodinâmicos. 
3. CASUÍSTICA E MÉTODOS 


\section{CASUÍSTICA E MÉTODOS}

\subsection{Sujeitos}

Foram avaliados 28 voluntários saudáveis do sexo masculino, divididos em dois grupos de 14 sujeitos. Os voluntários selecionados foram alunos da graduação e pósgraduação da Universidade de São Paulo, campus Ribeirão Preto. Os grupos foram emparelhados quanto à idade, índice de massa corpórea (IMC), nível socioeconômico (do sujeito e do chefe da família), nível de ansiedade traço e intensidade do medo de falar em público.

Os critérios de exclusão foram: uso de qualquer medicação concomitante, história de doença neurológica, distúrbios psiquiátricos, problemas renais, pulmonares, hepáticos ou cardiovasculares, fumantes, hipertensos, alcoolistas, usuários de drogas de abuso e insuficiência hepática. No processo de triagem, o nível de ansiedade foi avaliado por meio do Inventário de Ansiedade de Beck (BECK et al., 1988). A intensidade do medo de falar em público foi avaliada por meio da escala Auto-Avaliação de Falar em Público (AAFP) (HOFFMAN e DI BARTOLO, 2000). Para excluir a possibilidade de uso nocivo do álcool foram incluídos sujeitos com escore menor que 3 na escala FAST (HODGSON et al., 2002). Para se excluir qualquer possibilidade de transtorno psiquiátrico se utilizou as escalas PHQ-2 (KROENKE et al., 2003) e SRQ (WHO, 1993) como triagem prévia e posteriormente ainda foi aplicada a versão em português (DEL-BEN et al, 2001a) da entrevista clínica estruturada para o DSM-IV (FIRST et al., 1997) por uma médica psiquiátrica devidamente treinada e qualificada. A classe socioeconômica (dos sujeitos e do chefe da família) foi avaliada pelo Critério de Classificação Socioeconômico - Brasil (CCSEB, 1997). 
Os voluntários foram instruídos a não comer e a não beber, exceto água, durante 2 horas antes do experimento e a não fazer exercícios e ingerir bebidas alcoólicas e xantínicas no período de 24 horas antes do experimento.

Os voluntários foram randomicamente alocados para receberem administração intranasal de ocitocina (Syntocinon ${ }^{\circledR}$, Novartis, Brasil) ou placebo (veículo do Syntocinon ${ }^{\circledR}$, Novartis, Brasil). Os sujeitos ficaram “cegos” quanto a substância administrada até o final do experimento.

\subsection{Administração da ocitocina ou placebo}

Foi realizada, aos voluntários, a administração intranasal de OT (Syntocinon ${ }^{\circledR}$ - Spray Nasal - Novartis, Brasil) ou placebo (veículo do Syntocinon ${ }^{\circledR}$, Novartis, Brasil) em uma dose única de 24 UI de OT ou placebo, sendo que foram feitas 3 aplicações de 4 UI por narina. A administração da OT ou do placebo foi realizada 50 (cinqüenta) minutos antes da medida de preparação do discurso. O tempo de escolha foi baseado em estudos anteriormente realizados (HEINRICHS et al., 2003; KOSFELD et al., 2005) e também na cinética da OT (BORN et al., 2002).

\subsection{Medidas de Avaliação}

\subsubsection{Instrumentos de Avaliação}

Para avaliação dos estados subjetivos durante o TSFP, foram utilizadas as seguintes escalas de auto-avaliação: 
1) Escala Analógica de Humor - EAH (Visual Analogue Mood Scale -VAMS) (NORRIS, 1971). Trata-se de uma escala composta por 16 itens, sendo que cada um destes possui uma linha reta de $100 \mathrm{~mm}$ que liga dois adjetivos opostos. O sujeito deve assinalar como se sente no momento do preenchimento com relação a cada uma das condições com um traço vertical, sendo que o centro da linha é como o mesmo se sente habitualmente e seguindo para os opostos aumenta a intensidade de uma ou outra condição. Esta escala foi traduzida por Zuardi et al. (1993) e a mesma foi dividida em 4 fatores (sedação mental, sedação física, ansiedade, outros sentimentos e atitudes) semelhantes a versão original. No entanto, o presente estudo utilizou a nomenclatura proposta por Parente et al., 2005, os quais propuseram os seguintes nomes: (1) ansiedade; (2) sedação (no lugar de sedação mental); (3) prejuízo cognitivo (no lugar de sedação física) e (4) desconforto (no lugar de outros sentimentos e atitudes). (Anexo 1).

2) Escala de Sintomas Somáticos (ESS) (Bodily Symptoms Scale - BSS) (ZUARDI et al, 1993), a qual é designada para avaliar sintomas somáticos que podem indiretamente afetar a ansiedade. É composta por 21 itens, nos quais os indivíduos assinalam como se sentem no momento, variando de nada (0) até extremamente (5) (Anexo 2).

\section{3) Versão de “Estado” da escala de Auto-Avaliação ao Falar em Público (AAFP)} (Self-Statements During Public Speaking - SSPS): É composta por 10 itens, sendo que podem ser divididas em auto-avaliação positiva (itens 1, 3, 5, 6 e 9) e auto-avaliação negativa (itens 2, 4, 7, 8 e 10). A pessoa deve imaginar o que pensa de si em uma situação de falar em público. Tendo em mente esta situação, deve concordar ou não com as afirmações dos 10 itens, variando de 0 (discorda totalmente) até 5 (cinco) concorda totalmente. Para a avaliação os pontos são somados, sendo que na pontuação dos pontos negativos, há a inversão dos valores, ou seja, 0 torna-se 5 e vice-versa (HOFFMAN e DI BARTOLO, 2000; adaptação de CRIPPA et al., 2004) (Anexo 3). 
Antes do experimento, cada um dos participantes realizou uma sessão de treinamento para completar as escalas.

\subsubsection{Medidas Fisiológicas / Psicofisiológicas}

As medidas fisiológicas e psicofisiológicas foram realizadas ao longo de períodos de 2 minutos nos diferentes pontos de avaliação (Tabela 1) e incluíram pressão arterial (PA), número de respostas de flutuações espontâneas de condutância da pele (SF), média do nível de condutância da pele (SCL) e média de freqüência cardíaca (FC, calculada a partir do intervalo entre as batidas).

A PA foi avaliada por meio de um aparelho de mercúrio (Becton Dicknson, Brasil). As outras medidas foram gravadas por meio de um sistema psicofisiológico totalmente computadorizado (Contact Precision Instruments, Reino Unido).

\subsubsection{Coleta de sangue}

Foi coletado sangue para dosagem plasmática da cortisol e ACTH nos tempos -0:15; $0: 36 ; 0: 50 ; 1: 11 ; 1: 36$ e $1: 56$.

A coleta do sangue foi realizada nos tempos determinados com o voluntário na posição sentada e foi retirado $10 \mathrm{~mL}$ de sangue em cada ponto. O sangue foi imediatamente transferido para tubos de polipropileno. Para a coleta de ACTH foi utilizado EDTA como anticoagulante. As amostras para estudo de cortisol foram transferidas para tubos com gel separador. Todos os tubos foram mantidos imersos em gelo durante a sessão experimental. As amostras de sangue para a determinação de ACTH e cortisol foram centrifugados a 3000 rpm durante 15 minutos em centrífuga refrigerada a $4{ }^{\circ} \mathrm{C}$ e as alíquotas de plasma e soro, 
respectivamente, foram congeladas em tubo de polipropileno em uma temperatura de $-20{ }^{\circ} \mathrm{C}$ até a análise.

\subsection{Protocolo Clínico}

\subsubsection{Teste de Simulação de Falar em Público}

Cada voluntário participou de somente uma sessão experimental. Eles foram randomicamente alocados para receber a OT ou placebo, em um procedimento simples-cego.

O procedimento de TSFP foi similar ao usado por McNair et al. (1982) com as modificações introduzidas por Guimarães et al. (1987). A sessão experimental foi conduzida em uma sala com atenuação sonora e temperatura controlada. Após um período de adaptação de 15 minutos, as medidas basais (B) foram realizadas seguidas pela administração da OT ou placebo. Após $36 \mathrm{~min}$ as medidas pré-teste (PT) foram realizadas. Imediatamente após, os sujeitos sentados em frente a uma televisão assistiram a um videotape pré-gravado com instruções sobre a tarefa que iriam desempenhar. Aos sujeitos foi dito que eles teriam dois minutos para preparar um discurso de quatro minutos sobre "o sistema de transporte de suas cidades”, que seria gravado e posteriormente analisado por um psicólogo. Medidas de preparação do discurso (Pr) foram tomadas antes dos sujeitos começarem a falar em frente a uma filmadora enquanto vendo sua própria imagem na tela. O discurso foi interrompido no meio (após dois minutos) para que pudessem ser tomadas medidas subjetivas de ansiedade de performance (S). Quinze minutos após o fim do discurso as primeiras medidas pós-teste foram realizadas (F1) e 20 minutos depois as últimas medidas foram tomadas (F2). 
Tabela 1 - Protocolo para coleta de dados.

\begin{tabular}{|c|c|c|}
\hline Horário & Fase & Procedimento \\
\hline$-0: 30$ & Adaptação & $\begin{array}{l}\text { Chegada ao laboratório, } 1^{\text {a }} \text {. parte do termo de } \\
\text { consentimento }\end{array}$ \\
\hline$-0: 15$ & Medidas Basais (B) & EAH, AAFP, ESS, SCL, SF, FC, PA, coleta de sangue \\
\hline 0 & Administração da droga & Voluntários receberão ocitocina ou placebo \\
\hline$+0: 36$ & Pré-teste (PT) & EAH, AAFP, ESS, SCL, SF, FC, PA, coleta de sangue \\
\hline$+0: 46$ & $\begin{array}{l}\text { Instrução na tela da } \\
\text { televisão }\end{array}$ & $\begin{array}{l}\text { Orientados a preparar discurso sobre sistema de } \\
\text { transportes; } 2^{\text {a }} \text { parte do termo de consentimento }\end{array}$ \\
\hline$+0: 48$ & Preparação do discurso & \\
\hline$+0: 50$ & $\begin{array}{l}\text { Medidas da preparação } \\
\text { (Pr) }\end{array}$ & EAH, AAFP, ESS, SCL, SF, FC, PA, coleta de sangue \\
\hline$+1: 01$ & Início do discurso & $\begin{array}{l}\text { Sujeitos falam em frente à câmera, vendo-se na tela da } \\
\text { televisão }\end{array}$ \\
\hline$+1: 03$ & $\begin{array}{l}\text { Ansiedade de } \\
\text { performance (S) }\end{array}$ & EAH, AAFP, ESS SCL, SF, FC, PA \\
\hline$+1: 09$ & Discurso continua & \\
\hline$+1: 11$ & Término do discurso & Coleta de Sangue \\
\hline$+1: 26$ & Pós-teste 1 (F1) & EAH, AAFP, ESS, SCL, SF, FC, PA \\
\hline$+1: 36$ & Dosagem plasmática & Coleta de Sangue \\
\hline$+1: 46$ & Pós-teste 2 (F2) & EAH, AAFP, ESS, SCL, SF, FC, PA \\
\hline$+1: 56$ & Dosagem plasmática & Coleta de Sangue \\
\hline
\end{tabular}




\subsection{Determinação plasmática do ACTH}

A determinação quantitativa do ACTH em plasma com EDTA foi realizado no Analisador IMMULITE / IMMULITE 1000 e trata-se de um ensaio imunométrico quimioluminescente em fase-sólida. Os kits foram fornecidos pela DPC MedLab, Brasil.

As análises foram realizadas dentro de um prazo máximo de 30 dias. Antes do doseamento, as amostras foram descongeladas em banho de gelo e mantidas permanentemente a $4{ }^{\circ} \mathrm{C}$ ou menos. Os resultados analíticos foram apresentados em $\mathrm{pg} / \mathrm{mL}$ e a sensibilidade analítica foi de $9 \mathrm{pg} / \mathrm{mL}$. O volume da amostra utilizado para análise foi de 75 $\mu l$.

\subsection{Determinação sérica do cortisol}

A determinação quantitativa do hormônio cortisol em soro foi realizada no Analisador IMMULITE / IMMULITE 1000 e trata-se de um imunoensaio competitivo quimioluminescente em fase-sólida. Os kits foram fornecidos pela DPC MedLab, Brasil.

As análises foram realizadas dentro de um prazo máximo de 30 dias. Antes do doseamento, as amostras foram descongeladas em banho de gelo e mantidas permanentemente a $4{ }^{\circ} \mathrm{C}$ ou menos. Os resultados analíticos foram apresentados em $\mu \mathrm{g} / \mathrm{dL}$ e a sensibilidade analítica foi de $0,2 \mu \mathrm{g} / \mathrm{mL}$. O volume da amostra utilizado para análise foi de 75 $\mu l$.

\subsection{Análise Estatística}

Os dados da EAH, AAFP, frequência cardíaca (FC), pressão arterial sistólica e diastólica (PAS e PAD), condutância elétrica da pele, cortisol e ACTH foram avaliados 
usando um modelo de efeitos mistos para cada variável dependente. Os modelos lineares de efeitos mistos (efeitos aleatórios e fixos) são utilizados na análise de dados onde as respostas de um mesmo indivíduo estão agrupadas e a suposição de independência entre observações num mesmo grupo não é adequada (SCHALL, 1991). Esses modelos têm como pressuposto que seus resíduos tenham distribuição normal com média 0 e variância $\sigma^{2}$. O modelo proposto é dado por:

$$
y_{i j k}=\eta+\omega_{i}+\beta_{j}+\delta_{k}+\phi_{j k}+\varepsilon_{i j k}
$$

onde $y_{i j k}$ é a observação da variável resposta em questão do i-ésimo indivíduo, no j-ésimo grupo, no $k$-ésimo tempo. $\eta$ é uma constante (um intercepto); $\omega_{i}$ é um efeito aleatório ( $i=1, \ldots$, 20); $\beta_{j}$ é o efeito do $j$-ésimo tratamento $(j=1,2) ; \delta_{k}$ é o efeito do $k$-ésimo tempo $(k=1, \ldots, 6)$; $\phi_{j k}$ é a interação entre o j-ésimo grupo $(j=1,2)$ e o $k$-ésimo tempo $(k=1, \ldots, 6)$ e $\varepsilon_{i j}$ é o erro associado, com distribuição $\mathrm{N}\left(0, \sigma^{2}\right)$. Foi utilizado o procedimento PROC MIXED do software SAS versão 9.

O modelo de efeitos mistos utilizado na análise dos dados é similar a uma análise de variância (ANOVA) em duas vias, mas com a diferença de tratar os sujeitos amostrados como uma amostra aleatória proveniente de uma população, e não como efeitos fixos.

Pelo fato da variável número de flutuações da condutância se tratar de uma variável do tipo contagem foi proposto um modelo de Poisson, ou seja $y_{\mathrm{ijk}}$ é o número de flutuações observado para o i-ésimo indivíduo no j-ésimo grupo e no k-ésimo tempo. Logo, o modelo é dado por:

$$
\boldsymbol{P}\left(\boldsymbol{Y}_{i j \mathrm{k}}=y_{i j \mathrm{k}}\right)=\frac{e^{-\lambda_{i j k}} \lambda_{i j k}}{y_{i j k} !}
$$


onde,

$$
\lambda_{i j k}=e^{\eta+\omega_{i}+\beta_{j}+\delta_{k}+\phi_{j k}+\varepsilon_{i j k}}
$$

Os resultados foram expressos em média \pm erro padrão da média (epm). O nível de significância considerado foi de p-valor $<0,05$. A análise descritiva das variáveis encontra-se no item “APÊNDICE”.

Os itens individuais da ESS foram analisados em cada ponto de avaliação usando a análise Wilcoxon para dados não-paramétricos.

Para se verificar se os grupos estavam emparelhados foi utilizado o teste exato de Fisher para a análise da classe social e das escalas FAST e PHQ-2 e foi utilizado o teste t de Student para a análise da idade, IMC, AAFP e IAB.

\subsection{Aspectos Éticos}

Os voluntários receberam informações detalhadas sobre o projeto de pesquisa, tendo liberdade de optar pela participação no estudo. Os participantes foram incluídos após serem informados, em detalhes, sobre o estudo e preencherem corretamente o Termo de Consentimento Livre e Esclarecido (Anexo 4). O protocolo de estudo foi aplicado aos voluntários somente após aprovação do Comitê de Ética em Pesquisa do HCFMRP - USP (Anexo 5). Estudos prévios foram conduzidos em humanos com doses entre 20 e 60 UI e nenhum efeito adverso foi reportado (BRUINS, 1992; FEHM-WOLFSDORF, 1988; PITMAN et al., 1993). Além disto, na composição da amostra foram selecionados apenas sujeitos do sexo masculino a fim de evitar prováveis efeitos indesejáveis nas mulheres como contração uterina.

Todos os procedimentos foram conduzidos de acordo com a Declaração de Helsinque e as normas éticas do Ministério da Saúde (C.N.S. Resolução nº 196 de 10/10/96).

Os voluntários receberam $\mathrm{R}$ \$20,00 como ajuda de custo pelo tempo dispensado, transporte e alimentação. 
4. RESULTADOS 


\section{RESULTADOS}

\subsection{Sujeitos}

Os sujeitos dos grupos OT e placebo estavam emparelhados quanto à idade, IMC, escores no FAST (para excluir uso nocivo do álcool), AAFP, IAB, PHQ-2 (índice de depressão), SRQ-2 (nível de psicopatologia) e nível sócio-econômico (Tabela 2).

Tabela 2 - Características dos grupos em estudo

\begin{tabular}{|c|c|c|c|}
\hline \multirow[b]{3}{*}{ VARIÁVEIS } & \multicolumn{2}{|c|}{ TIPO DE TRATAMENTO } & \multirow[b]{3}{*}{$p$ - valor } \\
\hline & \multirow{2}{*}{$\begin{array}{l}\text { Grupo ocitocina } \\
(\mathrm{n}=10) \\
\text { Média } \pm \text { desvio- }\end{array}$} & Grupo placebo $(n=10)$ & \\
\hline & & Média \pm desvio-padrão & \\
\hline Idade & & & \\
\hline (anos) & $23,8 \pm 2,4$ & $23,6 \pm 3,1$ & 0,8 \\
\hline IMC & $25,1 \pm 4,4$ & $24,2 \pm 4,3$ & 0,6 \\
\hline AAFP & $38,3 \pm 8,1$ & $37,7 \pm 4,7$ & 0,8 \\
\hline $\mathrm{IAB}$ & $10,5 \pm 8,1$ & $10,6 \pm 8,7$ & 0,9 \\
\hline FAST & & & 0,8 \\
\hline PHQ-2 & & & 0,2 \\
\hline $\begin{array}{l}\text { SRQ-12 } \\
\text { SFR }\end{array}$ & & & 0,3 \\
\hline $\begin{array}{l}\text { CCSEB } \\
\text { (sujeito) }\end{array}$ & & & 0,2 \\
\hline $\begin{array}{l}\text { CCSEB } \\
\text { (chefe da }\end{array}$ & & & \\
\hline família) & & & 0,4 \\
\hline
\end{tabular}

\subsection{Escala Analógica de Humor}

Os resultados obtidos nos 16 itens da EAH foram agrupados em quatro fatores de acordo com seus maiores pesos relativos (Tabela 3). Os fatores foram divididos em: ansiedade, sedação, prejuízo cognitivo e desconforto (ZUARDI et al., 1993). 
Tabela 3 - Distribuição da Escala Analógica de Humor de acordo com seus maiores pesos relativos.

\begin{tabular}{|c|c|c|}
\hline FATORES & ESCALAS & PESOS \\
\hline 1. Ansiedade & 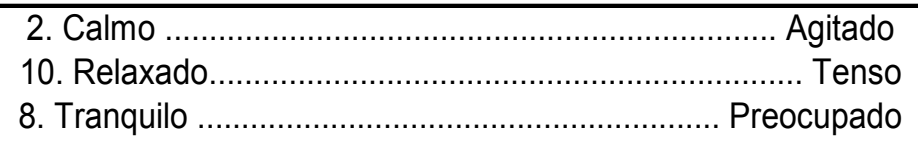 & $\begin{array}{l}0,79684 \\
0,79314 \\
0,74407\end{array}$ \\
\hline 2. Prejuízo Cognitivo & 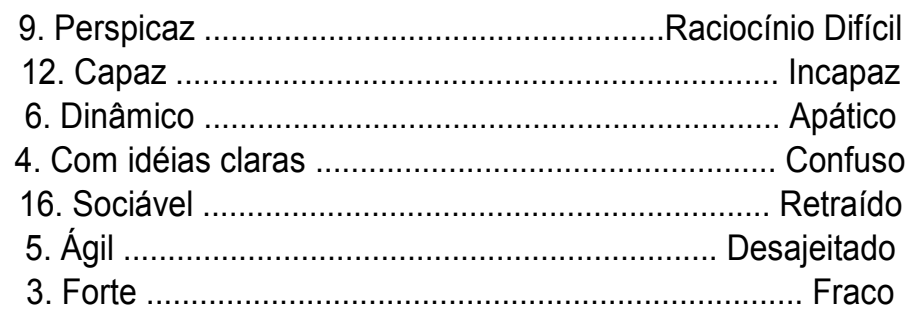 & $\begin{array}{l}0,79269 \\
0,78759 \\
0,75456 \\
0,69263 \\
0,64888 \\
0,64236 \\
0,58922\end{array}$ \\
\hline 3. Sedação & 1. Alerta & $\begin{array}{l}0,77782 \\
0,59093\end{array}$ \\
\hline 4. Desconforto & 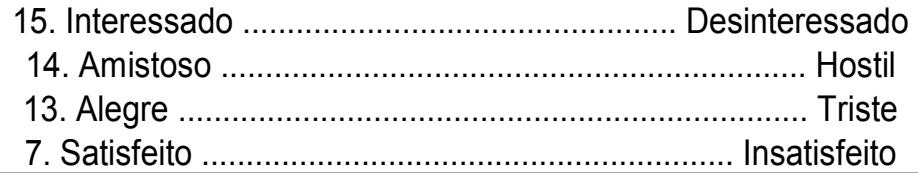 & $\begin{array}{l}0,72303 \\
0,70477 \\
0,69215 \\
0,56842\end{array}$ \\
\hline
\end{tabular}

FONTE: Zuardi et al., 1993

\section{A. FATOR ANSIEDADE}

Análises intragrupos mostraram que houve indução da ansiedade em ambos os grupos.

Sendo que no grupo placebo, houve aumento da ansiedade na fase Pr em relação às fases B $(\mathrm{p}$-valor $=0,03), \mathrm{PT}(\mathrm{p}$-valor = 0,005) e em seguida diminuição nas fases F1 (p-valor < 0,001) e F2 (p-valor < 0,001). A ansiedade também foi maior na fase S em relação às fases PT (pvalor $=0,01), \mathrm{F} 1(\mathrm{p}$-valor $=0,002)$ e F2 (p-valor = 0,002). No grupo ocitocina, a ansiedade na fase Pr foi maior somente em relação à fase PT (p-valor =0,001). Além disto, houve uma diminuição significativa da ansiedade na fase PT em relação à fase $\mathrm{B}$ (p-valor $=0,01$ ). Comparações intergrupos para cada fase mostraram que o grupo placebo $(52,7 \pm 1,8 \mathrm{~mm})$ mostrou-se mais ansioso que o grupo ocitocina $(46,5 \pm 2,0 \mathrm{~mm})$ na fase PT, p-valor $=0,03$ (Figura 2). 


\section{Escala Analógica de Humor - Ansiedade}

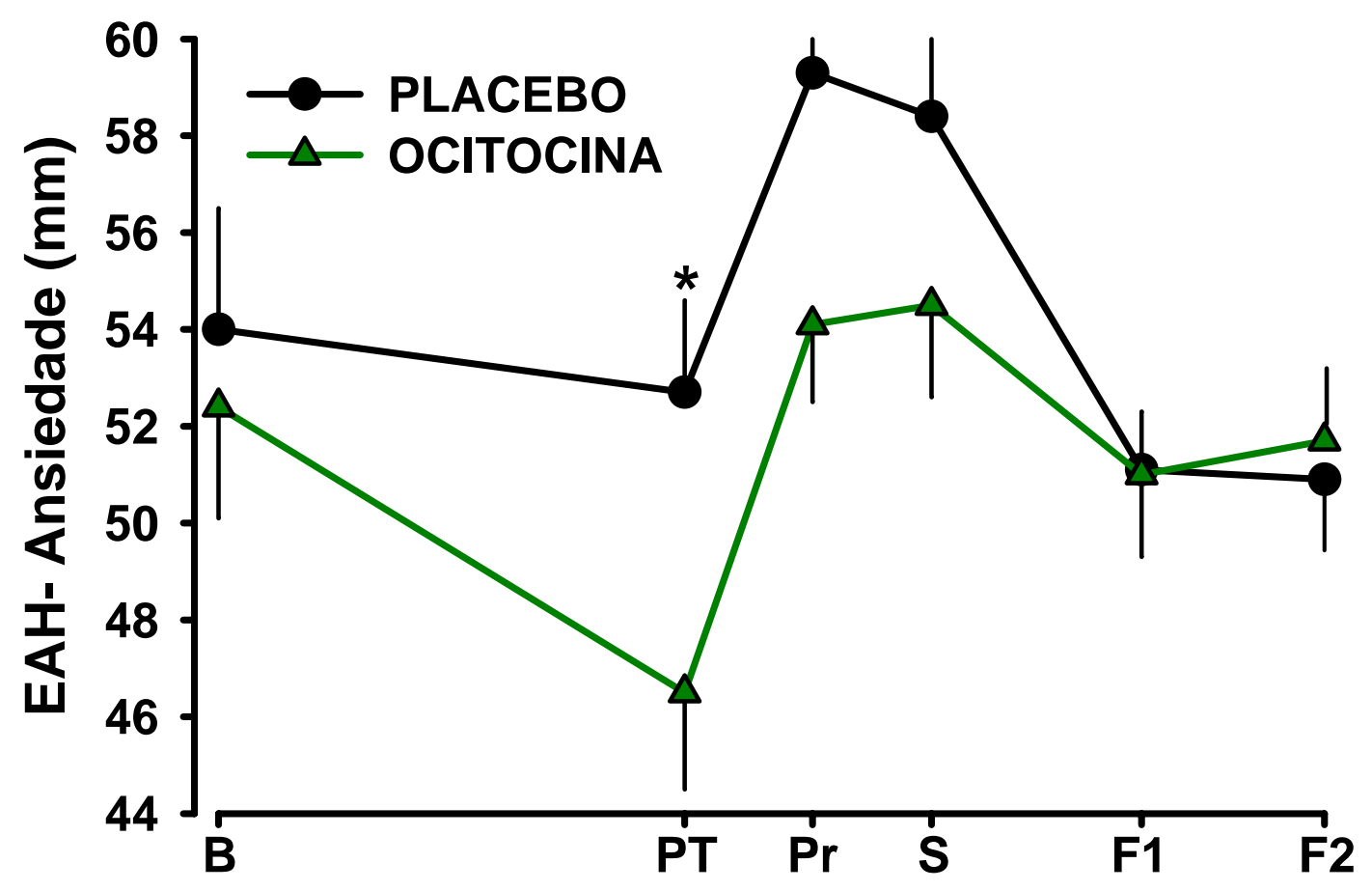

Fases

Figura 2- Efeitos da ocitocina e do placebo na ansiedade subjetiva avaliada pela Escala Analógica de Humor (EAH) em voluntários saudáveis submetidos ao Teste de Simulação de Falar em Público. Os resultados estão expressos por média \pm epm $(\mathrm{mm})$. As escalas foram aplicadas em diferentes fases durante a sessão experimental: basal (B), pré-estresse (PT), preparação (Pr), performance (S), pós-teste 1 (F1) e pós-teste 2 (F2). * $\mathrm{p}$ - valor $<0,05$ entre os dois tratamentos. 


\section{B. PREJUÍZO COGNITIVO}

Comparações intra e intergrupos não mostraram diferenças estatísticas nas diferentes fases (Figura 3).

\section{Escala Analógica de Humor - Prejuízo Cognitivo}

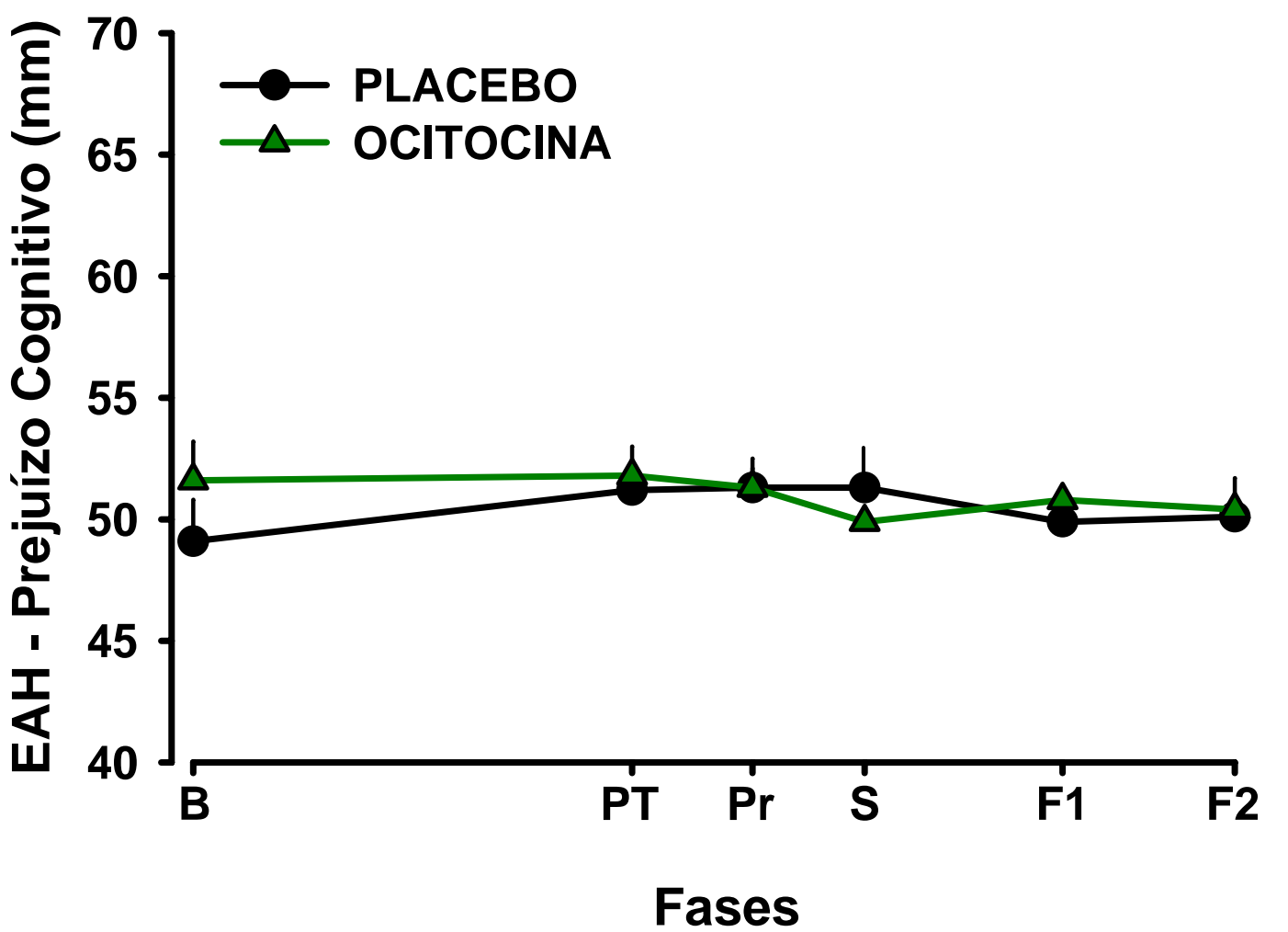

Figura 3 - Efeitos da ocitocina do placebo no prejuízo cognitivo avaliada pela Escala Analógica de Humor (EAH) em voluntários saudáveis submetidos ao Teste de Simulação de Falar em Público. Os resultados estão expressos por média \pm epm $(\mathrm{mm})$. As escalas foram aplicadas em diferentes fases durante a sessão experimental: basal (B), pré-teste (PT) (Pr), performance (S), pós-teste 1 (F1) e pós-teste 2 (F2). 


\section{SEDAÇÃO}

Comparações intragrupos mostraram que no grupo placebo, houve menor sedação na Pr em relação às fases B (p-valor < 0,001) e PT (p-valor < 0,001), F1 (p-valor < 0,001) e F2 (p-valor < 0,001). A sedação na fase $S$ também foi menor em relação às fases $B$ (p-valor = 0,003), PT (p-valor = 0,003), F1 (p-valor = 0,008) e F2 (p-valor < 0,001). No grupo ocitocina, houve menor sedação na fase Pr em relação às fases B (p-valor $=0,009)$ e PT (p-valor < 0,001). Também houve menor sedação na fase $S$ em relação às fases $B(p$-valor $=0,02$ ) e PT (p-valor $<0,001)$ Comparações intergrupos para cada fase mostraram que o grupo ocitocina apresentou maior sedação mental que o grupo placebo nas fases PT (56,7 $\pm 2,0$ mm; 47,5 \pm 2,5 mm, p-valor = 0,003), $\operatorname{Pr}(47,1 \pm 1,7 \mathrm{~mm} ; 39,0 \pm 2,9 \mathrm{~mm}, \mathrm{p}$-valor $=0,01)$ e S $(47,7 \pm 1,3$ $\mathrm{mm} ;$ 41,0 \pm 3,0 mm, p-valor = 0,02) (Figura 4). 


\section{Escala Analógica de Humor - Sedação}

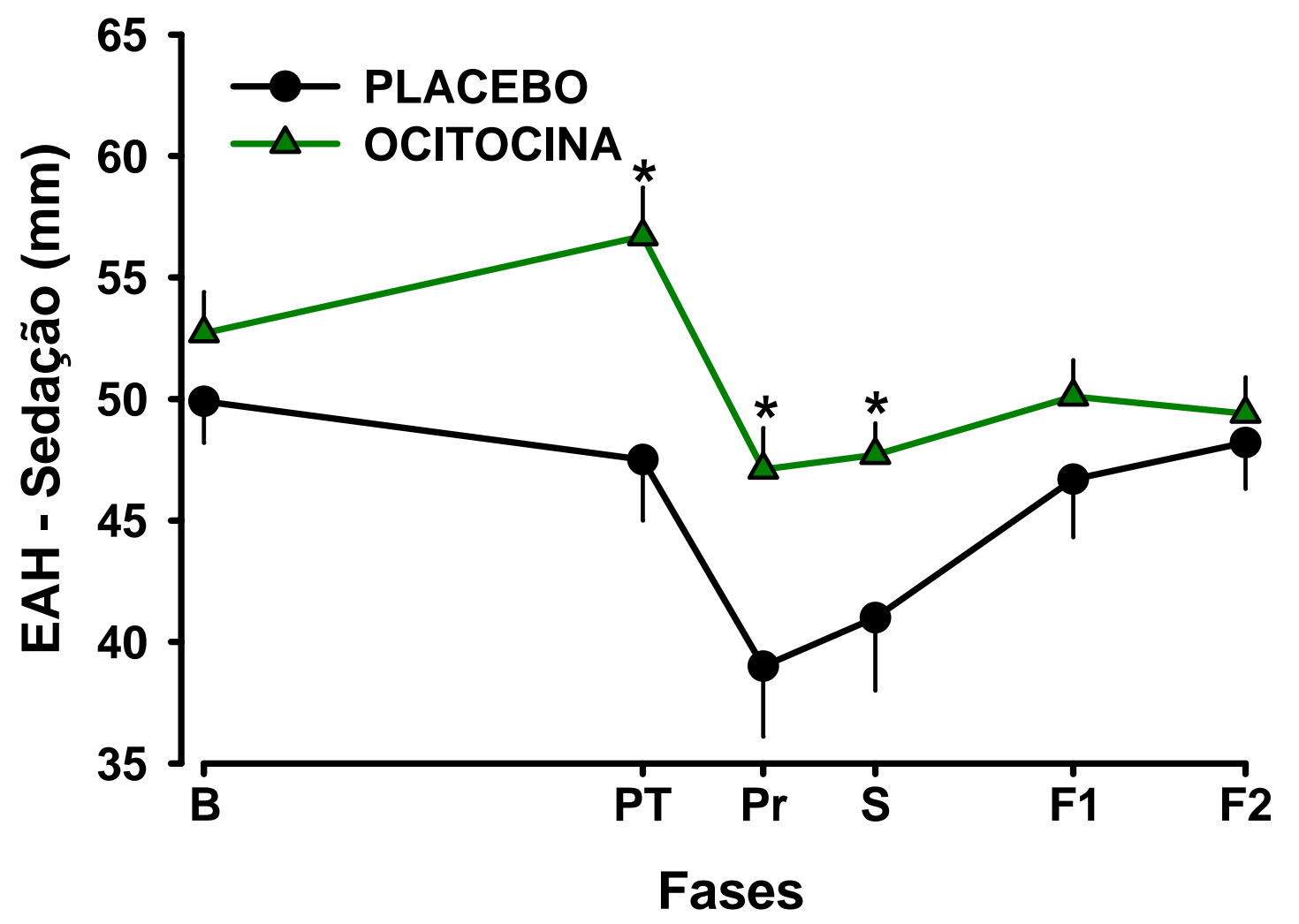

Figura 4 - Efeitos da ocitocina e do placebo na sedação avaliada pela Escala Analógica de Humor (EAH) em voluntários saudáveis submetidos ao Teste de Simulação de Falar em Público. Os resultados estão expressos por média \pm epm (mm). As escalas foram aplicadas em diferentes fases durante a sessão experimental: basal (B), pré-teste (PT), preparação (Pr), performance (S), pós-teste 1 (F1) e pós-teste 2 (F2). * p $<0,05$ entre os dois tratamentos. 


\section{DESCONFORTO}

Comparações intergrupos não mostraram diferenças estatísticas nas diferentes fases

(Figura 5).

\section{Escala Analógica de Humor - Desconforto}

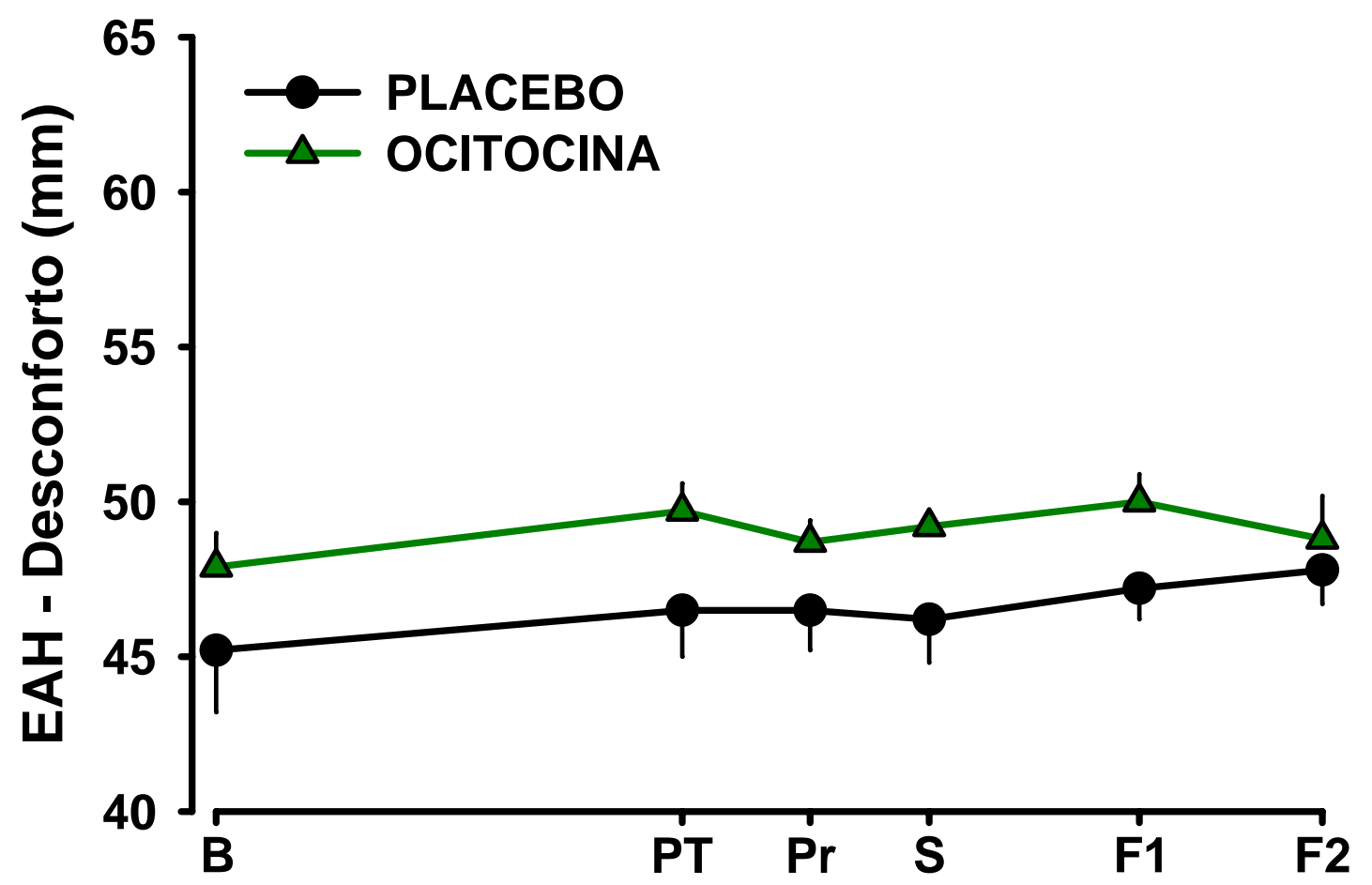

Fases

Figura 5 - Efeitos da ocitocina e do placebo no desconforto avaliada pela Escala Analógica de Humor (EAH) em voluntários saudáveis submetidos ao Teste de Simulação de Falar em Público. Os resultados estão expressos por média \pm epm (mm). As escalas foram aplicadas em diferentes fases durante teste 2 (F2). 


\subsection{Auto-avaliação ao falar em público}

Com a finalidade de analisar os dados obtidos nos 10 itens da escala de AAFP, os resultados foram divididos em 3 subescalas: negativa, positiva e total. A pontuação total máxima é de 50 pontos, sendo que quanto maior o valor, menor o medo de falar em público. No eixo “y” está a pontuação obtida.

\section{A. Auto-avaliação positiva ao falar em público}

Comparações intragrupos no grupo placebo não mostraram diferenças significativas. No grupo ocitocina, houve aumento da avaliação positiva em relação à fase B nas fases F1 (pvalor $=0,01)$ e F2 (p-valor $=0,01)$. Comparações intergrupos não mostraram diferenças estatísticas nas diferentes fases (Figura 6). 


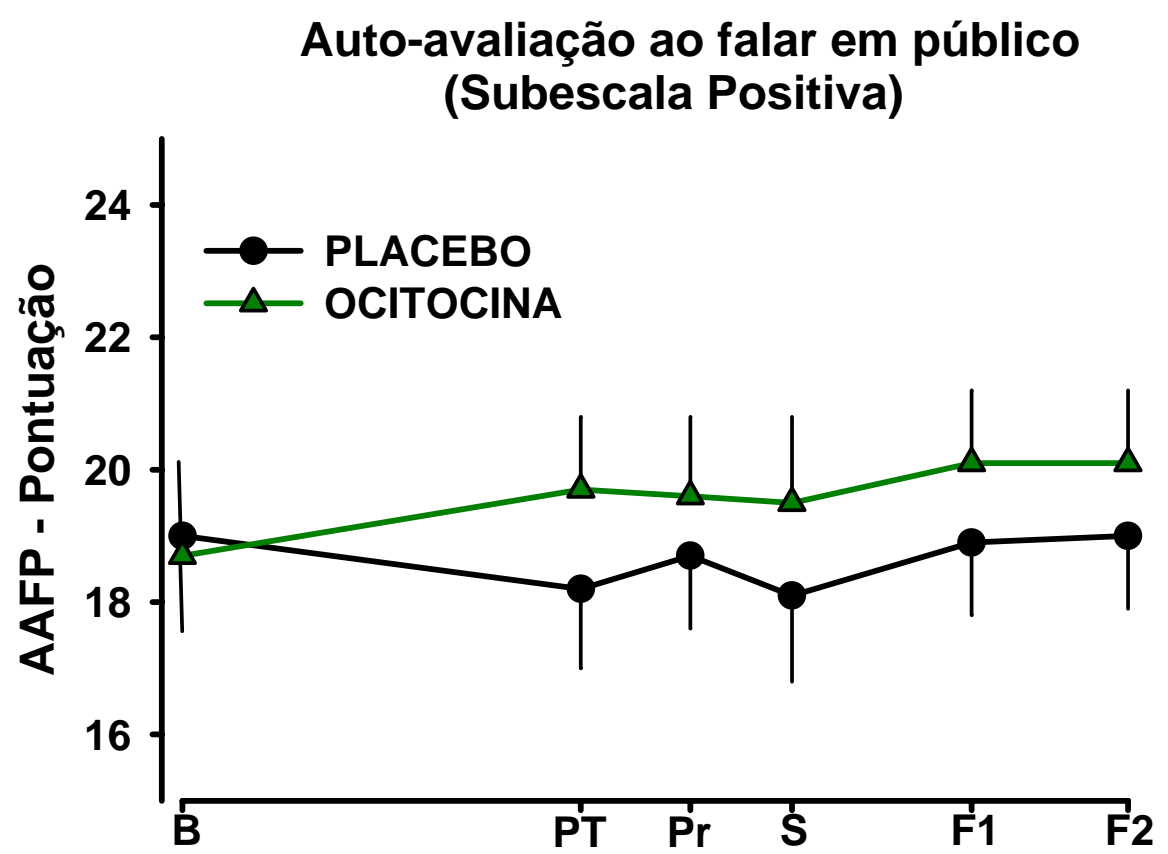

Fases

Figura 6 - Efeitos da ocitocina e do placebo na auto-avaliação positiva ao falar em público em voluntários saudáveis submetidos ao Teste de Simulação de Falar em Público. Os resultados estão expressos por média \pm epm. As escalas foram aplicadas em diferentes fases durante a sessão experimental: basal (B), pré-teste (PT), preparação (Pr), performance (S), pós-teste 1 (F1) e pós-teste 2 (F2). 


\section{B. Auto-avaliação negativa ao falar em público}

Comparações intragrupos no grupo placebo mostraram que na fase Pr a auto-avaliação negativa foi maior quando comparada com as fases F1 (p-valor $=0,04)$ e F2 (p-valor = 0,03). Já no grupo ocitocina, a auto-avaliação negativa foi menor na fase Pr em relação à fase B (pvalor $=0,02)$ e também nas fases $F 1(p$-valor $=0,009)$ e F2 $(p$-valor $=0,001)$ em relação à fase B. Comparações intergrupos não mostraram diferenças estatísticas nas diferentes fases (Figura 7). 


\section{Auto-avaliação ao falar em público (Subescala negativa)}

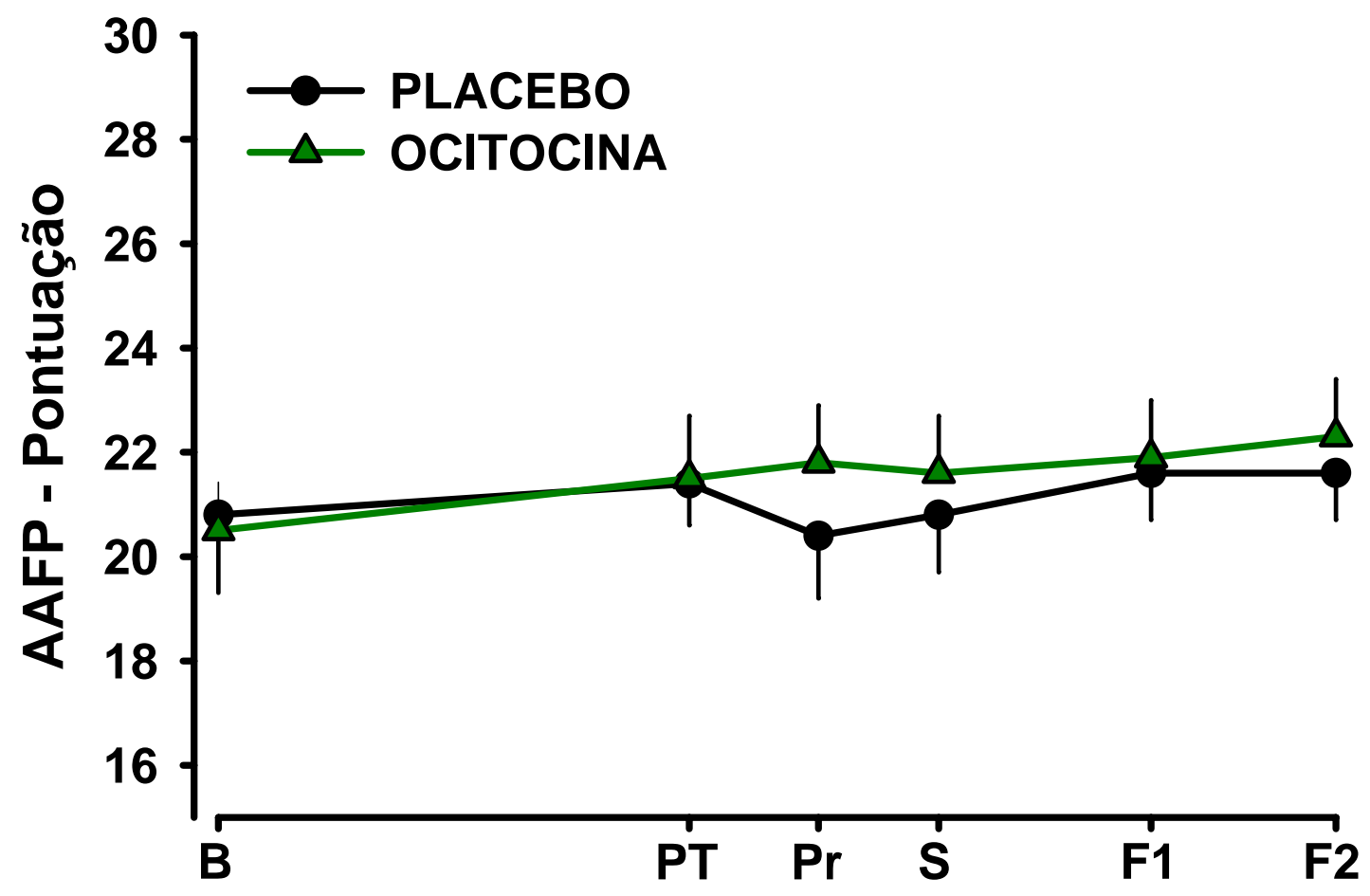

Fases

Figura 7- Efeitos da ocitocina e do placebo na auto-avaliação negativa ao falar em público em voluntários saudáveis submetidos ao Teste de Simulação de Falar em Público. Os resultados estão expressos por média \pm epm. As escalas foram aplicadas em diferentes fases durante a sessão experimental: basal (B), pré-teste (PT), preparação (Pr), performance (S), pós-teste 1 (F1) e pós-teste 2 (F2). O aumento da pontuação indica que é menor a auto-avaliação negativa ao falar em público, uma vez que ao discordar destas afirmações a pontuação do sujeito aumenta. 


\section{Auto-avaliação ao falar em público (escore total)}

Comparações intergrupos não mostraram diferenças estatísticas nas diferentes fases

(Figura 8). No entanto, somente no grupo teste houve aumento do escore total nas fases PT

$(41,2 \pm 2,0 \mathrm{~mm}), \mathrm{p}-$ valor $=$ 0,02, $\operatorname{Pr}(41,4 \pm 2,0 \mathrm{~mm}), \mathrm{p}-$ valor $=0,01, \mathrm{~S}(41,1 \pm 2,3 \mathrm{~mm}), \mathrm{p}$

- valor $=0,03, \mathrm{~F} 1(40,5 \pm 1,5 \mathrm{~mm}), \mathrm{p}-$ valor $=0,002$, e F2 $(40,6 \pm 1,5 \mathrm{~mm}), \mathrm{p}-$ valor $=$

0,0004 em relação a fase B $(39,2 \pm 1,0 \mathrm{~mm})$.

\section{Auto-avaliação ao falar em público (Pontos totais)}

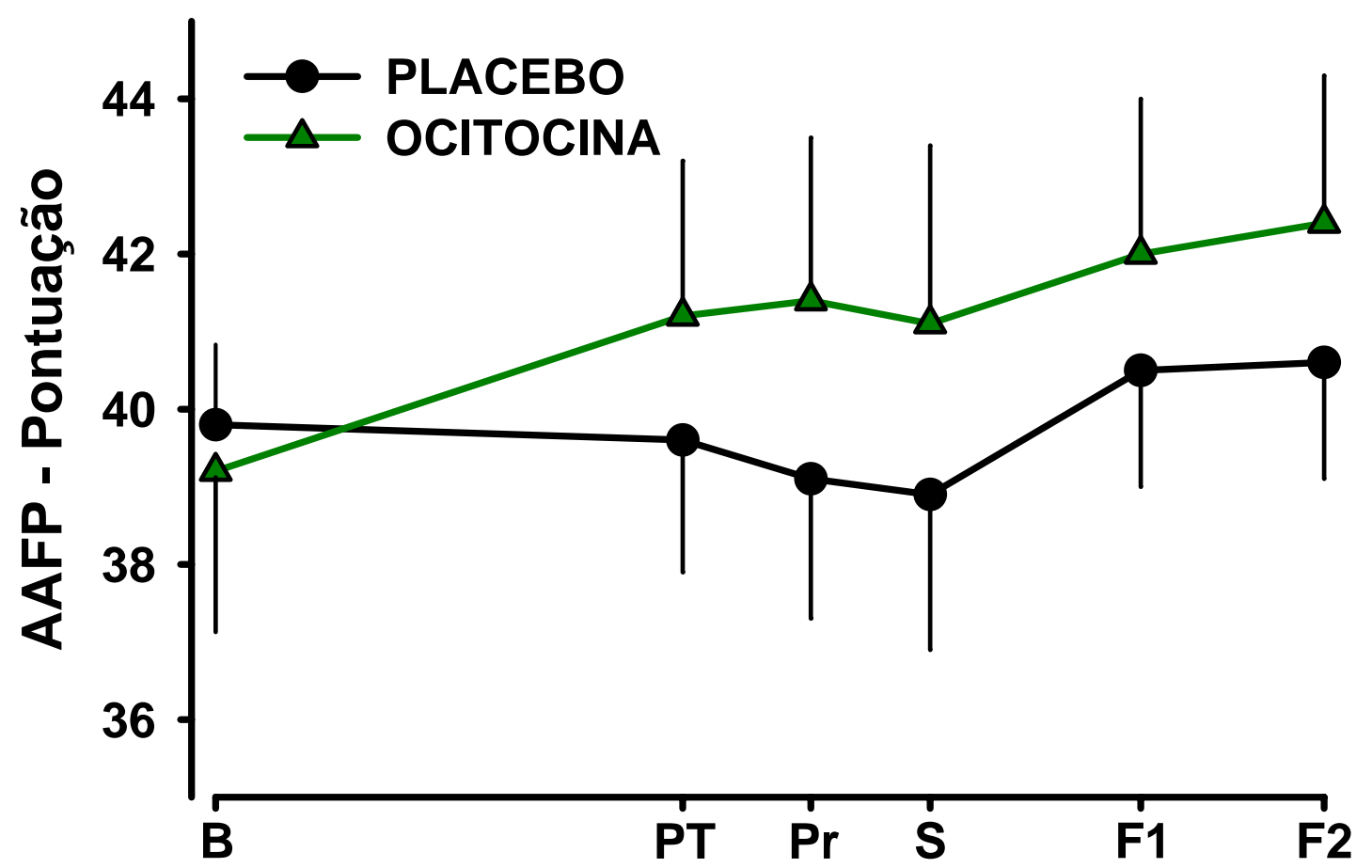

Fases

Figura 8 - Efeitos da ocitocina e do placebo na auto-avaliação ao falar em público (pontos totais) em voluntários saudáveis submetidos ao Teste de Simulação de Falar em Público. Os resultados estão expressos por média \pm epm. As escalas foram aplicadas em diferentes fases durante a sessão experimental: basal (B), préteste $(\mathrm{PT})$, preparação $(\mathrm{Pr})$, performance $(\mathrm{S})$, pós-teste $1(\mathrm{~F} 1)$ e pós-teste 2 (F2). Quanto maior a pontuação, menor o medo de falar em público. 


\subsection{Escala de Sintomas Somáticos}

Com relação aos sintomas somáticos, o grupo ocitocina apresentou letargia (item 3) maior em S e F1. Além disto, o grupo placebo apresentou mais palpitação (item 11) nas fases P e S (Tabela 4).

Tabela 4- Diferenças encontradas na escala de sintomas somáticos.

\begin{tabular}{llr}
\hline \multicolumn{1}{c}{ ÍTEM DA ESCALA } & FASE & $\boldsymbol{p}$ - valor \\
\hline 3. Letárgico & $\mathrm{S}$ & 0,04 \\
& $\mathrm{~F} 1$ & 0,04 \\
& $\mathrm{P}$ & 0,04 \\
11. Com palpitação & $\mathrm{S}$ & 0,04 \\
\hline
\end{tabular}

\subsection{Frequência Cardíaca}

Comparações intragrupos mostraram, no grupo placebo, que na fase B a FC foi maior em relação às fases PT (p-valor $=0,02), S(p$-valor $=0,003), F 1(p$-valor $=0,003)$ e F2 (pvalor $=0,003)$ e que a fase Pr também obteve maior $\mathrm{FC}$ em relação às fases $\mathrm{P}$ ( $\mathrm{p}$-valor $=$ 0,003), S (p-valor < 0,001), F1 (p-valor < 0,001) e F2 (p-valor < 0,001). No grupo ocitocina, a fase B obteve maior FC em relação às fases PT (p-valor = 0,003), S (p-valor < 0,001), F1 (pvalor $<0,001)$ e F2 (p-valor < 0,001). A FC na fase Pr também foi superior em relação às fases PT (p-valor = 0,03), S (p-valor < 0,001), F1 (p-valor < 0,001) e F2 (p-valor $<0,001)$. Comparações intergrupos não mostraram diferenças estatísticas nas diferentes fases (Figura 9). 


\section{Frequência Cardíaca}

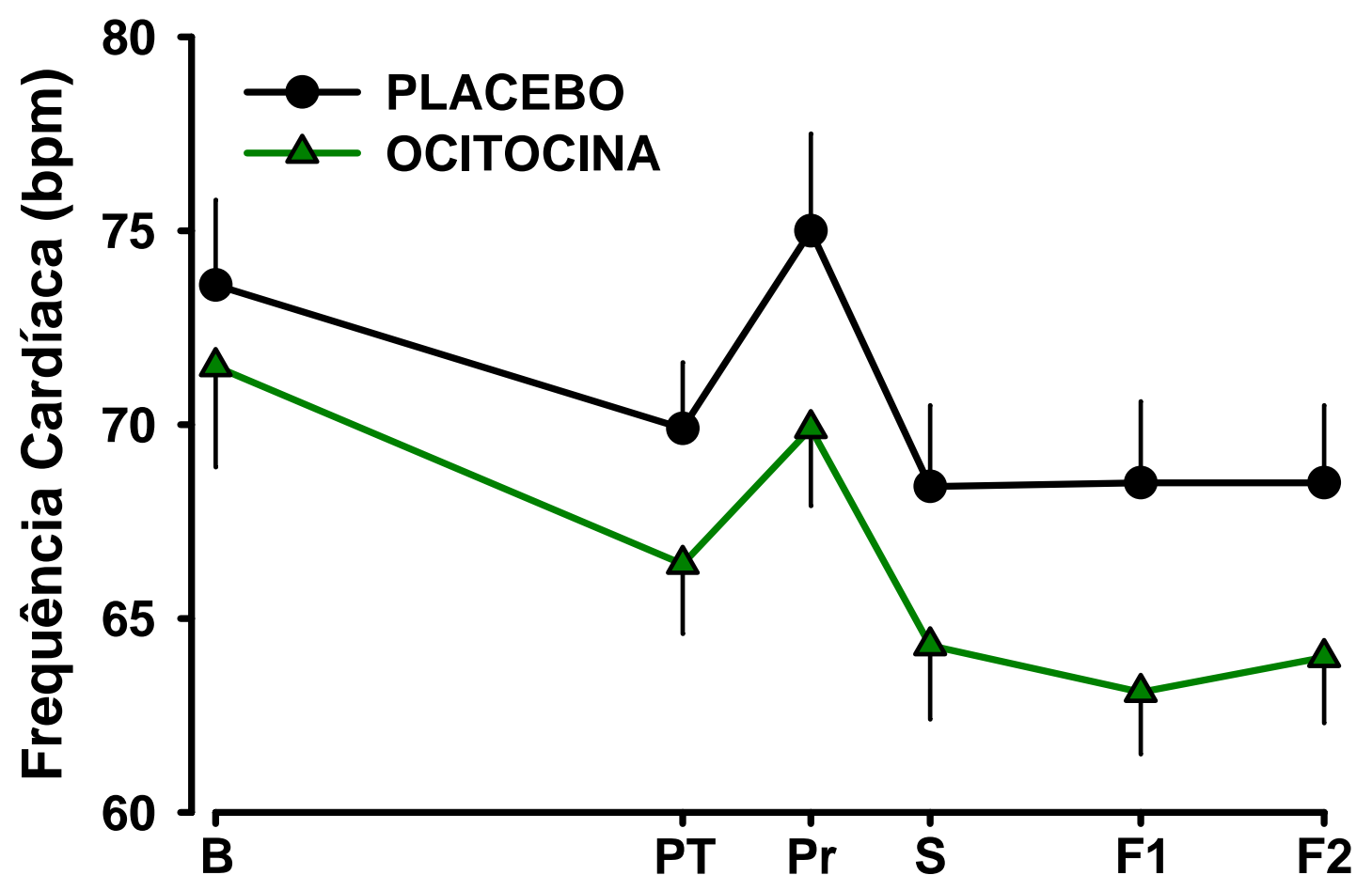

Fases

Figura 9 - Efeitos da ocitocina e do placebo na freqüência cardíaca (FC) em voluntários saudáveis submetidos ao Teste de Simulação de Falar em público. Os resultados estão expressos por média \pm epm (bpm). As escalas foram aplicadas em diferentes fases durante a sessão experimental: basal (B), pré-estresse (P), antecipatória (A), performance (S), pós-estresse 1 (F1) e pós-estresse 2 (F2). bpm = batimentos por minuto. 


\subsection{Pressão arterial sistólica}

Comparações intragrupo no grupo placebo mostrou pressão arterial sistólica (PAS) maior na fase Pr em relação às fases PT (p-valor = 0,002), F1 (p-valor = 0,005) e F2 (p-valor $=0,004)$. A fase $S$ também teve maior PAS em relação às fases $\mathrm{P}(\mathrm{p}$-valor $=0,001), \mathrm{F} 1$ (pvalor $=0,004)$ e F2 (p-valor $=0,003)$. No grupo ocitocina, a PAS foi maior na fase Pr em relação às fases B (p-valor = 0,003), PT (p-valor = 0,009), F1 (p-valor < 0,001) e F2 (p-valor $<$ 0,001). Comparações intergrupos não mostraram diferenças estatísticas nas diferentes fases (Figura 10). 


\section{Pressão arterial sistólica}

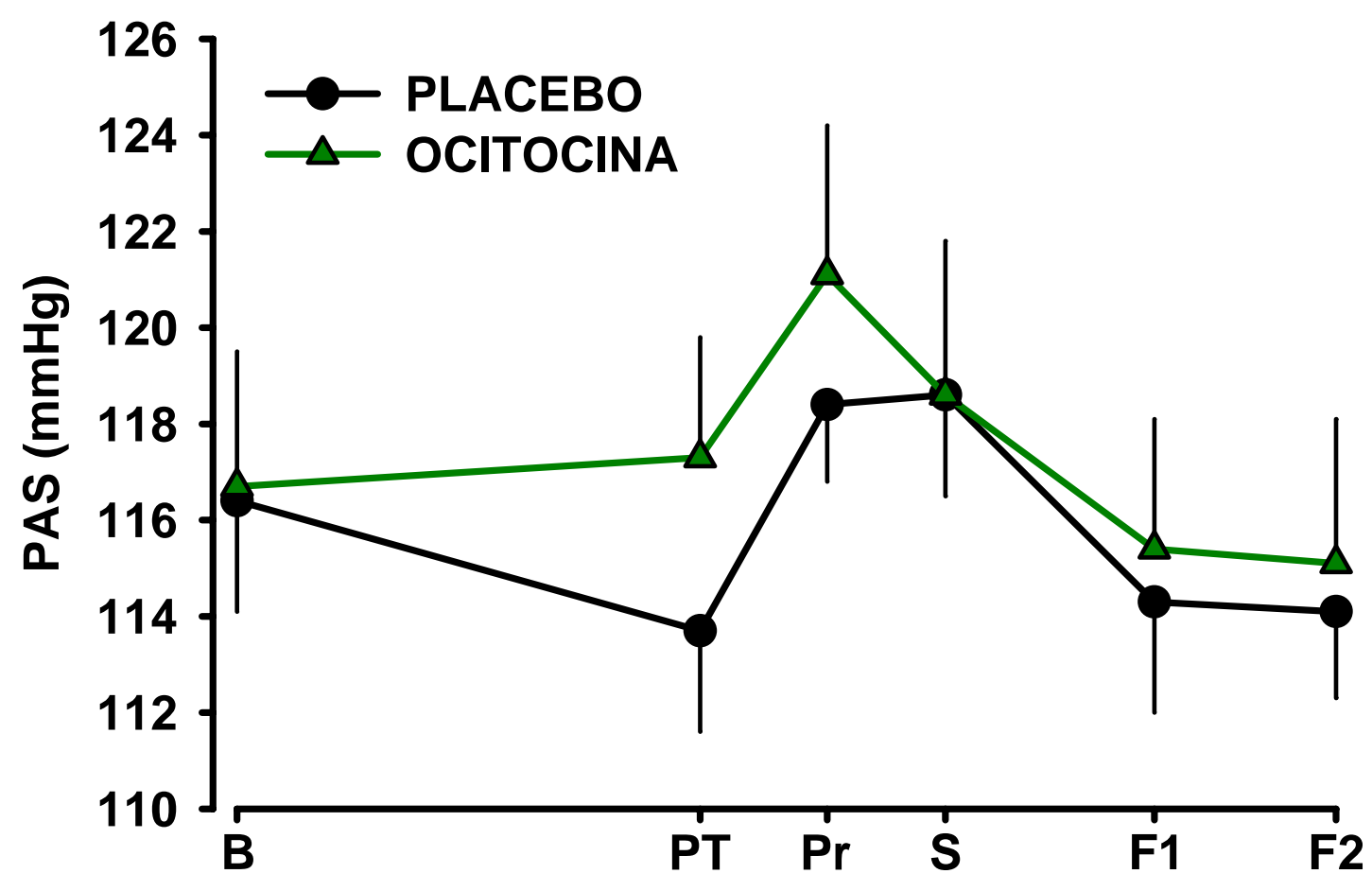

Fases

Figura 10 - Efeitos da ocitocina e do placebo na pressão arterial sistólica (PAS) em voluntários saudáveis submetidos ao Teste de Simulação de Falar em Público. Os resultados estão expressos por média \pm epm (mmHg). As escalas foram aplicadas em diferentes fases durante a sessão experimental: basal (B), pré-teste (PT), preparação (Pr), performance (S), pós-teste 1 (F1) e pós-teste 2 (F2). mmHg = milímetros de mercúrio. 


\subsection{Pressão arterial diastólica}

Comparações intra e intergrupos não mostraram diferenças estatísticas nas diferentes fases (Figura 11).

\section{Pressão Arterial Diastólica}

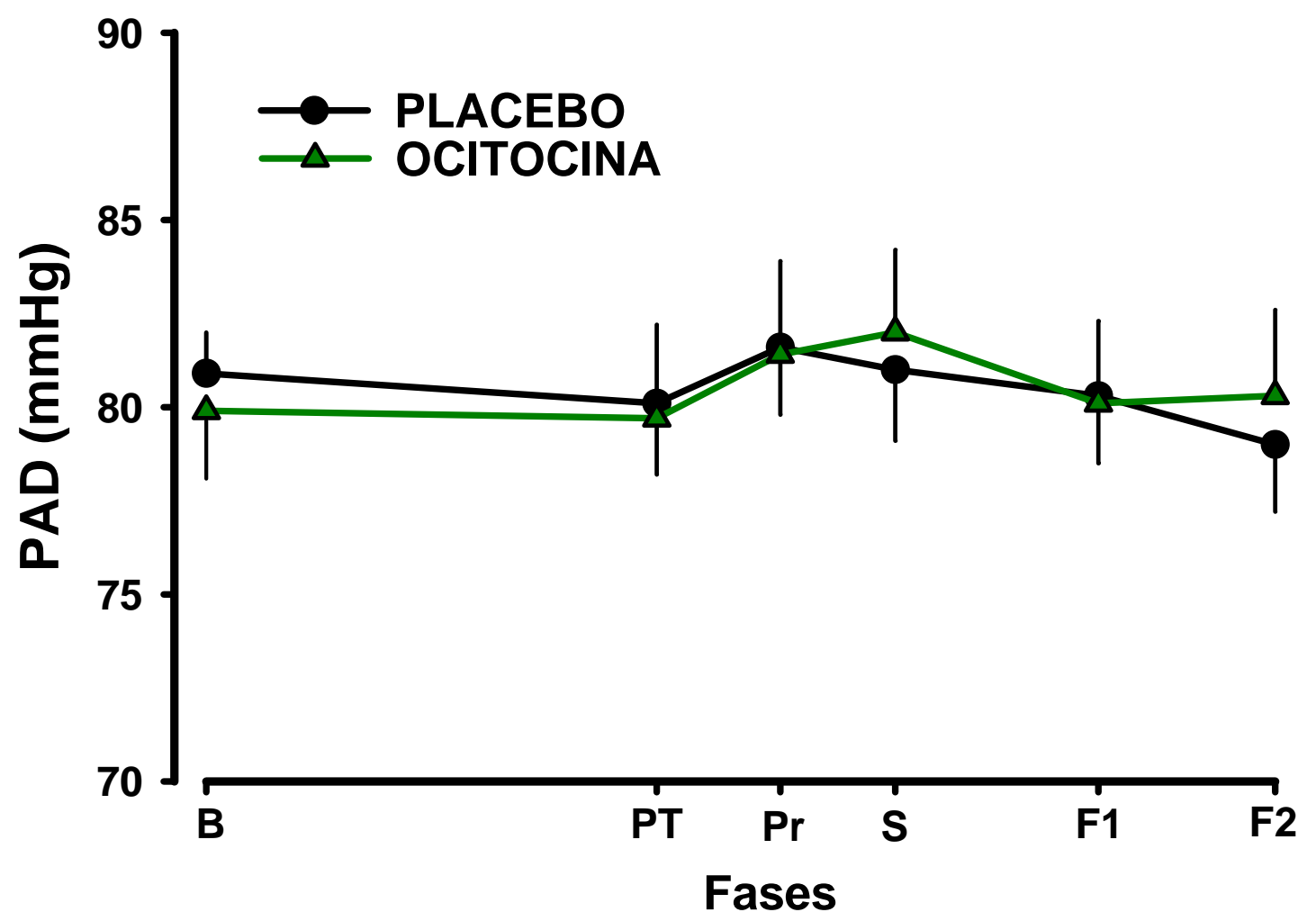

Figura 11 - Efeitos da ocitocina e do placebo na pressão arterial diastólica (PAD) em voluntários saudáveis submetidos ao Teste de Simulação de Falar em Público. Os resultados estão expressos por média \pm epm (mmHg). As escalas foram aplicadas em diferentes fases durante a sessão experimental: basal (B), pré-estresse $(\mathrm{P})$, antecipatória $(\mathrm{A})$, performance $(\mathrm{S})$, pós-estresse $1(\mathrm{~F} 1)$ e pós-estresse $2(\mathrm{~F} 2)$. $\mathrm{mmHg}=$ milímetros de mercúrio. 


\subsection{Nível de condutância da pele}

Comparações intragrupos mostraram, no grupo placebo, maior condutância da pele (SCL) na fase PT em relação às fases F1 (p-valor =0,006) e F2 (p-valor =0,02). A fase Pr também teve maior SCL em relação às fases B (p-valor < 0,001), S (p-valor = 0,02), F1 (pvalor < 0,001) e F2 (p-valor < 0,001). No grupo ocitocina, a fase B obteve maior SCL em relação às fases $\mathrm{P}(\mathrm{p}$-valor $=0,01), \mathrm{S}(\mathrm{p}$-valor = 0,002), F1 (p-valor < 0,001) e F2 (p-valor = 0,001). Também foi maior na fase Pr em relação às fases $S$ (p-valor $=0,002), F 1$ (p-valor $=$ 0,001) e F2 (p-valor = 0,01). O grupo placebo apresentou maior nível de condutância da pele do que o grupo ocitocina nas fases $\mathrm{P}(2,8 \pm 0,2 \mu \mathrm{S} ; 2,0 \pm 0,2 \mu \mathrm{S}$; p-valor $=0,02)$ e A $(3,1 \pm$ $0,3 \mu S ; 2,3 \pm 0,3 \mu S$; p-valor $=0,02)$, $S(2,7 \pm 0,2 \mu S ; 1,9 \pm 0,2 \mu S$; p-valor $=0,03)$ e F2 $(2,4$ $\pm 0,2 \mu S ; 1,8 \pm 0,2 \mu S ;$ p-valor $=0,02)($ Figura 12$)$. 


\section{Nível de Condutância}

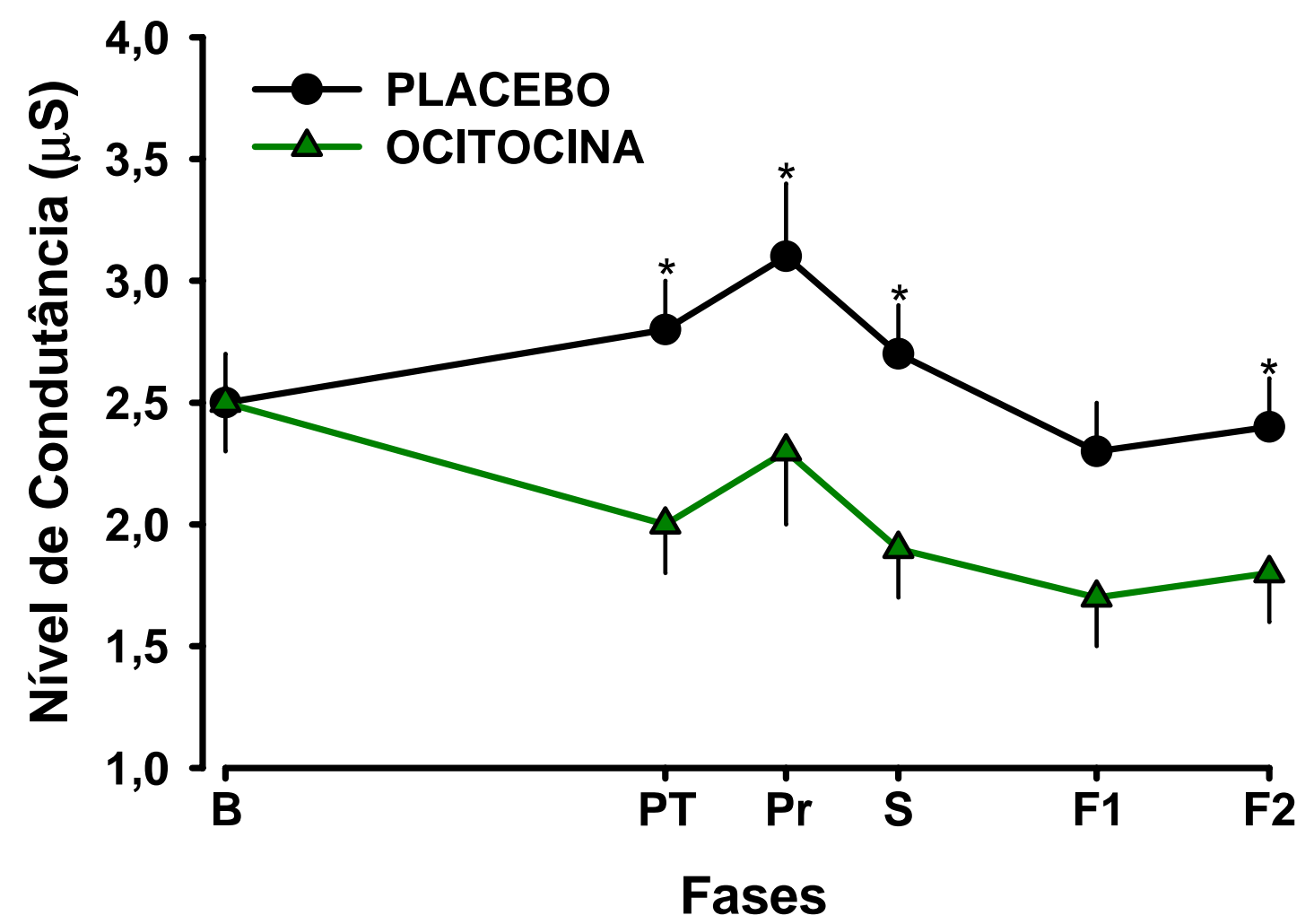

Figura 12 - Efeitos da ocitocina e do placebo na condutância em voluntários saudáveis submetidos ao Teste de Simulação de Falar em Público. Os resultados estão expressos por média \pm epm ( $\mu S)$. As escalas foram aplicadas em diferentes fases durante a sessão experimental: basal (B), pré-teste (P), antecipatória (A), performance (S), pós-teste 1 (F1) e pós-teste 2 (F2). $\mathrm{S}=$ Siemens. ${ }^{*} \mathrm{p}<0,05$ entre os dois tratamentos. 


\subsection{Número de flutuações da condutância}

Comparações intragrupo no grupo placebo mostraram maior número de flutuações espontâneas (SF) nas fases Pr e S em relação à fase F1 com p-valor = 0,003 e p-valor = 0,03, respectivamente. No grupo ocitocina, o SF foi maior na fase Pr em relação às fases $S$ (p-valor $<$ 0,001) e F2 (p-valor = 0,002). Comparações intergrupos não mostraram diferenças estatísticas nas diferentes fases (Figura 13).

\section{Número de flutuações da condutância}

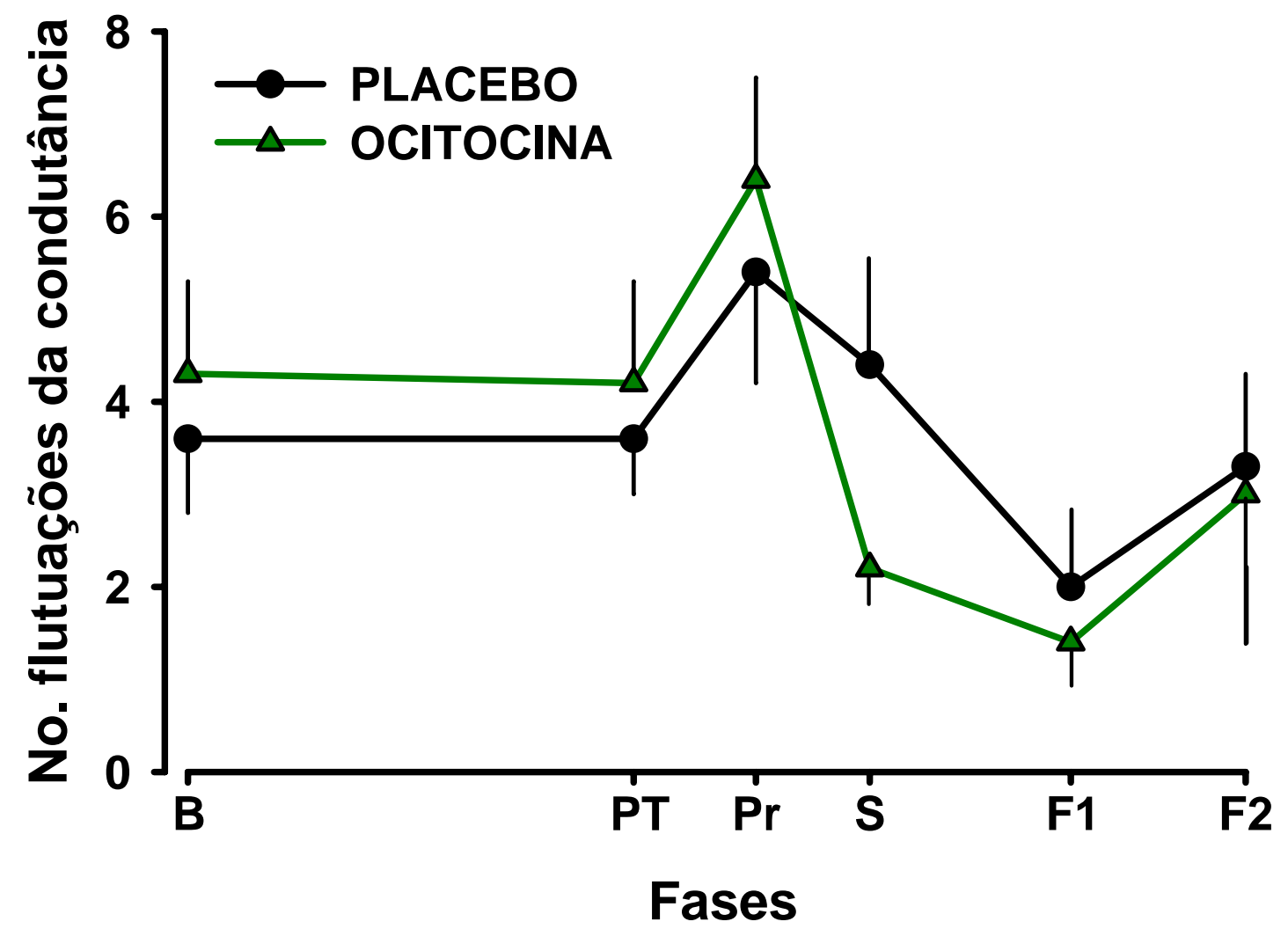

Figura 13 - Efeitos da ocitocina e do placebo no número de flutuações da condutância em voluntários saudáveis submetidos ao Teste de Simulação de Falar em Público. Os resultados estão expressos por média \pm epm. Considera-se 1 flutuação uma variação de 20\% acima da linha de base. As escalas foram aplicadas em diferentes fases durante a sessão experimental: basal (B), pré-teste (P), preparação (Pr), performance (S), pósteste 1 (F1) e pós-teste 2 (F2). 


\subsection{Cortisol}

Comparações intergrupos não mostraram diferenças estatísticas nas diferentes fases (Figura 14). Houveram diferenças intragrupos em ambos os grupos, no entanto não possuem significado experimental porque o comportamento de decréscimo do cortisol ao longo do tempo deve-se ao ciclo circadiano e não há fatores intrínsicos à sessão experimental.

\section{Cortisol}

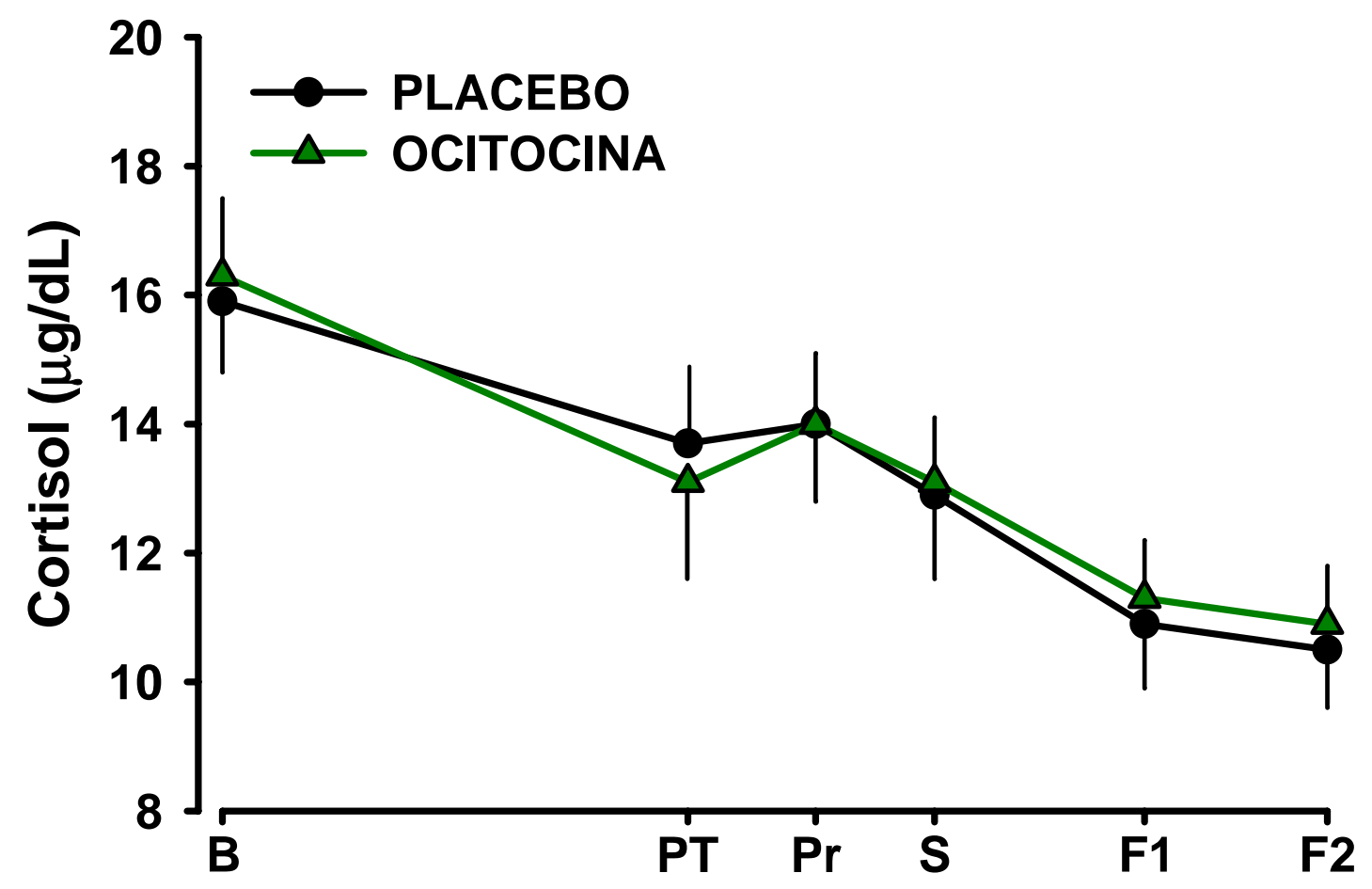

Fases

Figura 14 - Efeitos da ocitocina e do placebo no cortisol em voluntários saudáveis submetidos ao Teste de Simulação de Falar em Público. Os resultados estão expressos por média \pm epm ( $\mu \mathrm{g} / \mathrm{dL})$. As escalas foram aplicadas em diferentes fases durante a sessão experimental: basal (B), pré-estresse (P), antecipatória (A), performance (S), pós-estresse 1 (F1) e pós-estresse 2 (F2). 


\subsection{Hormônio Adrenocorticotrófico (ACTH)}

Comparações intergrupos não mostraram diferenças estatísticas nas diferentes fases (Figura 15). Houveram diferenças intragrupos em ambos os grupos, no entanto não possuem significado experimental porque o comportamento de decréscimo do cortisol ao longo do tempo deve-se ao ciclo circadiano e não há fatores intrínsicos à sessão experimental.

\section{Hormônio adrenocorticotrófico (ACTH)}

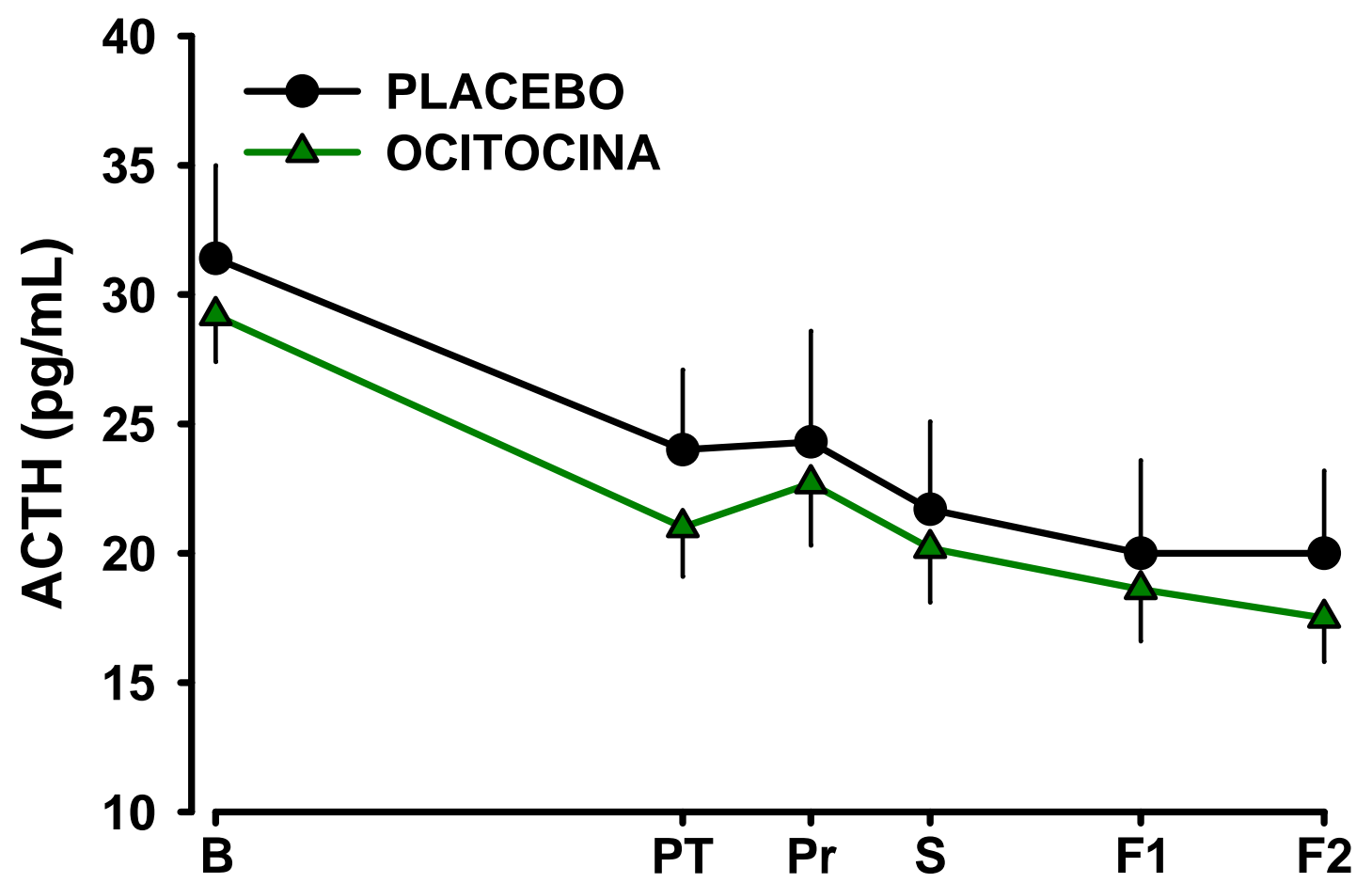

Fases

Figura 15 - Efeitos da ocitocina e do placebo no hormônio adrenocorticotrófico (ACTH) em voluntários saudáveis submetidos ao Teste de Simulação de Falar em Público. Os resultados estão expressos por média \pm epm (pg/mL). As escalas foram aplicadas em diferentes fases durante a sessão experimental: basal (B), pré-teste (PT), preparação (Pr), performance (S), pós-teste 1 (F1) e pós-teste 2 (F2). 
5. DISCUSSÃO 


\section{DISCUSSÃO}

O estudo da ansiedade possui algumas dificuldades práticas como as limitações das técnicas usadas nas investigações das funções neuronais em humanos, problemas na extrapolação dos dados obtidos em animais para a clínica e, por último, os diferentes tipos de transtornos de ansiedade que são classificados pela psiquiatria (GRAEFF; HETEM, 2004). Os modelos animais de ansiedade, embora necessários e úteis, não excluem a necessidade de estudos em seres humanos. Existem vários modelos que vêm sendo utilizados em humanos para estudar a ansiedade experimental, sendo que cada um destes possui instrumentos específicos que permitem avaliar a ansiedade que foi gerada. Os modelos podem ser divididos em psicológicos e químicos. No primeiro caso, a ansiedade é induzida através de estímulos / situações externas ao indivíduo e no segundo caso, são utilizadas drogas para induzir os sintomas (GUIMARÃES et al., 2004).

Estudos epidemiológicos revelaram que o medo de falar em público possui alta prevalência entre estudantes (GEER, 1965) e que é independente do gênero, da etnia ou da idade (PHILLIPS et al., 1997). Além disto, falar em público é o medo social mais freqüente (FURMARK et al., 1999; STEIN et al., 1994) e também é um dos principais sintomas da fobia social (BRUNELLO et al., 2000; STEIN et al., 1996). Por estas razões e com o objetivo de obter um modelo clínico de ansiedade, McNair et al. (1982) desenvolveu o TSFP. Este modelo foi modificado por Guimarães et al. (1987), o qual foi utilizado neste estudo.

O TSFP tratou-se de um modelo interessante para o presente trabalho porque estudos anteriores mostraram que este teste é eficiente na indução da ansiedade em voluntários saudáveis e também na detecção de efeitos ansiolítico ou ansiogênico de alguns fármacos (GUIMARÃES et al., 1987; PALMA et al., 1994; ZUARDI et al., 1993;). 
O TSFP exige a utilização de escalas de auto-avaliação, ou seja, escalas preenchidas pelo próprio sujeito, como instrumentos para mensurar a ansiedade e ainda permite realizar algumas medidas fisiológicas. Como já descrito anteriormente, o presente trabalho utilizou como escalas de auto-avaliação a EAH (NORRIS, 1971), a ESS (ZUARDI et al., 1993) e a escala de AAFP (HOFFMANN; DIBARTOLO, 2000). Além disto, outras medidas foram avaliadas para se observar mudanças fisiológicas relacionadas à ansiedade. São elas: nível de condutância da pele, números de flutuações da condutância da pele, pressão arterial, freqüência cardíaca, nível sérico de cortisol e nível plasmático de ACTH.

De acordo com pesquisas realizadas em bases de dados, este é o primeiro estudo que tem como objetivo avaliar uma possível ação ansiolítica da OT em humanos no modelo do TSFP. Os estudos que buscam essa possível ação são recentes em animais e escassos em humanos. Como já descrito, essa hipótese surgiu a partir de descobertas de vias e receptores ocitocinérgicos localizados em regiões cerebrais envolvidas com os circuitos neurais que estão envolvidos na modulação da ansiedade. Em roedores, foram realizados estudos com camundongos deficientes em OT ou pela administração da OT diretamente no cérebro (MANTELLA et al., 2003; AMICO et al., 2004). Já em humanos, os estudos foram desenvolvidos pela administração intranasal de OT, uma vez que foi encontrado o neuropeptídeo no líquor (BORN et al., 2002). Baseado neste estudo cinético e em outros realizados em humanos (KOSFELD et al., 2005; HEINRICHS et al., 2003) que utilizam a via intranasal, optamos em realizar a administração da OT 50 minutos antes da ansiedade A, fase na qual há grande aumento da ansiedade, uma vez que é o momento imediatamente anterior à fala em frente à câmera. Os resultados são discutidos à seguir.

A EAH trata-se de uma escala interessante porque permite avaliar outros estados subjetivos, além da ansiedade, como o prejuízo cognitivo, a sedação e o desconforto. 
Com relação ao fator ansiedade (Fig. 2), observou-se que ambos os grupos apresentaram indução da ansiedade, o que pode ser observado por um aumento significativo da mesma da fase PT para a Pr. No entanto, observou-se que somente no grupo OT houve diminuição significativa da ansiedade da fase B para a PT, o que sugere que a OT facilita a habituação da ansiedade antecipatória. Esses dados são reforçados pela diferença significativa encontrada entre os grupos na fase PT (p-valor =0,03). Vale ressaltar que uma diminuição da ansiedade na fase $\mathrm{P}$ em relação à fase $\mathrm{B}$ e em relação ao placebo é muito semelhante ao comportamento dos benzodiazepínicos, os quais estão relacionados com níveis menores de ansiedade em PT. No entanto, os mesmos não conseguem impedir a ansiedade na fase Pr, talvez pelo tipo de ansiedade gerada. Esses resultados são contrários, em geral, ao que acontece com fármacos que atuam na transmissão serotoninérgica, os quais não alteram o nível de ansiedade na fase PT (GRAEFF et al., 2003). McNaughton e Corr (2004) propõem que as estruturas que comandam as reações medo e a ansiedade são entidades categoricamente distintas, inter e intra conectadas, e que elas atuam de acordo com a distância da ameaça de forma que todas as estrututras participam de todos comportamentos. Sendo assim, durante o TSFP, vias do sistema de defesa de ambas as reações são ativadas, sendo que há ansiedade antecipatória da fase basal até a pré-teste e reações de medo nas fases de preparação e performance, já que é um estímulo aversivo. Dentre estas estruturas envolvidas, foram encontrados receptores de ocitocina na amigdala (CONDES-LARA et al., 1994; KREMARIK et al., 1993; MANTELLA et al., 2003), no septo (INSEL et al., 1993; MANTELLA et al., 2003; McCARTHY et al., 1996), no hipocampo e no hipotálamo (MANTELLA et al., 2003; SOFRONIEW, 1983). Esses achados sustentam o resultado da diminuição da ansiedade antecipatória na fase PT, mas deixa uma lacuna com relação à não modulação da ansiedade nas fases Pr e S, uma vez que estas estruturas também estão relacionadas com a ansiedade social. Um fato a se considerar é que, no TSFP, provavelmente há a ativação de vias 
envolvidas no pânico, o qual tem grande participação da matéria cinzenta periaquedutal (PAG) (PARENTE et al., 2005; DEL-BEN et al., 2001), estrutura ainda pouco estudada na relação oxitocina/ansiedade. Sendo assim, pode ser que a ansiedade não foi menor nas fases Pr e S devido à ausência de receptores ocitocinérgicos, os quais poderiam estar envolvidos na modulação da ansiedade nestas fases. No entanto, Ogawa, Kow e Pfaff (1992) sugerem a presença de receptores de ocitocina na PAG. Outro fator a se considerar é a dose em questão, já que a resposta neste tipo de modelo mostra-se dose-dependente (GRAEFF et al., 2001; SILVA, 2001). Desta forma, fazem-se necessários outros estudos com outras doses de ocitocina, bem como aplicar o modelo em pacientes com fobia social para fechar a correlação entre ocitocina e tipo de ansiedade modulada no TSFP. Os resultados do fator sedação (Fig. 4) reforçam a idéia de uma função ansiolítica para a ocitocina, semelhante aos benzodiazepínicos. No entanto, foram encontradas diferenças estatísticas não somente na fase PT (p-valor $=0,003)$, como também nas fases Pr $(p$-valor $=0,01)$ e S (p-valor $=0,02)$. Esses resultados são interessantes porque mostra que a escala foi capaz de discernir ansiedade de sedação, o que muitas vezes pode ser confundido. O mesmo comportamento foi observado nas medidas da condutância da pele (Fig. 12), nas quais o grupo OT apresentou menor SCL nas fases PT (p-valor $=0,02)$, Pr (p-valor $=0,02)$, S (p-valor $=0,03)$ e F2 $(\mathrm{p}$-valor $=0,02)$. Esses resultados indicam que houve uma menor ativação do simpático no grupo ocitocina, já que glândulas sudoríparas das palmas das mãos se encontram sob controle neural colinérgico do sistema nervoso simpático, ou ainda uma possível ação antimuscarínica da OT. No entanto, ao contrário dos resultados da SCL que indica menor ativação do simpático, a FC (Fig. 9), a PAS (Fig. 10) e PAD (Fig. 11) não foram diferentes em nenhuma das fases na dependência do tratamento. Isso indica que não há correlação entre a atividade eletrodérmica e parâmetros hemodinâmicos quando o simpático é ativado. Fowles $(1980,2000)$ sugere que a atividade eletrodérmica está envolvida com a ansiedade antecipatória, enquanto alterações da 
FC estão mais relacionadas com o medo. Sendo assim, há mais um indício que suporta a hipótese da ação da OT na ansiedade antecipatória. No estudo também não houve correlação entre SCL e SF (Fig. 13), já que não houve diferenças do SF no decorrer do teste. Isso pode ser explicado por estudos de neuroimagem que mostram que a atividade eletrodérmica (SCL) e as alterações transitórias da condutância, como as SF, são regidas por diferentes sistemas neurais (NAGAI et al., 2004), sendo que no primeiro caso há a participação do córtex préfrontal medial. Este está associado com a advertência de futuras punições (BECHARA et al., 1999), o que mais uma vez é compatível com a relação entre SCL e ansiedade antecipatória que é evidenciada no presente estudo.

A escala de AAFP foi avaliada em 3 partes: a auto-avaliação positiva, a auto-avaliação negativa e a auto-avaliação total ao falar em público. Nos dois primeiros casos, a pontuação varia entre 0 e 25 pontos e a total possui pontuação máxima de 50. É importante observar que nas avaliações positivas e totais quanto maior a pontuação, menor o medo de falar em público e no caso da auto-avaliação negativa quanto maior a pontuação, menor o medo de falar em público (explicações no item 3.3.1). Na auto-avaliação positiva (Figura 6), não houve diferenças intergrupos. Já a análise intragrupo mostrou que somente o grupo ocitocina viu-se mais positivamente nas fases F1 e F2 em relação à fase B. Na auto-avaliação negativa (Fig. 7), embora comparações entre os grupos também não mostraram diferenças nas diferentes fases, vale observar que na fase Pr o grupo placebo viu-se mais negativamente em realção às fases F1 e F2. No entanto, no grupo ocitocina o comportamento foi contrário, sendo que a auto-avaliação negativa foi menor na fase Pr em relação às fases B, F1 e F2. Com relação à pontuação total (Fig. 8), somente o grupo ocitocina apresentou aumento da pontuação no decorrer do teste, sendo que o medo de falar em público foi menor em todas as fases em relação à fase B. Estes dados sugerem que a OT diminui o medo de falar em público no TSFP. Recentemente, Damásio (2005) mostrou que a OT aumenta a confiança em terceiros e este 
dado pode indicar que este neuropeptídeo também aumenta a autoconfiança do sujeito em uma situação de falar em público, mesmo não tendo ocorrido diferenças intergrupos nas diferentes fases na dependência do tempo. Além disto, Kirsch et al. (2005), em um estudo de neuroimagem, mostraram que, durante o teste da faces, houve menor ativação da amigdala no grupo que recebeu OT. Esses resultados sugerem um possível papel da OT na fobia social e na confiança, já que o aumento de sua ativação está relacionado à fobia (STEIN et al., 2002) e sua lesão com o aumento da confiança (ADOLPHS et al., 1998). Esses dados reforçam a idéia que a ocitocina pode ter não somente uma ação na ansiedade antecipatória, como também na ansiedade social no TSFP e que estudos com outras doses e fóbicos sociais são necessários.

No presente estudo não foram encontrados aumentos significativos de cortisol e ACTH durante as fases (Figuras 13 e 14). No entanto, devido a algumas limitações da metodologia não foi possível concluir se a OT atua no eixo HPA. Talvez, o tempo de preparo do discurso (2 minutos) tenha sido pouco para produzir um aumento detectável nos níveis de cortisol na fase A, assim como para a fase S. Além disto, a queda do hormônio no período da manhã devido ao ciclo circadiano tenha “mascarado” um possível aumento destes hormônios. No entanto, outros estudos com o TSFP são controversos, já que alguns não obtiveram mudanças nos níveis de cortisol (BECKER et al., 1996; LUPIEN et al., 1997) e outros tiveram resultados com aumento do cortisol (NICOLSON; VAN DIEST, 2000; BUCHANAN et al., 1999). Além disto, Garcia-Leal et al. (2005) sugerem que o TSFP ativam mecanismos cerebrais semelhantes aos de ataques em pânicos, uma vez que alguns estudos mostraram que os níveis de cortisol permanecem inalterados durante crises de pânico espontâneas ou induzidos experimentalmente. De qualquer forma, estes dados indicam que o TSFP não ativa o eixo HPA. 
6. CONCLUSÃO 


\section{CONCLUSÃO}

O presente estudo sugere que a OT na dose de 24 UI possui ação na ansiedade antecipatória de voluntários saudáveis submetidos ao TSFP e não na ansiedade social induzida pelo teste. No entanto, faz-se necessários novos estudos com outras doses e em fóbicos sociais, já que os dados da AAFP total mostraram que no decorrer da sessão experimental somente o grupo ocitocina apresentou diminuição do medo de falar em público. Além disto, seria interessante estudar o efeito da ocitocina em outros modelos experimentais de ansiedade para delinear de forma clara o tipo de ansiedade que a OT modula. Espera-se que este estudo contribua com o desenvolvimento de intervenções terapêuticas em transtornos de ansiedade e com o desenvolvimento de possíveis fármacos agonistas. 


\section{REFERÊNCIAS BIBLIOGRÁFICAS}




\section{REFERÊNCIAS BIBLIOGRÁFICAS}

AIRES, M.M. Fisiologia.29 th ed. New York: W>B> Saunders, 2000. 553p.

ADOLPHS, R.; TRANEL, D.; DAMASIO, A.R. The human amygdala in social judgment. Nature, v. 393, p. 470-474, 1998.

AMICO, J.A.; MANTELLA, R.C.; VOLLMER, R.R., LI, X.. Anxiety and stress response in female oxytocin deficient mice. J Neuroendocr, v. 16, p. 319-324, 2004.

ANAND, A.; SHEKHAR, A. Brain imaging studies in mood and anxiety disorders. Ann NY Acad Sci, v. 985, p. 370-388, 2003.

BALE, T.L., DAVIS, A.M., AUGER, A.P. et al.. CNS region specific oxytocin receptor expression: importance in regulation of anxiety and sex behavior. J Neurosci, v. 21, p. 25462552, 2001.

BECHARA, A.; DAMASIO, H.; DAMASIO, A.R.; LEE, G.P. Different contribuitions of the human amydala and ventromedial prefrontal cortex to decision-making. J Neurosci., v. 19, p. 5473, 1999.

BECK, A.T., EPSTEIN, N., BROWN, G., STEER, R.A.. An inventory measuring clinical anxiety: Psychometric properties. J Consult Clin Psychol, v. 56, p. 893-897, 1988.

BECKER, L.C.; PEPINE, C.J.; BONSALL, R. et al. Left ventricular, peripheral vascular and neurohumoral responses to mental stress in normal middle-aged men and women.

Circulation, v. 94, p. 2768-2777, 1996.

BERNATOVA, I.; RIGATTO, K.V.; KEY, M.P. et al. Stress-induced pressor and corticosterone responses in oxytocin-deficient mice. Exp Physiol, v. 85, p. 549-557, 2004.

BORN, J.; LANGE, T.; KERN, W. et al. Sniffing neuropeptides: a transnasal approach to the human brain. Nat Neurosci, v. 5, p. 514-516, 2002.

BRUINS, J.; HIJIMAN, R.; VAN REE, J.M.. Effect of a single dose of des-glycinamide(8)vasopressin or oxytocin on cognitive processes in young healthy subjects. Peptides, v.13, p. 461-468, 1992.

BRUNELLO, N.; DEN BOER, J.A.; JUDD, L.L. et al.. Social Phobia: diagnosis and epidemiology, neurobiology and pharmacology, comorbidity and treatment. J Affect Disorders, v. 60, p. 61-74.

BUCHANAN, T.W.; AL'ABSI, M.; LOVALLO, W.R. Cortisol fluctuates with increases and decreases in negative affect. Psychoneuroendocr, v. 24, p. 227-241, 1999.

BUIJS, R.M. Vasopressin and oxytocin - their role in neurotransmission. Pharmac Ther, v. 22, p. 127-141, 1983. 
BUJIS, R.M. Intra and extrahypothalamic vasopressin and oxitocin pathways in the rat. Pathways to the limbic system, medulla oblongata and spinal cord. Cell Tissue Res, v. 192, p. 423-429, 1978.

CARTER, C.S. Neuroendocrine perspectives on social attachment and love. Psychoneur, v.23, p. 779-818, 1998.

CCSEB (Critério de Classificação Sócio-Econômica Brasil). Associação Brasileira de Anunciantes, Associação Nacional das Empresas de Pesquisa de Mercado (ANEP), Associação Brasileira dos Institutos de Pesquisa de Mercado (ABIPEME), 1997.

CHALMERS, D.T.; LOWENBERG T.W.; DESOUZA, E.E. Localization of novel corticotropin-releasing factor receptor (CRF2) mRNA expression to specific subcortical nuclei in rat brain: comparison with CRF1 receptor mRNA expression. J Neurosci, v.15, p. 6340-6350, 1995.

CHARNEY, D.S. Neuroanatomical circuits modulating fear and anxiety behaviors. Acta Psycgiatr Scand, v. 108, no. 417, p. 38-50, 2003.

CHARNEY, D.S.; DREVETS, W.C. Neurobiological basis of anxiety disorders. In: DAVIS, K.L.et al.. Neuropsychopharmacology: the fifth generation of progress. Baltimore: Lippincott / Williams \& Wilkins, 2004, p. 901-930.

CONDES-LARA, M.; VEINANTE, P.; RABAI M. et al. Correlation between oxytocin neuronal sensitivity and oxytocin-binding sites in the amydala of the rat: eletrophysiological and histoautoradiographic study. Brain Res, v. 637, p. 277-286, 1994.

CRIPPA, J.A.; ZUARDI, A.W.; GARRIDO, G.E. et al. Effects of cannabidiol (CBD) on regional cerebral blood flow. Neuropsychopharmac, v. 29, p. 417-426, 2004.

CULLINAN, W.E.; HERMAN, J.P.; WATSON, S.J.. Ventricular subicular interaction with the hypothalamic paraventricular nucleus: evidence for a relay in the bed nucleus of the stria terminalis. J Comp Neurol, v. 332, p. 1-20, 1993.

DAMASIO, A.R.; TRANEL, D.; DAMASIO H. Individuals with sociopathic behavior caused by frontal damage fail to respond autonomically to social stimuli. Behav Brain Res, v. 41, p. 81-94, 1990.

DAMPNEY, R.A.L. Functional organisation of central pathways regulating the cardiovascular system. Physiol Ver, v. 74, p. 323-364, 1994.

DAVIS, M. Neural circuitry of anxiety and stress disorders. In: DAVIS, K.L.et al..

Neuropsychopharmacology: the fifth generation of progress. Baltimore: Lippincott / Williams \& Wilkins, 2002, p. 931-951.

DAVIS, M.; SHI C.J. The amydala. Curr Biol, v. 10, no. 131, 2000.

DAYAS, C.V.; BULLER, K.M.; DAY, T.A.. Neuroendocrine responses to na emotional stress: evidence for involvement of the medial but not the central amydala. Euro J Neurosci, p. 2312-2322, 1999. 
DEL-BEN, C.M.; VILELA, J.A.A.; CRIPPA, J.A.S. et al. Confiabilidade teste-reteste da Entrevista Clínica Estruturada para o DSM-IV - Versão Clínica (SCID-CV) traduzida para o português. Rev Bras Psiquiatr, v. 23, n.3, p.156-9, 2001a.

DEL-BEN, C.M.; VILELA, J.A.A.; HETEM, L.A.B. et al. Do panic patients process unconditionaned fear vs. conditioned anxiety differently than normal subjects? Psychiatry Res., v. 104, p. 227, 2201b.

DUNN, J.D.; WHITENER, J. Plasma corticosterone responses to electrical stimulation of the amygdaloid complex: cytoarchitectural specificity. Neuroendocrinol, v. 42, p. 211-217, 1986.

EBNER, K.; WOTJAK, C.T.; LANDGRAF, R.; ENGELMANN, M.. A single social defeat experience selectively stimulates the release of oxytocin, but not vasopressin, within the septal brain área of male rats. Brain Res, 872, p. 87-92, 2000.

EISENBERGER, N.I.; LIEBERMAN, M.D.; WILLIAMS, K.D. Does rejection hurt? Na FMRI study of social exclusion. Science, v. 302, p. 290-302, 2003.

ELIAS, L.L.K.; ANTUNES-RODRIGUES, J.; ELIAS, P.C. et al.. Effect of plasma osmolality on pituitary-adrenal responses to corticotropin-releasing hormone and atrial natriuretic peptide changes in central diabetes insipidus. J Clin Endoc Metab, v. 4, p. 12431247, 1997.

ENGELMANN, M.; WOTJAK, C.T.; EBNER, K.; LANDGRAF, R.. Behavioural impact of intraseptally released vasopressin and oxytocin in rats. Exp Physiol, v. 85, p. 125S-130S, 2000.

FAVARETTO, A.L.; BALLEJO, G.O.; ALBUQUERQUE-ARAÚJO, W.I. et al. Oxytocin releases atrial natriuretic peptide from rat atria in vitro that exerts negative inotropic and chronotropic action. Pept, v. 18, p. 1377-1381, 1997.

FEHM-WOLFSDORF, G.; BACHHOLZ, G.; BORN, J. et al.. Vasopressin but not oxytocin enhances cortical arousal: na integrative hypothesis on behavioral effects of neurohypophyseal hormones. Psychopharmac, v. 94, p. 496-500, 1988.

FERGUSON, J.N.; ALDAG, J.M.; INSEL, T.R; YOUNG, L.J.. Oxytocin in the medial amydala is essential for social recognition in the mouse. J Neurosci, v.21, p. 8278-8285, 2001.

FERGUSON, J.N.; YOUNG, L.J.; HEAM, E.F., et al.. Social amnesia in mice lacking the oxytocin gene. Nat Genet, v.25, p. 284-288, 2000.

FIRST, M.B.; SPITZER, R.L.; GIBBON, M.; WILLIAMS, J.B.W.. Structured Clinical Interview for DSM-IV Axis I Disorders (SCID), Clinician Version. Washington: American Psychiatric Press, 1997.

FOSTER, C.D.; MACDONALD, I.A. The assay of the catecholamine content of small volumes of human plasma. Biomed Chromatogr, v. 13, p. 209-215, 1999. 
FOWLES, D.C. The three arousal model: implications of Gray's two-factor learning theory for heart rate, electrodermal activity and psychopathy. Psychophys, v. 17, p. 87, 1980.

FOWLES, D.C. Electrodermal hyporeactivity and antisocial behavior: does anxiety mediate the relationship? J Affect Disord, v. 61, p. 177-189, 2000.

FURMARK, T.; TILLFORS, M.; MARTEINSDOTTIR, I. et al.. Social Phobia in the general population: prevalence and sociodemographic profile. Soc Psych Psych Epid, v. 34, p. 416424, 1999.

GARCIA-LEAL, C.; PARENTE, A.C.B.V.; DEL-BEM, C.M. et al. Anxiety and salivary cortisol in the symptomatic and nonsymptomatic panic patients and healthy volunteers performing simulated public speaking. Psych Res, v. 133, p. 239-252, 2005.

GEER, J.H. The development of scale to measure fear. Behav Res Ther, v. 193, p. 785-795, 1965.

GIBBS, D.M.. Dissociation of oxytocin, vasopressin and corticotropin secretion during diferents types of stress. Life sci, v. 35, p. 487-491, 1984.

GRAEFF, F.G.; HETEM, L.A.B. Neurobiolologia. In: GRAEFF, F.G.; HETEM, L.A.B.. Transtornos de Ansiedade. São Paulo: Atheneu, 2004, p.107-132.

GRAEFF, F.G.; SILVA, DEL BEM, C.M.; ZUARDI, A.W. et al.. Comparison between two models of experimental anxiety in healthy volunteers and panic disorder patients. Neurosc Biobehav Ver, v. 25, p. 753-759, 2001.

GRAY, T.S.; CARNEY, M.E.; MAGNUSON, D.J.. Direct projections from the central amydaloid nucleus to the hypothalamic paraventricular nucleus; possible role in stressinduced ACTH release. Neuroendocr, v.50, p. 433-446, 1989.

GRAY, J.A.; MCNAUGHTON, N. The neuropsychology of anxiety: an enquiry into the functions of the septo-hippocampal system. 2th ed. Oxford: Oxford University Press, 2000.

GUIMARÃES, F.S.; ZUARDI, A.W.; GRAEFF, F.G. Effect of chlorimipramine and maprotiline on experimental anxiety in humans. J Psychopharmac, v. 1, p. 184-192, 1987.

GUIMARÃES, F.S.; ZUARDI, A.W.; HETEM, L.A.B.. Ansiedade experimental humana.In: GRAEFF, F.G.; HETEM, L.A.B.. Transtornos de Ansiedade. São Paulo: Atheneu, 2004, p.75-104.

GUTKOWSKA, J.; JANKOWSKI, M.; LAMBERT, C. et al.. Oxytocin releases atrial natriuretic peptide by combining with oxytocin receptors in the heart. Proc Natl Acad Sci USA, v. 94, p. 11704-11709, 1997.

HASHIGUCHI, H.YeS.H.; MORRIS, M.; ALEXANDER, N.. Single and repeated environmental stress. Effect on plasma oxytocin, corticosterone, catecholamines and behavior. Physiol Behav, v. 61, p. 731-736, 1997. 
HEINCHS, M., NEUMANN, I.; EHLERT, U.. Lactation and stress: protective effects of breast-feeding in humans. Stress, v. 5, p. 195-203, 2002.

HEINRICHS, M.; BAUMGARTNER, T.; KIRSCHBAUM, C.; EHLERT, U.. Social support and oxytocin interact to suppress cortisol and subjective responses to psychosocial stress. Biol Psych, v. 54, p. 1389-1398, 2003.

HERMAN, J.P., CULLINAN, W.E.. Neurocircuity of stress: central control of the hipothalamo-pituitary-adrenocortical axis. Trends Neurosci, v. 20, p. 78-84, 1997.

HERMAN, J.P., PREWITT, C.M.F., CULLIMAN, W.E.. Neuronal circuit regulation of the hypothalamo-pituitary-adrenocortical stress axis. Crit Ver Neurobiol, v. 1996, p. 371-394, 1996.

HETTEMA, J.M.; NEALE, M.C.; KENDLER, K.S. A review and meta-analysis of the genetic epidemiology of anxiety disorders. Am J Psychiatry, v. 158, p. 1568-1578, 2001.

HIGUCHO, T.; NEGORO, H.; ARITA, J.. Reduced responses of prolactin and catecholamine to stress in the lactating rat. J Endocr, v. 122, p. 495-498, 1989.

HODGSON, R.; ALWYN, T.; JOHN, B. et al. The FAST Alcohol Screening Test. Alcohol Alcohol, v. 37, n. 1, p. 61-66, 2002.

HOFFMANN, S.G.; DIBARTOLO, P.M.. An instrument to assess self-statements during public speaking: scale development and preliminary psychometric properties. Behav Therapy, v. 31, p. 499-515, 2000.

HOLMES, A.; HEILIG, M.; RUPNIAK, N.M. et al. Neuropeptide systems as novel therapeutic targets for depression and anxiety disorders. Trends Pharmacol Sci, v. 24, p. 580-588, 2003.

HURLEY, K.M.; HERBERT, H.; MOGA, M.M.; SAPER, C.B.. Efferent projections of the infralimbic system cortex of the rat. J Comp Neurol, v. 308, p. 249-276, 1991.

INGRAM, C.D.; MOOS, F.. Oxytocin-containing pathway to the bed nuclei of the stria terminalis of the lactating rat brain: immunocytochemical and in vitro eletrophysiological evidence. Neurosci, v. 47, p. 439-452, 1992.

INSEL, T.R.; YOUNG, J.L.. The neurobiology of attachment. Nature rev neurosci, v.2, p. 129-136, 2001.

INSEL, T.R.; YOUNG, L.; WITT, D.M. et al. Gonadal steroids have paradoxical effects on brain oxytocin receptors. J Neuroendocrinol, v. 5, p. 619-628, 1993.

JANKOWSKI, M.; HAJJAR, F.; KAWAS, S.A. et al. Rat heart: a site of oxytocin production and action. Proc Natl Acad Sci USA, v. 95, p. 14558-14563, 1998.

JANKOWSKI, M.; WANG, D.; HAJJAR, F.. Oxytocin and its receptors are synthesized in the rat vasculature. Proc Nat Acad Sci USA, v. 97, p. 6207-6211, 2000. 
KANG, Y.S.; PARK, J.H. Brain uptake and the analgesic effect of oxytocin - its usefulness as na analgesic agent. Arch Pharm Res, v. 23, n. 4, p. 391-395, 2000.

KENDRICK, K.M., KEVERNE, E.B., HILTON, M.R.; GOODE, J.A. Cerebrospinal fluid levels of acetylcholinesterase, monoamines and oxytocin during labour, parturition, vaginocervical stimulation, lamb separation and suckling in sheep. Neuroendocrin, v. 44, p. 149-156, 1986.

KIM, J.; GORMAN, J. The psychobiology of anxiety. Clin Neurosc Res, v. 4, p. 335-347, 2005.

KIRSCH, P.; ESSLINGER, C.; CHEN, Q. Oxytocin modulates neural circuitry for social cognition and fear in humans. J Neurosci, v. 25, p. 11489-11493, 2005.

KNOX, S.S.; UVNAS-MOBERG, K.. Social isolation and cardiovascular disease: na atherosclerotic pathway? Psychoneuroendocr, v. 23, p. 877-890, 1998.

KOSFELD, M.; HEINRICHS, M.; ZAK, P.J. et al.. Oxytocin increase trust in humans. Nature, v. 435, p.673-676, 2005.

KREMARIK, P.; FREUND-MERCIER, M.J.; STOECKEL, M.E.. Histoautoradiographic detection of oxytocin and vasopressin-binding sites in the telencephalon of the rat. J Comp Neurol, v. 333, p. 343-359, 1993.

KROENKE, K.; SPITZER, R.L.; WILLIAMS, J.B. The Patient Health Questionnaire-2: validity of a two-item depression screener. Med Care, v. 41, n. 11, p. 1284-1292, 2003.

LEDOUX, J. The emotional brain, fear and the amydala. Cell Mol Neurobiol, v. 23, p. 727738, 2003.

LIGHT, K.C.; GREWEN, K.M.; AMICO, J.A. et al.. Deficits in plasma oxytocin responses and increased negative affect, stress and blood pressure in mothers with cocaine exposure during pregnancy. Addic Behav, v. 29, p. 1541-1564, 2004.

LIGHT, K.C.; GREWEN, K.M.; AMICO, J.A. et al.. Oxytocinergic activity is linked to lower blood pressure and vascular resistance during stress in postmenopausal women on estrogen replacement. Horm Behav, v. 47, p. 540-548, 2005.

LIGHT, K.C.; SMITH, T.E.; JOHNS, J.M. et al.. Oxytocin responsivity in mothers of infants: a preliminary study of relationships with blood pressure during laboratory stress and normal ambulatory activity. Health Psychol, v. 19, p. 560-567, 2000.

LIGHTMAN, S.L.; YOUNG, W.S.. Lactation inhibits stress-mediated secretion of corticosterone and oxytocin and hypothalamic accumulation of corticotropin-releasing factor and enkephalin messenger ribonucleic acids. Endocr, v. 124, p. 2358-2364, 1989.

LUPIEN, S.J.; GAUDREAU, B.M.; TCHITEYA, B.M. et al. Stress-induced declarative memory impairment in helathy elderly subjects: relationship to cortisol reactivity. J Clin Endocrinol Metabol, v. 82, p. 2070-2075, 1997. 
MANTELLA, R.C.; VOLLMER, R.R.; LI, X.; AMICO, J.A.. Female oxytocin-deficient mice display enhanced anxiety-related behavior. Endocrin, v. 144, p. 2291-2296, 2003.

MANTELLA, R.C.; VOLLMER, R.R.; RINAMAN, L. et al. Enhanced corticosterone concentrations and attenuated Fos expression in the medial amydala of female oxytocin knockout mice exposed to psychogenic stress. Am J Physiol Regul Integr Comp Physiol, v. 287, p. 1494-1504, 2004.

McCARTHY, M.M.; McDONALD, C.H.; BROOKS, P.J.; GOLDMAN, D.. An anxiolytic action of oxytocin is enhanced by estrogen in the mouse. Physiol Behav, v. 60, p. 1209-1215, 1996.

McNAIR, D.M.; FRANKENTHALER, L.M.; CZERLINSKI, T. et al.. Simulated public speaking as a model of clinical anxiety. Psychopharmac, v. 77, p. 7-10, 1982.

MCNAUGHTON, N.; CORR, P.J. A two-dimensional neuropsychology of defense: fear/anxiety and defensive distance. Neurosc Biobehav Rev., v. 28, p. 285-305, 2004.

MICHELINI, L.C.; MARCELO, M.C.; AMICO, J. et al. Oxytocinergic regulation of cardiovascular function: studies in oxytocin-deficient mice. Am J Physiol Heart Circ Physiol, v. 284, p. 2269-2276, 2003.

MUKADDAM-DAHER, S.; YIN, Y.; ROY, J. et al. Negative inotropic and chronotropic effects of oxytocin. Hipert, v. 38, p. 292-296, 2001.

NAGAI, Y.; CRITCHLEY, H.D.; FEATHERSTONE, E. et al. Activity in ventromedial precortex covaries with sympathetic skin conductance level: a physiological account of a “default mode” of brain function. Neurolmage, v. 22, p. 243, 2004.

NEUMANN, I.D.. Involvement of the brain oxytocin system in stress coping: interactions with the hipothalamo-pituitary-adrenal axis. Prog Brain Res, v. 139, p. 147-162, 2002.

NEUMANN, I.D.; JOHSTONE, H.A.; HATZINGER, M.et al..Attenuated neuroendocrine response to emotional and physical stressors in pregnant rats involve adenohypophysial changes. J Physiol, v. 508, p. 289-300, 1998.

NEUMANN, I.D.; KROMER, S.A.; TOSCHI, N.; EBNER, K.. Brain oxytocin inhibts the (re)activity of hipothalamo-pituitary-adrenal axis in male rats: involvement of hypothalamic and limbic brain regions. Regul Pept, v.96, p.31-38, 2000a.

NICOLSON, N.A.; VAN DIEST, R.. Salivary cortisol in vital exhaustion. J Psychosom Res, v. 49, p. 335-342, 2000.

NISHIOKA, T.; ANSELMO-FRANCI, J.A.; LI, P.et al.. Stress increases oxytocin release within the hypothalamic paraventricular nucleus. Brain Res, v. 781, p. 56-60, 1998.

NORRIS, H.. The action of sedatives on brain stem oculomotor systems in man.

Neuropharmac, v. 10, p. 181-191, 1971. 
OGAWA, S., KOW, L.M., PFAFF, D.W. Effects of lordosis-relevant neuropeptides on midbrain periaqueductal gray neuronal activity in vitro. Peptides, v. 13, p. 965-975, 1992.

PALMA, S.M.; GUIMARÃES, F.S.; ZUARDI, A.W. Anxiety induced by simulated public speaking and Stoop Color Word Test in healthy subjects: effects of different trait-anxiety levels. Braz J Med Biol Res, v. 27, p. 2895-2902, 1994.

PARENTE, A.C.B.V.; GARCIA-LEAL, C.; DEL-BEN; C.M. et al. Subjective and neurovegetative changes in healthy volunteers and panic patients performing simulated public speaking. Eur Neuropsychophar, v. 15, p. 663-671, 2005.

PARKER, K.J.; BUCKMASTER, C.L.; SCHATZBERG, A.F. Intranasal oxytocin administration attenuates the ACTH stress response in monkeys. Psychoneuroendocr, v. 30, p. 924-929, 2005.

PEDERSEN, C.; PRANJE JR., A.J.. Induction of maternal behavior in virgins rats after intracerebroventricular administration of oxytocin. Proc Natl Acad Sci, v.76, p. 6661-6665, 1979.

PETERSSON, M.; ALSTER, P.; LUNDEBERG, T.; UVNAS-MOBERG, K.. Oxytocin causes a long-term decrease of blood pressure in female and male rats. Physiol Behav, v. 60, p. 1311-1315, 1996.

PHILLIPS, G.C.; JONES, G.E.; RIEGER, E.R. et al.. Normative data for the personal report of confidence as a speaker. J Anx Dis, v. 11, p. 215-220, 1997.

PITMAN, R.K.; ORR, S.P.; LASKO, N.B.. Effects of intranasal vasopressin and oxytocin on physiologic responding during personal combat imagery in vietnam veterans with posttraumatic stress disorder. Psychiatry Res, v. 48, p. 107-117, 1993.

PREWITT, C.M.; HERMAN, J.P.. Anatomical interactions between the central amydaloid nucleus and the hypothalamic paraventricular nucleus of the rat: a dual tract-tracing analysis. J Chem Neuroanat, v. 15, p. 173-185, 1998.

ROGERS, R.D.; RAMNAMI, N.; MACKAY, C. et al. Distinct portions of anterior cingulate cortex and medial prefrontal cortex are activated by reward processing in separable phases of decision-making cognition. Biol Psychiatry, v. 55, p. 594-602, 2004.

ROSS, T.M.; MARTINEZ, P.M.; RENNER, J.C et al. Intranasal administration of interferon beta bypasses the blood-brain barrier to target the central nervous system and cervical lymph nodes: a non-invasive treatment strategy for multiple sclerosis. J Neuroimmunol, v. 151, p. 66-77, 2004.

SANCHEZ, M.M.; YOUNG, L.J.; PLOTSKY, P.M. et al. Autoradiographic and in situ hybridization localization of corticotrophin-releasing factor 1 and 2 receptors in the nonhuman primate brain. J Comp Neurol, v.408, p. 365-377, 1999.

SAWCHENKO, P.E.; BROWN, E.R.; CHAN, R.W.K. The paraventricular nucleus of the hypothalamus and the functional neuroanatomy of visceromotor response to stress. Prog Brain Res, v. 107, p. 201-222, 1996. 
SAWCHENKO, P.E.;SWANSON, L.W. Immunohistochemical identification of neurons in the paraventricular nucleus of the hypothalamus that project to the medulla or the spinal cord in the rat. J Comp Neurol, v. 205, p. 260-272, 1982.

SCHALL, R.. Estimation in generalized linear models with random effects, Biometrika, v. 78, n.4, p. 719-727, 1991.

SILVA, M.; HETEM, L.A.B.; GUIMARÃES, F.S. et al. Opposite effects of nefazodona in two human models of anxiety. Psychopharmac, v. 156, p. 454-460, 2001.

SOFRONIEW, M.V. Morphology of vasopressin and oxytocin neurones and their central e vascular projections. Prog Brain Res, v.60, p. 101-114, 1983.

SOFRONIEW, M.V.; SCHRELL, U. Evidence for a direct projection from oxytocin and vasopressin neurons in the hypothalamic paraventricular nucleus to the medulla oblongata: immunohistochemical visulisation of both the horseradish peroxidase transported and the peptide produced in the same neuron. Neurosci Lett, v. 22, p. 211-217, 1981.

STEIN, M.B.; WALKER, J.R.; FORDE, D.R.. Public-speaking fears in a community sample. Prevalence, impact on functioning and diagnosis classification. Arch Gen Psych, v. 53, p. 169-174, 1996.

STEIN, M.B.; WALKER, J.R.; FORDE, D.R.. Setting diagnostic thresholds for social phobia: considerations from a community survey of social anxiety. Am J Psych, v. 151, p. 408-412, 1994.

STEIN, M.B.; GOLDIN, P.R.; SAREEN, J. et al. Increased amygdale activation to angry and contemptuous faces in generalized social phobia. Arch Gen Psychiatry, v. 59, p. 1027-1034, 2002.

STOECKEL, M.E.; FREUND-MERCIER, M.S.; FALACIOS, J.M. et al. Autoradiographic localization of binding sites for oxytoxin and vasopressin in the rat kidney. J Endocrinol, v. 113, p. 179-182, 1987.

STRICKER, E.M., VERBALIS, J.G.. Interaction of osmotic and volume stimuli in regulation of neurohypophyseal secretion in rats. Am J Physiol, v.250, p. R267-R275, 1986.

STROHLE, A.; HOLSBOER, F. Stress responsive neurohormones in depression and anxiety. Pharmacopsych, v. 36, no. 3, p. 207-214, 2003.

SULLIVAN, G.M.; COPLAN, J.D.; GORMAN, J.M. Psychoneuroendocrinology of anxiety disorders. Psychiatr Clin N Am, v. 21, p. 397-412, 1998.

SULLIVAN, G.M.; COPLAN, J.D.; KENT, J.M. et al. The noradrenergic system in pathological anxiety and phobias. Biol Psychiatry, v. 46, p. 1205-1218, 1999.

THIBONNIER, M.; CONARTY, D.M.; PRESTON, J.A. et al.. Human vascular endothelial cells express oxytocin receptors. Endocr, v. 140, p. 1301-1309, p. 1999. 
TRIBOLLET, E.; BARBERIS, C.; JARD, S. et al. Localization and pharmacological characterization of high affinity binding sites for vasopressin and oxytocin in the rat brain by light microscopic autoradiography. Brain res, v. 442, p. 105-118, 1988.

UVNAS-MOBERG, K. Oxytocin may mediate the benefits of positive social interaction and emotions. Psychoneur, v. 23, p. 819-835, 1998.

VERBALIS, J.G.; MC CANN, M.J.; MCHALE, C.M.; STRICKER, E.M.. Oxytocin secretion in response to cholecystokinin and food: diferentiation of nausea from satiety. Science, v. 232, p. 1417-1419, 1986.

WHO (World Health Organization). A user's guide to Self-Reporting Questionnaire. Geneva. 1993.

WIGGER, A.; NEUMANN, I.D.. Endogenous opioid regulation of stress-induced oxytocin release within the hypothalamic paraventricular nucleus is reversed in late pregnancy: a microdialysis study. Neurosci, v. 112, p. 121-129, 2002.

WINDLE, R.J.; SHANKS, N.; LIGHTMAN, S.L., INGRAM, C.D.. Central oxytocin administration reduces stress-induced corticosterone release and anxiety behavior in rats. Endocrin, v. 138, p. 2829-2834, 1997a.

WINDLE, R.J.; WOOD, S.; SHANKS, N. et al.. Endocrine and behavioural responses to noise stress: comparison of virgin and female rats during non-disrupted maternal activity. J Neuroendocr, v. 9, p. 407-414, 1997b.

WOTJAK, C.T.; GANSTER, J.; KOHL, G. et al.. Dissociated central and peripheral release of vasopresin, but not oxytocin, in response to repeated swin stress: new insight into the secretory capacities of peptidergic neurons. Neurosci, v. 85, p. 1209-1222, 1998.

WOTJAK, C.T.; NARUO, T.; MURAOKA, S. et al.. Forced swimming stimulates the expression of vasopressin and oxytocin in magnocellular neurons of the rat hypothalamic paraventricular nucleus. Eur J Neurosci, v. 13, p. 2273-2281, 2001.

YEHUDA, R.; SOUTHWICK, S.M.; KRYSTAL, J.H. et al. Enhanced supression of cortisol following dexamethasone administration in posttraumatic stress disorder. Am J Psychiatry, v.150, p. 83-86, 1993.

YOUNG, J.L.; LIM, M.M., GINGRICH, B.; INSEL, T.R.. Cellular mechanismsof social attachment. Horm Behav, v. 40, p. 133-138, 2001.

ZUARDI, A.W.; COSME, R.A.; GRAEFF, F.G., GUIMARÃES, F.S.. Effects of ipsapirone and cannabidiol on human experimental anxiety. J Psychopharmac, v. 7, p. 82-88, 1993. 
ANEXOS 


\section{ANEXOS}

ANEXO 1 - Escala Analógica de Humor

\section{A M S}

SUJEITO:

FASE:.....

INSTRUÇÕES: Avalie como você se sente agora em relação aos itens abaixo e marque cada linha com um traço vertical no ponto que melhor descreve seus sentimentos. O centro de cada linha indica como você habitualmente se encontra e as extremidades indicam o máximo de cada condição.

ALERTA

SONOLENTO

CALMO

AGITADO

FORTE

FRACO

CONFUSO

COM IDÉIAS

CLARAS

ÁGIL

DESAJEITA-

DO

APÁTICO

DINÂMICO

SATISFEITO

INSATISFEI-

PREOCUPADO

TO

RACIOCÍNIO

DIFÍCIL

TRANQUILO

PERSPICAZ

TENSO

RELAXADO

ATENTO

INCAPAZ

DISTRAÍDO

CAPAZ

ALEGRE

TRISTE

HOSTIL

AMISTOSO

INTERESSADO DESINTERES-

SADO

RETRAÍDO SOCIÁVEL 
ANEXO 2 - Escala de Sintomas Somáticos

\begin{tabular}{|c|c|c|c|c|c|c|}
\hline \multicolumn{7}{|c|}{ ESCALA DE SINTOMAS SOMÁTICOS } \\
\hline \multirow{2}{*}{\multicolumn{3}{|c|}{$\begin{array}{l}\text { NOME: } \\
\text { Instruções: avalie como você se sente agora } \\
\text { em relação aos itens abaixo e faça um círculo } \\
\text { ao redor do número que melhor expresse este } \\
\text { seu estado atual. }\end{array}$}} & \multicolumn{2}{|c|}{ DATA: } & \multicolumn{2}{|c|}{ SCORE: } \\
\hline & & & & & & \\
\hline & $\begin{array}{c}\text { NADA } \\
(0)\end{array}$ & $\begin{array}{l}\text { MUITO } \\
\text { POUCO } \\
\text { (1) }\end{array}$ & $\begin{array}{c}\text { POUCO } \\
(2)\end{array}$ & $\begin{array}{c}\text { MODERA } \\
\text { DAMENTE } \\
\text { (3) }\end{array}$ & $\begin{array}{l}\text { MUITO } \\
\text { (4) }\end{array}$ & $\begin{array}{c}\text { EXTREMA } \\
\text { MENTE } \\
\text { (5) }\end{array}$ \\
\hline 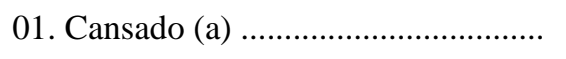 & 0 & 1 & 2 & 3 & 4 & 5 \\
\hline 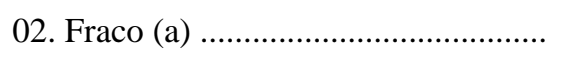 & 0 & 1 & 2 & 3 & 4 & 5 \\
\hline 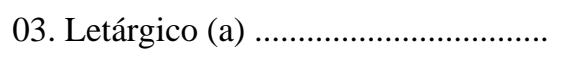 & 0 & 1 & 2 & 3 & 4 & 5 \\
\hline 04. Com dor ou peso na cabeça............ & 0 & 1 & 2 & 3 & 4 & 5 \\
\hline 05. Com tensão muscular ........................ & 0 & 1 & 2 & 3 & 4 & 5 \\
\hline 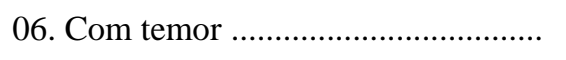 & 0 & 1 & 2 & 3 & 4 & 5 \\
\hline 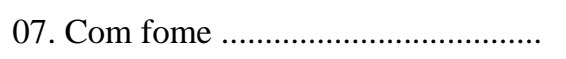 & 0 & 1 & 2 & 3 & 4 & 5 \\
\hline 08. Com sede & 0 & 1 & 2 & 3 & 4 & 5 \\
\hline 09. Com dificuldade de coordenação .. & 0 & 1 & 2 & 3 & 4 & 5 \\
\hline 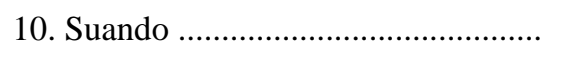 & 0 & 1 & 2 & 3 & 4 & 5 \\
\hline 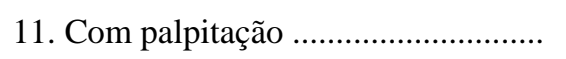 & 0 & 1 & 2 & 3 & 4 & 5 \\
\hline 12. Com dificuldade de respirar .......... & 0 & 1 & 2 & 3 & 4 & 5 \\
\hline 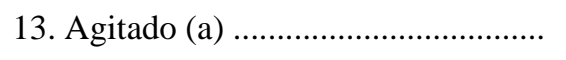 & 0 & 1 & 2 & 3 & 4 & 5 \\
\hline 14. Com vontade de urinar ....................... & 0 & 1 & 2 & 3 & 4 & 5 \\
\hline 15. Com náusea ou mal-estar gástrico & 0 & 1 & 2 & 3 & 4 & 5 \\
\hline 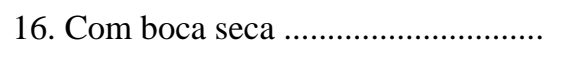 & 0 & 1 & 2 & 3 & 4 & 5 \\
\hline 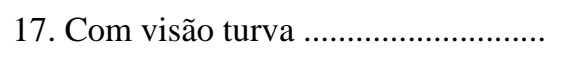 & 0 & 1 & 2 & 3 & 4 & 5 \\
\hline 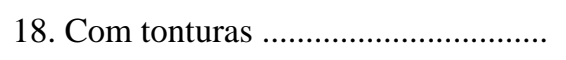 & 0 & 1 & 2 & 3 & 4 & 5 \\
\hline 19. Com vontade de evacuar .................. & 0 & 1 & 2 & 3 & 4 & 5 \\
\hline 20. Com dificuldade de urinar .............. & 0 & 1 & 2 & 3 & 4 & 5 \\
\hline 21. Com formigamento ............................... & 0 & 1 & 2 & 3 & 4 & 5 \\
\hline
\end{tabular}




\section{ANEXO 3 - Auto-avaliação ao falar em público}

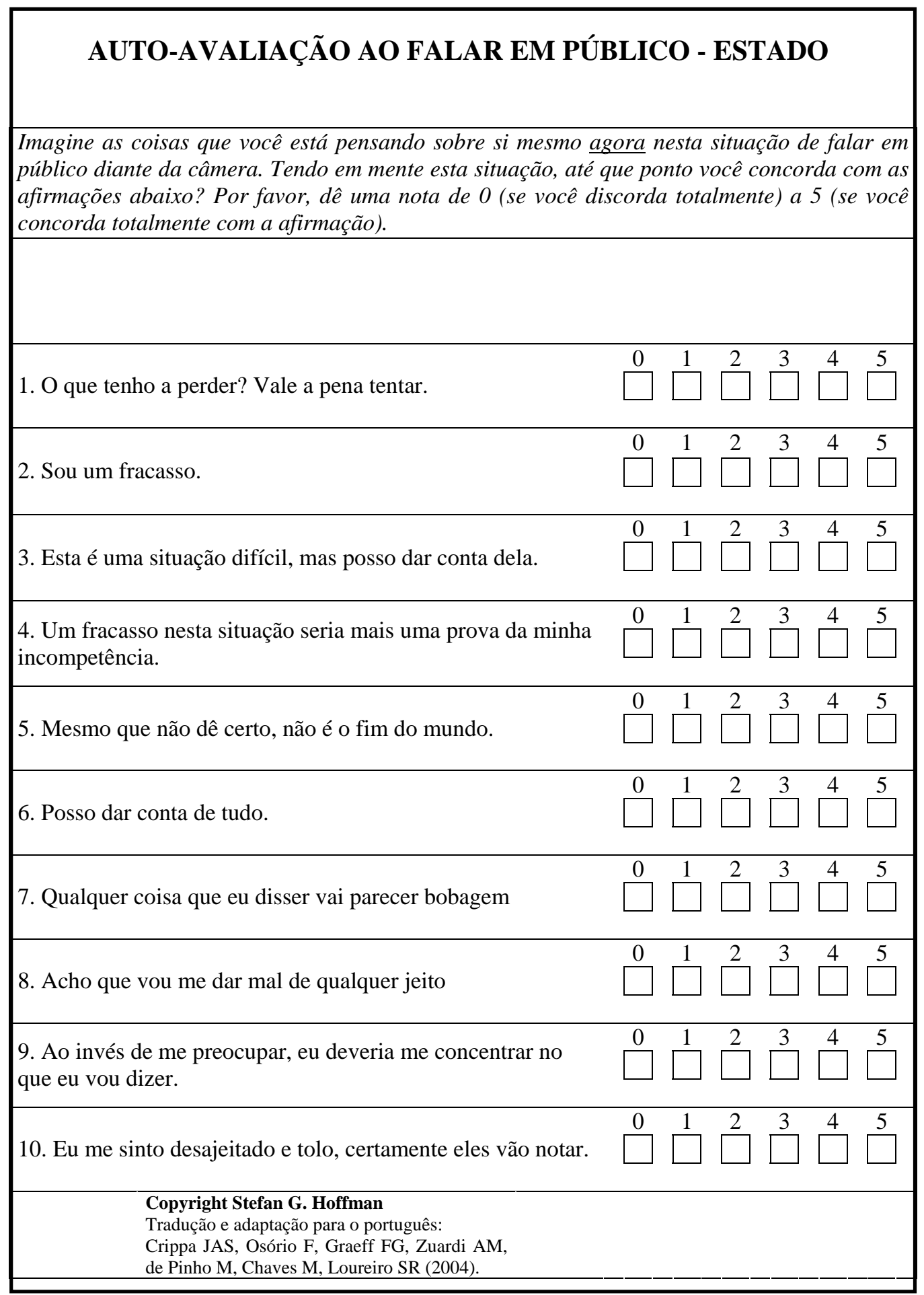




\section{ANEXO 4 - Termo de Consentimento Livre e Esclarecido}

\section{TERMO DE CONSENTIMENTO LIVRE E ESCLARECIDO}

Você está sendo convidado a participar de uma pesquisa clínica intitulada como "Efeito da ocitocina sobre a ansiedade experimental induzida em voluntários saudáveis”, a qual será acompanhada pelos seguintes pesquisadores: Danielle Chaves - mestranda de Toxicologia da Faculdade de Ciências Farmacêuticas de Ribeirão Preto - USP, Professora Dra. Regina Helena Costa Queiroz - Faculdade de Ciências Farmacêuticas de Ribeirão Preto - USP e Professor Dr. José Alexandre de Souza Crippa - Faculdade de Medicina de Ribeirão Preto - USP.

Esta pesquisa tem como objetivo avaliar a ação de uma substância chamada ocitocina. Algumas de suas ações são conhecidas, tais como sua participação na amamentação e durante o parto. Além disto, está ligada com o comportamento sexual, promoção de relações sociais positivas, ingestão de comida, resposta ao estresse, ação ansiolítica e etc. Neste projeto temos como objetivo avaliar a ação desta substância na ansiedade. Sua colaboração deverá ser voluntária e será de grande importância para o nosso trabalho no entendimento da ansiedade. O estudo será composto de duas partes.

Na primeira parte, sua participação consistirá em preencher escalas para nos dizer como você está se sentindo neste momento. Estas escalas são bastante simples, mas nós faremos um treinamento antes de iniciarmos os procedimentos. Também mediremos sua pressão arterial e pulso, além de fazermos uma coleta de sangue. Em seguida administraremos através de um spray nasal uma solução, a qual pode ser a ocitocina ou outra solução ausente da substância. Outros estudos já foram desenvolvidos e nenhum prejuízo foi reportado.

Geralmente, quando as pessoas ficam nervosas, as mãos ficam suadas. Por isso vamos verificar o suor da pele, através de um aparelho específico.

A segunda parte do estudo consistirá em participar de uma situação simulada de falar em público sobre os meios de transporte de sua cidade. Você terá dois minutos para preparar o discurso, e então fará a apresentação do mesmo, o qual terá uma duração de quatro minutos. Este discurso será gravado em videotape. Para tanto precisamos de sua autorização para a gravação. Durante e após a realização do discurso, você deverá também, responder a alguns questionários a respeito de como está se sentindo naquele momento, e nós também mediremos sua pressão arterial, seu pulso, seu suor da pele e ainda faremos novas coletas de sangue, como fizemos na primeira parte do estudo. Esta atividade durará em torno de uma hora e dez minutos.

A sua participação neste estudo contribuirá para que possamos ampliar a nossa compreensão a respeito das alterações que ocorrem nas reações normais de ansiedade e sua relação com a ocitocina. Com estas informações poderemos ajudar pessoas portadoras de transtornos ansiosos, melhorando a forma de tratamento destas pessoas. Caso no decorrer das atividades desista de participar, poderemos interrompê-las, sem qualquer constrangimento.

Seus dados serão confidenciais e serão unicamente de uso da farmacêutica-pesquisadora Danielle Chaves para elaboração da dissertação de mestrado e sua posterior publicação em forma de artigo, sem sua identificação pessoal. Assomemos a responsabilidade por qualquer ônus que a participação no estudo possa acarretar.

Qualquer dúvida que você tenha poderá entrar em contato conosco.

Prof. Dr. José Alexandre Crippa Médico

CRM - 80893

Telefone: $3602-2201$ Profa. Dra. Regina Helena Costa
Queiroz

Telefone: 3602-4259
Danielle Chaves

Farmacêutica - Pesquisadora

Telefone: 3602-4259 
Eu, RG tendo lidos as informações acima, voluntariamente concordo em participar do referido projeto de pesquisa, estando ciente dos meus direitos e da possibilidade de desistência sem quaisquer ônus ou prejuízo. 
ANEXO 5 - Aprovação do Comitê de Ética em Pesquisa do HCFMRP

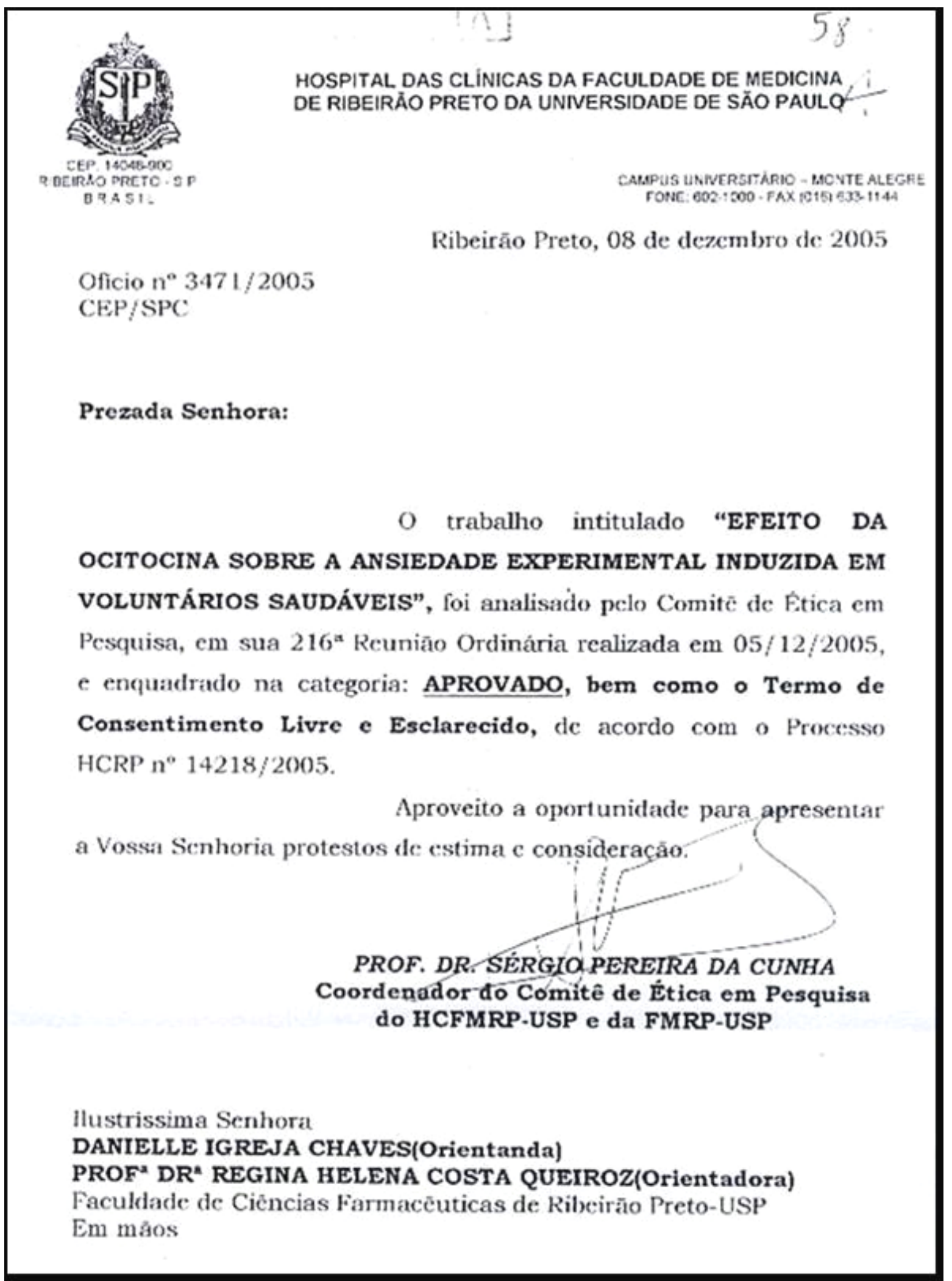


APÊNDICE 


\section{APÊNDICE}

Tabela 1: Descrição para as variáveis da escala Escala Analógica de Humor (EAH)

\begin{tabular}{|c|c|c|c|c|c|c|c|c|c|}
\hline Variável & Grupo & Fase & Média & $\begin{array}{l}\text { Desvio- } \\
\text { padrão }\end{array}$ & $\begin{array}{c}\text { Erro } \\
\text { padrão da } \\
\text { média }\end{array}$ & Variância & Mínimo & Mediana & Máximo \\
\hline \multirow{12}{*}{ 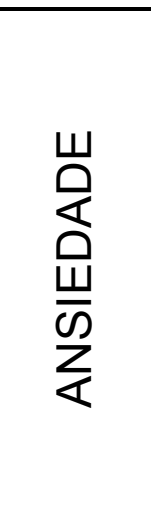 } & \multirow{6}{*}{ 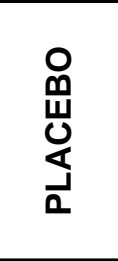 } & B & 54,0 & 9,3 & 2,5 & 86,5 & 42,5 & 53,5 & $\overline{76,6}$ \\
\hline & & PT & 52,7 & 7,0 & 1,9 & 49,5 & 34,4 & 53,1 & 66,1 \\
\hline & & $\mathrm{Pr}$ & 59,3 & 9,6 & 2,6 & 93,0 & 46,4 & 56,9 & 79,1 \\
\hline & & S & 58,4 & 10,2 & 2,7 & 103,4 & 39,1 & 55,2 & 76,0 \\
\hline & & F1 & 51,1 & 4,7 & 1,2 & 21,7 & 43,5 & 50,8 & 60,2 \\
\hline & & F2 & 50,9 & 5,7 & 1,5 & 32,8 & 37,4 & 52,6 & 57,2 \\
\hline & \multirow{6}{*}{ 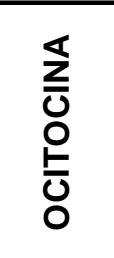 } & $B$ & 52,4 & 8,7 & 2,3 & 76,0 & 37,3 & 51,5 & 75,6 \\
\hline & & PT & 46,5 & 7,4 & 2,0 & 55,0 & 31,6 & 47,9 & 57,5 \\
\hline & & $\operatorname{Pr}$ & 54,1 & 6,2 & 1,6 & 38,5 & 47,3 & 52,6 & 68,2 \\
\hline & & S & 54,5 & 7,2 & 1,9 & 51,5 & 45,4 & 53,2 & 72,6 \\
\hline & & F1 & 51,0 & 6,6 & 1,8 & 44,1 & 41,3 & 50,4 & 68,8 \\
\hline & & F2 & 51,7 & 6,1 & 1,6 & 37,3 & 44,4 & 51,0 & 70,9 \\
\hline \multirow{12}{*}{ 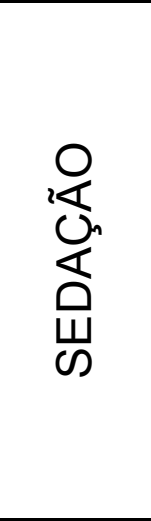 } & \multirow{6}{*}{ 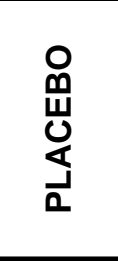 } & $B$ & 47,3 & 10,4 & 1,7 & 107,0 & 22,6 & 48,9 & 62,4 \\
\hline & & PT & 47,5 & 9,4 & 2,5 & 88,6 & 28,4 & 47,8 & 64,2 \\
\hline & & $\operatorname{Pr}$ & 39,0 & 11,0 & 2,9 & 119,9 & 18,3 & 40,1 & 56,8 \\
\hline & & S & 41,0 & 11,3 & 3,0 & 127,0 & 28,1 & 40,6 & 66,4 \\
\hline & & F1 & 46,7 & 9,2 & 2,4 & 84,4 & 24,4 & 47,0 & 67,0 \\
\hline & & F2 & 48,3 & 7,3 & 1,9 & 53,3 & 32,0 & 48,4 & 62,5 \\
\hline & \multirow{6}{*}{$\begin{array}{l}\text { ż } \\
\overline{0} \\
\text { o } \\
\overline{0}\end{array}$} & $B$ & 52,8 & 6,3 & 1,7 & 40,3 & 46,1 & 49,6 & 67,1 \\
\hline & & PT & 56,7 & 7,5 & 2,0 & 55,5 & 47,6 & 56,0 & 74,3 \\
\hline & & $\operatorname{Pr}$ & 47,1 & 6,3 & 1,7 & 39,6 & 41,0 & 45,8 & 65,8 \\
\hline & & $S$ & 47,7 & 4,8 & 1,3 & 23,5 & 36,3 & 47,9 & 56,6 \\
\hline & & F1 & 51,0 & 5,6 & 1,5 & 30,9 & 41,9 & 50,4 & 63,3 \\
\hline & & F2 & 49,4 & 5,6 & 1,5 & 31,2 & 40,9 & 48,6 & 60,2 \\
\hline \multirow{12}{*}{ 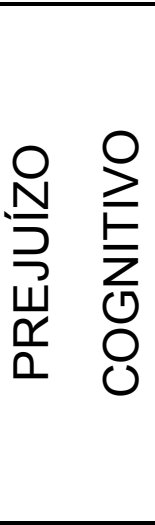 } & \multirow{6}{*}{ 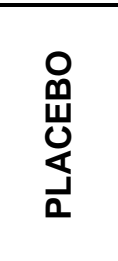 } & $B$ & 49,1 & 6,3 & 1,7 & 39,7 & 29,3 & 50,6 & 55,7 \\
\hline & & PT & 51,2 & 3,7 & 1,0 & 13,3 & 39,6 & 52,1 & 55,3 \\
\hline & & $\operatorname{Pr}$ & 51,3 & 4,4 & 1,2 & 19,4 & 38,6 & 52,3 & 57,0 \\
\hline & & S & 51,3 & 6,5 & 1,7 & 42,1 & 35,2 & 51,3 & 59,6 \\
\hline & & F1 & 49,9 & 4,8 & 1,3 & 22,7 & 35,2 & 51,2 & 54,1 \\
\hline & & $\mathrm{F} 2$ & 50,1 & 6,1 & 1,6 & 36,8 & 29,9 & 51,6 & 54,4 \\
\hline & \multirow{6}{*}{ 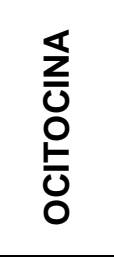 } & B & 51,6 & 6,1 & 1,6 & 37,5 & 41,6 & 50,8 & 70,0 \\
\hline & & PT & 51,8 & 4,7 & 1,2 & 21,8 & 43,4 & 51,2 & 62,9 \\
\hline & & $\operatorname{Pr}$ & 51,3 & 3,1 & 0,8 & 9,4 & 44,9 & 51,1 & 57,0 \\
\hline & & $S$ & 49,9 & 2,4 & 0,6 & 5,8 & 46,3 & 50,5 & 54,3 \\
\hline & & F1 & 50,8 & 1,8 & 0,5 & 3,1 & 48,1 & 50,6 & 53,9 \\
\hline & & F2 & 50,5 & 2,0 & 0,5 & 4,0 & 45,5 & 51,1 & 53,3 \\
\hline \multirow{12}{*}{ 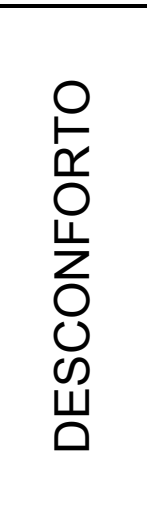 } & \multirow{6}{*}{$\vec{a}$} & $B$ & 45,2 & 7,7 & 2,0 & $\overline{58,5}$ & 23,2 & 47,9 & 50,1 \\
\hline & & PT & 46,5 & 5,8 & 1,5 & 33,2 & 31,1 & 48,2 & 53,1 \\
\hline & & $\mathrm{Pr}$ & 46,6 & 4,9 & 1,3 & 23,7 & 32,8 & 48,0 & 50,5 \\
\hline & & $S$ & 46,2 & 5,3 & 1,4 & 28,2 & 33,3 & 48,2 & 50,4 \\
\hline & & F1 & 47,2 & 3,8 & 1,0 & 14,3 & 37,0 & 48,4 & 51,0 \\
\hline & & $\mathrm{F} 2$ & 47,8 & 4,2 & 1,1 & 17,3 & 37,2 & 48,6 & 53,2 \\
\hline & \multirow{6}{*}{$\begin{array}{l}\frac{1}{u} \\
\overline{0} \\
\frac{\operatorname{co}}{0}\end{array}$} & $B$ & 48,0 & 4,2 & 1,1 & 17,9 & 39,9 & 48,6 & 56,9 \\
\hline & & PT & 49,7 & 3,5 & 0,9 & 12,1 & 45,0 & 49,1 & 57,0 \\
\hline & & $\mathrm{Pr}$ & 48,8 & 2,7 & 0,7 & 7,5 & 44,4 & 48,4 & 54,0 \\
\hline & & $S$ & 49,3 & 1,8 & 0,5 & 3,2 & 46,3 & 49,1 & 51,9 \\
\hline & & F1 & 49,9 & 3,4 & 0,9 & 11,6 & 46,0 & 48,5 & 57,8 \\
\hline & & F2 & 48,8 & 5,3 & 1,4 & 27,9 & 43,5 & 48,3 & 65,3 \\
\hline
\end{tabular}


Tabela 2: Descrição para as variáveis da escala auto-avaliação de falar em público (AAFP)

\begin{tabular}{|c|c|c|c|c|c|c|c|c|c|}
\hline Variável & Grupo & Fase & Média & $\begin{array}{l}\text { Desvio- } \\
\text { padrão }\end{array}$ & $\begin{array}{c}\text { Erro } \\
\text { padrão da } \\
\text { média }\end{array}$ & Variância & Mínimo & Mediana & Máximo \\
\hline \multirow{12}{*}{$\begin{array}{l}\underset{\nwarrow}{\geq} \\
\frac{\operatorname{E}}{\mathcal{O}} \\
\bigcirc \\
0\end{array}$} & \multirow{6}{*}{ 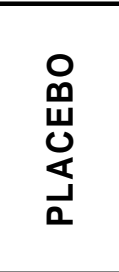 } & $B$ & 19,0 & 3,5 & 0,9 & 12,3 & 12 & 19 & 24 \\
\hline & & PT & 18,2 & 4,7 & 1,2 & 22,2 & 10 & 19 & 24 \\
\hline & & $\operatorname{Pr}$ & 18,7 & 4,2 & 1,1 & 17,3 & 12 & 19 & 24 \\
\hline & & $S$ & 18,1 & 5,1 & 1,3 & 25,6 & 10 & 19 & 24 \\
\hline & & F1 & 18,9 & 4,3 & 1,1 & 18,4 & 11 & 20 & 24 \\
\hline & & F2 & 19,0 & 4,1 & 1,1 & 17,1 & 11 & 19 & 23 \\
\hline & \multirow{6}{*}{$\begin{array}{l}\frac{1}{u} \\
0 \\
o \\
\frac{1}{0} \\
0\end{array}$} & $B$ & 18,7 & 4,2 & 1,1 & 17,6 & $\overline{10}$ & 19,5 & 25 \\
\hline & & PT & 19,7 & 4,0 & 1,1 & 16,2 & 10 & 21 & 25 \\
\hline & & $\mathrm{Pr}$ & 19,6 & 4,4 & 1,2 & 19,5 & 9 & 20 & 25 \\
\hline & & $S$ & 19,5 & 4,9 & 1,3 & 24,1 & 7 & 20 & 25 \\
\hline & & $\mathrm{F} 1$ & 20,1 & 4,0 & 1,1 & 15,8 & 10 & 20,5 & 25 \\
\hline & & F2 & 20,1 & 4,0 & 1,1 & 15,8 & 10 & 20 & 25 \\
\hline \multirow{12}{*}{ 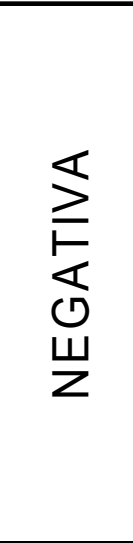 } & \multirow{6}{*}{ 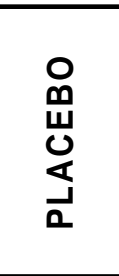 } & $B$ & 20,9 & 2,7 & 0,7 & 7,1 & 16 & 22 & 24 \\
\hline & & PT & 21,4 & 2,9 & 0,8 & 8,4 & 15 & 21,5 & 25 \\
\hline & & $\mathrm{Pr}$ & 20,4 & 4,5 & 1,2 & 20,1 & 11 & 22 & 25 \\
\hline & & $S$ & 20,9 & 4,3 & 1,1 & 18,7 & 12 & 23 & 25 \\
\hline & & $\mathrm{F} 1$ & 21,6 & 3,3 & 0,9 & 10,9 & 14 & 23 & 25 \\
\hline & & F2 & 21,6 & 3,3 & 0,9 & 10,9 & 14 & 22 & 25 \\
\hline & \multirow{6}{*}{$\begin{array}{l}\frac{\pi}{u} \\
0 \\
\frac{0}{0} \\
0\end{array}$} & $B$ & 20,5 & 4,6 & 1,2 & 21,3 & $\overline{9}$ & 21,5 & 25 \\
\hline & & PT & 21,5 & 4,5 & 1,2 & 20,0 & 12 & 23 & 25 \\
\hline & & $\operatorname{Pr}$ & 21,8 & 4,2 & 1,1 & 17,6 & 12 & 23 & 25 \\
\hline & & S & 21,6 & 4,3 & 1,1 & 18,3 & 12 & 22,5 & 25 \\
\hline & & F1 & 21,9 & 4,3 & 1,1 & 18,2 & 10 & 23 & 25 \\
\hline & & F2 & 22,3 & 4,0 & 1,1 & 15,8 & 13 & 23,5 & 25 \\
\hline \multirow{12}{*}{$\begin{array}{l}\frac{1}{\leftarrow} \\
\stackrel{\wp}{\ominus}\end{array}$} & \multirow{6}{*}{ 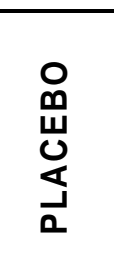 } & $B$ & 39,9 & 3,9 & 1 & $\overline{15,4}$ & 34 & 39,5 & 47 \\
\hline & & PT & 39,6 & 6,3 & 1,7 & 39,3 & 25 & 40 & 48 \\
\hline & & $\operatorname{Pr}$ & 39,1 & 6,6 & 1,8 & 44,0 & 25 & 40,5 & 48 \\
\hline & & $S$ & 38,9 & 7,5 & 2 & 56,2 & 23 & 40 & 47 \\
\hline & & $\mathrm{F} 1$ & 40,5 & 5,5 & 1,5 & 30,4 & 30 & 42 & 48 \\
\hline & & $\mathrm{F} 2$ & 40,6 & 5,7 & 1,5 & 33,0 & 28 & 42 & 47 \\
\hline & \multirow{6}{*}{$\begin{array}{l}\frac{5}{z} \\
0 \\
0 \\
\frac{1}{0} \\
0\end{array}$} & $B$ & 39,2 & 7,5 & 2 & 56,6 & $\overline{19}$ & 40 & 50 \\
\hline & & PT & 41,2 & 7,5 & 2 & 56,2 & 22 & 42,5 & 50 \\
\hline & & $\operatorname{Pr}$ & 41,4 & 7,9 & 2,1 & 62,9 & 21 & 44,5 & 50 \\
\hline & & $S$ & 41,1 & 8,5 & 2,3 & 72,5 & 19 & 44,5 & 50 \\
\hline & & $\mathrm{F} 1$ & 42,0 & 7,6 & 2 & 57,5 & 20 & 45 & 50 \\
\hline & & F2 & 42,4 & 7,2 & 1,9 & 51,5 & 23 & 45 & 50 \\
\hline
\end{tabular}


Tabela 3: Descrição para a variável frequência cardíaca (FC)

\begin{tabular}{|c|c|c|c|c|c|c|c|c|c|c|}
\hline Variá & ivel & Grupo & Fase & Média & $\begin{array}{l}\text { Desvio- } \\
\text { padrão }\end{array}$ & $\begin{array}{c}\text { Erro } \\
\text { padrão da } \\
\text { média }\end{array}$ & Variância & Mínimo & Mediana & Máximo \\
\hline \multirow{12}{*}{ 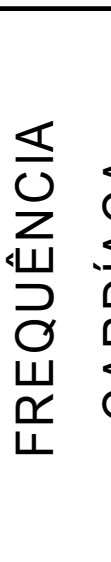 } & \multirow{12}{*}{$\begin{array}{l}\frac{1}{u} \\
\frac{1}{\alpha} \\
0 \\
\frac{1}{4} \\
0\end{array}$} & \multirow{6}{*}{ 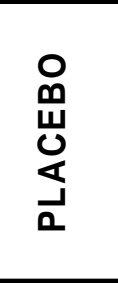 } & $B$ & 73.6 & 8.3 & 2,2 & 68.9 & 61,0 & 73.5 & 89.0 \\
\hline & & & PT & 69,9 & 6,2 & 1,7 & 39,1 & 60,0 & 70,0 & 81,0 \\
\hline & & & $\mathrm{Pr}$ & 74,9 & 9,5 & 2,5 & 90,4 & 62,0 & 72,5 & 97,0 \\
\hline & & & $S$ & 68,4 & 7,9 & 2,1 & 62,6 & 54,0 & 67,5 & 81,0 \\
\hline & & & F1 & 68,5 & 7,7 & 2,1 & 59,7 & 57,0 & 68,0 & 81,0 \\
\hline & & & $\mathrm{F} 2$ & 68,5 & 7,6 & 2,0 & 57,8 & 59,0 & 67,0 & 83,0 \\
\hline & & \multirow{6}{*}{ 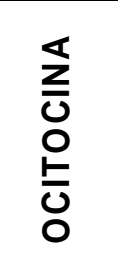 } & $\bar{B}$ & 71,4 & 10,0 & 2,7 & 100,7 & 58,0 & 68,5 & 89,0 \\
\hline & & & PT & 66,4 & 6,7 & 1,8 & 45,5 & 57,0 & 64,5 & 78,0 \\
\hline & & & $\operatorname{Pr}$ & 69,9 & 7,6 & 2,0 & 58,1 & 61,0 & 68,0 & 85,0 \\
\hline & & & $S$ & 64,3 & 7,0 & 1,9 & 48,8 & 55,0 & 64,0 & 81,0 \\
\hline & & & F1 & 63,1 & 6,2 & 1,6 & 38,2 & 52,0 & 64,5 & 74,0 \\
\hline & & & F2 & 63,9 & 6,1 & 1,6 & 37,5 & 53,0 & 64,0 & 78,0 \\
\hline
\end{tabular}

Tabela 4: Descrição para a variável pressão arterial (PA)

\begin{tabular}{|c|c|c|c|c|c|c|c|c|c|}
\hline Variável & Grupo & Fase & Média & $\begin{array}{l}\text { Desvio- } \\
\text { padrão }\end{array}$ & $\begin{array}{c}\text { Erro } \\
\text { padrão da } \\
\text { média }\end{array}$ & Variância & Mínimo & Mediana & Máximo \\
\hline \multirow{12}{*}{ 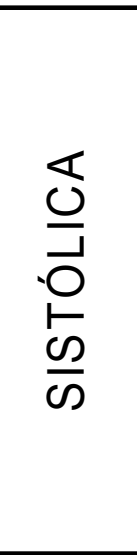 } & \multirow{6}{*}{ 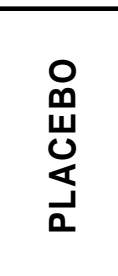 } & $B$ & 116,4 & 8,5 & 2,3 & 71,5 & 100,0 & 117,0 & 132,0 \\
\hline & & PT & 113,7 & 8,0 & 2,1 & 63,9 & 100,0 & 110,0 & 130,0 \\
\hline & & $\mathrm{Pr}$ & 118,4 & 6,0 & 1,6 & 35,8 & 110,0 & 118,0 & 130,0 \\
\hline & & $S$ & 118,6 & 8,1 & 2,1 & 64,9 & 110,0 & 116,0 & 134,0 \\
\hline & & F1 & 114,3 & 8,6 & 2,3 & 73,8 & 100,0 & 114,0 & 134,0 \\
\hline & & F2 & 114,1 & 6,7 & 1,8 & 44,6 & 104,0 & 114,0 & 132,0 \\
\hline & \multirow{6}{*}{$\begin{array}{l}\frac{\pi}{u} \\
0 \\
0 \\
\frac{1}{0}\end{array}$} & $B$ & 116,7 & $\overline{10,6}$ & 2,8 & 111,8 & 100,0 & 115,0 & 140,0 \\
\hline & & PT & 117,3 & 9,4 & 2,5 & 87,8 & 108,0 & 114,0 & 140,0 \\
\hline & & $\mathrm{Pr}$ & 121,1 & 11,7 & 3,1 & 135,8 & 110,0 & 118,0 & 148,0 \\
\hline & & S & 118,6 & 12,0 & 3,2 & 144,3 & 108,0 & 114,0 & 152,0 \\
\hline & & F1 & 115,4 & 10,1 & 2,7 & 101,2 & 104,0 & 112,0 & 140,0 \\
\hline & & F2 & 115,1 & 11,4 & 3,0 & 130,3 & 100,0 & 111,0 & 140,0 \\
\hline \multirow{12}{*}{ 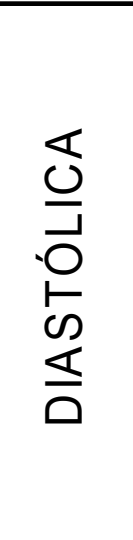 } & \multirow{6}{*}{ 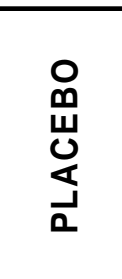 } & $B$ & 80,9 & $\overline{4,6}$ & $\overline{1,2}$ & 21,4 & 74,0 & 80,0 & 90,0 \\
\hline & & PT & 80,1 & 7,1 & 1,9 & 50,1 & 70,0 & 80,0 & 98,0 \\
\hline & & $\operatorname{Pr}$ & 81,6 & 6,9 & 1,8 & 48,1 & 70,0 & 80,0 & 98,0 \\
\hline & & $S$ & 81,0 & 7,2 & 1,9 & 51,5 & 70,0 & 80,0 & 94,0 \\
\hline & & F1 & 80,3 & 6,8 & 1,8 & 46,1 & 70,0 & 80,0 & 94,0 \\
\hline & & $\mathrm{F} 2$ & 79,0 & 6,8 & 1,8 & 46,0 & 70,0 & 79,0 & 90,0 \\
\hline & \multirow{6}{*}{ 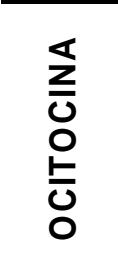 } & $\bar{B}$ & 79,9 & 6,2 & 1,7 & 39,1 & 70,0 & 80,0 & 92,0 \\
\hline & & PT & 79,7 & 9,3 & 2,5 & 86,7 & 70,0 & 80,0 & 98,0 \\
\hline & & $\mathrm{Pr}$ & 81,4 & 9,2 & 2,5 & 85,2 & 70,0 & 80,0 & 100,0 \\
\hline & & S & 82,0 & 8,2 & 2,2 & 67,7 & 70,0 & 80,0 & 100,0 \\
\hline & & F1 & 80,1 & 8,2 & 2,2 & 68,0 & 70,0 & 80,0 & 98,0 \\
\hline & & F2 & 80,3 & 8.6 & 2,3 & 73,1 & 70,0 & 79,0 & 100,0 \\
\hline
\end{tabular}


Tabela 5: Descrição para a variável nível de condutância da pele (SCL)

\begin{tabular}{|c|c|c|c|c|c|c|c|c|c|}
\hline \multirow[b]{2}{*}{ Variável } & \multirow[b]{2}{*}{ Grupo } & \multirow[b]{2}{*}{ Fase } & \multicolumn{2}{|r|}{ Desvio- } & \multicolumn{2}{|l|}{ Erro } & \multirow[b]{2}{*}{ Mínimo } & \multirow[b]{2}{*}{ Mediana } & \multirow[b]{2}{*}{ Máximo } \\
\hline & & & Média & padrão & $\begin{array}{l}\text { padrão da } \\
\text { média }\end{array}$ & Variância & & & \\
\hline \multirow{12}{*}{ 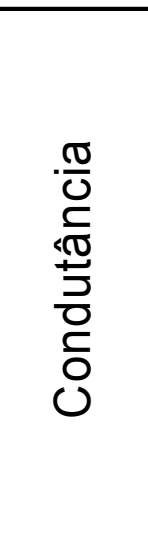 } & \multirow{6}{*}{ 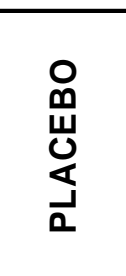 } & $B$ & 2,5 & 0,9 & 0,2 & $\overline{0,7}$ & 0,5 & $\overline{2,6}$ & 3,5 \\
\hline & & PT & 2,8 & 1,0 & 0,2 & 0,9 & 0,8 & 3,2 & 3,9 \\
\hline & & $\mathrm{Pr}$ & 3,2 & 1,2 & 0,3 & 1,4 & 1,5 & 3,2 & 5,2 \\
\hline & & S & 2,7 & 1,0 & 0,2 & 0,9 & 1,3 & 2,4 & 4,2 \\
\hline & & $\mathrm{F} 1$ & 2,3 & 0,9 & 0,3 & 0,7 & 1,2 & 2,3 & 3,6 \\
\hline & & $\mathrm{F} 2$ & 2,4 & 0,9 & 0,2 & 0,9 & 1,2 & 2,4 & 3,7 \\
\hline & \multirow{6}{*}{$\begin{array}{l}\frac{1}{z} \\
\frac{0}{0} \\
0 \\
\frac{E}{U}\end{array}$} & $B$ & 2,5 & 1,2 & 0,2 & $\overline{1,5}$ & 0,4 & 2,6 & 4,5 \\
\hline & & PT & 2,0 & 0,9 & 0,2 & 0,9 & 0,9 & 1,8 & 3,9 \\
\hline & & $\mathrm{Pr}$ & 2,3 & 1,2 & 0,3 & 1,5 & 0,8 & 2,0 & 4,9 \\
\hline & & $S$ & 1,9 & 0,9 & 0,2 & 0,8 & 0,7 & 1,6 & 3,5 \\
\hline & & F1 & 1,7 & 0,8 & 0,2 & 0,6 & 0,6 & 1,5 & 3,2 \\
\hline & & $\mathrm{F} 2$ & 1,9 & 0,8 & 0,2 & 0,6 & 0,8 & 1,8 & 3,3 \\
\hline
\end{tabular}

Tabela 6: Descrição para a variável número de flutuações da condutância (SF)

\begin{tabular}{|c|c|c|c|c|c|c|c|c|c|}
\hline Variável & Grupo & Fase & Média & $\begin{array}{l}\text { Desvio- } \\
\text { padrão }\end{array}$ & $\begin{array}{c}\text { Erro } \\
\text { padrão da }\end{array}$ & Variância & Mínimo & Mediana & Máximo \\
\hline ర & \multirow{6}{*}{$\boldsymbol{m}$} & $B$ & $\overline{3,6}$ & 3,2 & 0,8 & 9,9 & 0,0 & 3,0 & $\overline{11,0}$ \\
\hline \multirow{9}{*}{ 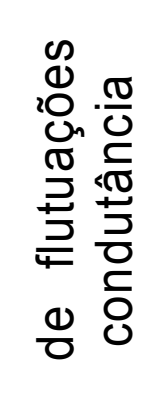 } & & PT & 3,6 & 2,3 & 0,6 & 5,5 & 0,0 & 3,0 & 8,0 \\
\hline & & $\mathrm{Pr}$ & 5,4 & 4,5 & 1,2 & 19,9 & 1,0 & 3,5 & 16,0 \\
\hline & & $S$ & 4,4 & 5,6 & 1,5 & 31,5 & 0,0 & 2,0 & 16,0 \\
\hline & & F1 & 2,0 & 3,2 & 0,8 & 10,2 & 0,0 & 0,0 & 9,0 \\
\hline & & $\mathrm{F} 2$ & 3,3 & 4,0 & 1,0 & 15,6 & 0,0 & 1,5 & 10,0 \\
\hline & \multirow{6}{*}{ 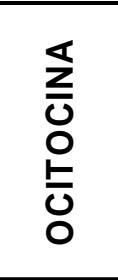 } & $B$ & 4,4 & 3,8 & 1,0 & 14,7 & 0,0 & 4,5 & 11,0 \\
\hline & & PT & 4,2 & 4,2 & 1,1 & 17,7 & 0,0 & 4,0 & 15,0 \\
\hline & & $\mathrm{Pr}$ & 6,4 & 4,2 & 1,1 & 17,8 & 0,0 & 6,5 & 13,0 \\
\hline & & $S$ & 2,3 & 2,1 & 0,6 & 4,5 & 0,0 & 2,0 & 6,0 \\
\hline 0 & & F1 & 1,4 & 1,7 & 0,5 & 3,0 & 0,0 & 1,0 & 5,0 \\
\hline Z & & $\mathrm{F} 2$ & 3,0 & 3,0 & 0,8 & 9,1 & 0,0 & 1,5 & 9,0 \\
\hline
\end{tabular}


Tabela 7: Descrição para a variável dosagem sérica de cortisol

\begin{tabular}{|c|c|c|c|c|c|c|c|c|c|}
\hline Variável & Grupo & Fase & Média & $\begin{array}{l}\text { Desvio- } \\
\text { padrão } \\
\end{array}$ & $\begin{array}{c}\text { Erro } \\
\text { padrão da } \\
\text { média }\end{array}$ & Variância & Mínimo & Mediana & Máximo \\
\hline \multirow{12}{*}{ 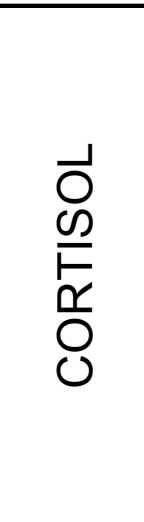 } & \multirow{6}{*}{ 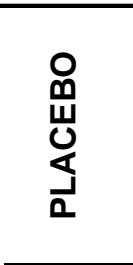 } & $B$ & 15,9 & $\overline{4,1}$ & 1,1 & $\overline{17,2}$ & 7,8 & 15,4 & 22,6 \\
\hline & & PT & 13,8 & 5,5 & 1,4 & 30,2 & 4,0 & 12,5 & 28,0 \\
\hline & & $\mathrm{Pr}$ & 14,0 & 4,5 & 1,2 & 20,4 & 4,8 & 13,6 & 20,4 \\
\hline & & S & 12,9 & 4,8 & 1,3 & 23,0 & 4,3 & 11,8 & 21,6 \\
\hline & & F1 & 10,9 & 3,7 & 1,0 & 13,4 & 3,6 & 10,1 & 18,3 \\
\hline & & $\mathrm{F} 2$ & 10,5 & 3,5 & 0,9 & 12,6 & 5,2 & 10,3 & 18,1 \\
\hline & \multirow{6}{*}{$\begin{array}{l}\frac{1}{0} \\
0 \\
\frac{1}{0} \\
0\end{array}$} & $B$ & 16,3 & 4,5 & 1,2 & 19,9 & 6,6 & 16,9 & 23,7 \\
\hline & & PT & 13,1 & 4,6 & 1,2 & 21,5 & 5,0 & 12,5 & 22,0 \\
\hline & & $\operatorname{Pr}$ & 14,0 & 4,3 & 1,1 & 18,7 & 4,9 & 14,4 & 20,5 \\
\hline & & S & 13,2 & 3,6 & 1,0 & 12,9 & 5,3 & 12,9 & 21,0 \\
\hline & & F1 & 11,3 & 3,3 & 0,9 & 11,1 & 4,1 & 11,2 & 18,4 \\
\hline & & F2 & 10,8 & 3,6 & 0,9 & 12,7 & 3,6 & 10,6 & 19,4 \\
\hline
\end{tabular}

Tabela 8: Descrição para a variável dosagem plasmática de ACTH

\begin{tabular}{|c|c|c|c|c|c|c|c|c|c|}
\hline Variável & Grupo & Fase & Média & $\begin{array}{l}\text { Desvio- } \\
\text { padrão }\end{array}$ & $\begin{array}{c}\text { Erro } \\
\text { padrão da } \\
\text { média }\end{array}$ & Variância & Mínimo & Mediana & Máximo \\
\hline \multirow{12}{*}{$\begin{array}{l}I \\
\qquad \\
\longleftarrow\end{array}$} & \multirow{6}{*}{ 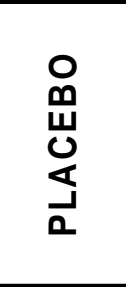 } & $\bar{B}$ & 31,4 & 13,4 & 3,5 & 178,3 & 14,1 & 30,9 & 71,5 \\
\hline & & PT & 24,0 & 11,5 & 3,1 & 133,2 & 11,9 & 21,5 & 55,2 \\
\hline & & $\mathrm{Pr}$ & 24,3 & 16,1 & 4,3 & 260,2 & 10,4 & 20,3 & 76,0 \\
\hline & & $S$ & 21,7 & 12,8 & 3,4 & 163,4 & 10,4 & 19,1 & 62,3 \\
\hline & & F1 & 20,0 & 13,5 & 3,6 & 182,9 & 10,1 & 17,7 & 63,9 \\
\hline & & $\mathrm{F} 2$ & 19,9 & 12,1 & 3,2 & 146,0 & 12,3 & 17,5 & 59,5 \\
\hline & \multirow{6}{*}{$\begin{array}{l}\frac{1}{z} \\
\frac{z}{0} \\
0 \\
\frac{1}{0}\end{array}$} & $\bar{B}$ & 29,6 & 6,8 & 1,8 & 46,7 & 12,4 & 29,9 & 43,6 \\
\hline & & PT & 20,7 & 7,3 & 1,9 & 52,9 & 10,1 & 20,1 & 38,2 \\
\hline & & $\mathrm{Pr}$ & 22,7 & 9,2 & 2,4 & 83,9 & 11,2 & 20,0 & 46,4 \\
\hline & & $S$ & 20,2 & 7,8 & 2,1 & 60,3 & 11,7 & 18,9 & 35,5 \\
\hline & & F1 & 18,6 & 7,4 & 2,0 & 55,3 & 10,5 & 16,2 & 36,5 \\
\hline & & F2 & 17,5 & 6,5 & 1,7 & 42,0 & 10,0 & 15,6 & 32,9 \\
\hline
\end{tabular}

